\title{
Gastbeitrag
}

Iris Därmann*

\section{Widerstands- und Gewaltforschung, überkreuz}


Abstract: This is a plea to interlink Resistance Studies and Violence Studies. Instead of invastigating the efficiency of violence alone and declaring violence absolutely and completely in and on its own, it is necessary to look at resistance practices (escape lines, fighting back), body politics and passivations (selfinjury, abortion, suicide) at the same time. For their part, resistance practices and passivations can not be measured by success but by the fact that they actually happened. People cannot be completely reduced to bare bodies without resistance. Resistance to violence has to be considered in its inconspicuous, lowthreshold and "flat" forms. In this elementary political sense resistance is understood as a punctually weakening violence and as seperation of powers in statu nascendi.

Keywords: Widerstandsforschung; Gewaltforschung; African American Studies; Holocaustforschung

*Prof. Dr. Iris Därmann, Humboldt-Universität zu Berlin, Institut für Kulturwissenschaft, Georgenstr. 47, D-10117 Berlin, email: daermann@culture.hu-berlin.de

An den Universitäten Gothenburg, Sussex, San Francisco und Amherst hat sich ein Resistance Studies Network ${ }^{1}$ etabliert, mit einem ausgeprägten Interesse für Revolutions- und Protestforschung. Im akademischen Jahr 2020 wird an der University of Massachusetts, Amherst, auch ein Graduiertenprogramm in Soziologie mit dem Schwerpunkt Resistance Studies angeboten. ${ }^{2}$ In der deutschsprachigen akademischen Landschaft gibt es noch kein vergleichbares Forschungsfeld, allerdings ein loses, mithin stark fragmentiertes Netz an kultur-, geschichts- und sozialwissenschaftlichen Einzelstudien.

Am Lehr- und Forschungsbereich "Kulturwissenschaftliche Ästhetik und Kulturtheorie" 3 des Instituts für Kulturwissenschaft der Humboldt-Universität zu Berlin sind derzeit Überlegungen im Gange, ein solches Netzwerk auch hierzulande aufzubauen.

1 In Gothenburg: Mikael Baaz, Mona Lilja, Michael Schulz \& Stellan Vinthagen; in Sussex: Louiza Odysseos; an der UMass, Amherst: Stellan Vinthagen; an der San Francisco State: Jason Ferreira. Resistence Studies Network. URL: http://resistancestudies.org (Zugriff am: 24.9.2019).

$2 \mathrm{Vgl}$. University of Massachusetts Amherst: Resistance Studies Initiative. URL: https://www.umass.edu/resistancestudies/ (Zugriff am 30.12.2018). An der UMass, Amherst wird seit 2015 ein Journal for resistance studies herausgegeben mit inzwischen vier erschienenen Heften: Journal of Resistance Studies. URL: https://resistance-journal.org/ (Zugriff am: 24.9.2019). https://resistance-journal.org/. 3 Humboldt-Universität zu Berlin: Kulturwissenschaftliche Ästhetik und Kulturtheorie. URL: https://www.aesthetik. hu-berlin.de/ (Zugriff am: 24.9.2019).
An dieser Stelle möchte ich jedoch (I.) die erkenntnistheoretischen, psychoanalytischen, ästhetischen und politischen Traditionsstränge befragen und, zumindest punktuell, historisch kontextualisieren. In einem weiteren Schritt (II.) geht es mir um eine konzeptionell enge Verschränkung von Gewalt- und Widerstandsforschung sowie um die Ausarbeitung eines flachen, niedrigschwelligen, nicht zuletzt aistethischen Widerstandsverständnisses. Schließlich möchte ich (III.) unter Rekurs auf die frühen African American Studies und die jüdische Holocaust-Forschung wegweisende alltagshistorische und soziologische Verfahren einer Gewalt- und Widerstandsforschung avant la lettre vor Augen führen.

Wovon müssten Forscherinnen und Forscher ausgehen, die an der interdisziplinären Untersuchung eines historisch-kulturell breiten Spektrums widerständiger Praktiken, Passivierungen, Aisthetiken, Geschichten und Theorien auf dem Feld der Resistance Studies interessiert wären? Was müssten sie gewärtigen? Welche Grenzen hätten sie in Frage zu stellen oder zu markieren? Vor welchen historischen Romantisierungen und ästhetischen Überschätzungen hätten sie sich zu hüten? Das akademische Begehren, Widerstand selbst noch dort zu finden, wo er beinahe unmöglich erscheinen musste oder sich bestenfalls in Graubereichen und ephemeren Ereignissen artikuliert hat, könnte nicht nur von einer generellen Herrschafts- und Machtverachtung herrühren, sondern auch Gefahr laufen, historische wie zeit- 
genössische Gewalt- und Machtverhältnisse zu verharmlosen und in ihrer Spezifik zu verkennen. Widerstandsforscherinnen und -forscher müssten daher zugleich Gewaltforschung betreiben, mit erheblicher historischer "Kontextsensibilität"4 ausgestattet sein und ein psychoanalytisch reflektiertes Verhältnis zu ihrem eigenen Untersuchungsbegehren unterhalten: Wer Widerstände untersucht, könnte wähnen, je schon auf der richtigen Seite zu stehen und in ein identifikatorisches, undeligiertes und verstärkendes Sprechen für jene vielen Namenlosen einzutreten, deren Stimme ungehört geblieben bzw. als "Geräusch" denunziert worden ist. ${ }^{5}$ Demgegenüber ist es wissenschaftlich wohl geboten, Vielstimmigkeit und Multiperspektivität in Betracht zu ziehen sowie unsichere Grenzverläufe, Verzweigungen und Beziehungsnetze zwischen Macht und Widerstand, Gewalt und Gegengewalt.

Neben Sprödigkeit gegenüber der eigenen Motivlage bedürfte es gerade auch der Gegenprobe: Es ginge darum, das (Un-)Mögliche des Widerstands zu denken und dessen Abwesenheitsformen zu untersuchen, wo nötig, "dem Widerstand [zu] widerstehen", ${ }^{6}$ verknüpft freilich mit der Frage, ob es überhaupt möglich ist, Menschen restlos zu unterwerfen, sie auf einen bloßen Körper, auf Haut, Knochen und Fleisch zu reduzieren, sie zu ,Werkzeugen', ,Händen', ,Stücken' zu machen und als sterbliche Menschen zu vernichten. Gibt es eine irreduzible Resistenz gegenüber absoluter Verfügungsgewalt? Gewaltund Machtsysteme ohne Handlungsspielräume, die auf Seiten von Tätern, Unterstützern und Zuschauern zur Entschärfung oder Verschärfung

4 Mar, Maria do/Dhawan, Nikita (2005): Postkoloniale Theorien. Eine kritische Einführung. Bielefeld: transcript, S. 24; vgl. auch Ott, Michaela (2018): Welches Außen des Denkens? Französische Theorie in postkolonialer Kritik? Wien/Berlin: Turia + Kant, S. 18.

5 Spivak, Gayatri Chakravorty (2008): "Can the subaltern speak?" Postkolonialität und subalterne Artikulation. Mit einer Einleitung von Hito Steyerl. Übersetzt von Alexander Joskowicz und Stefan Nowotny. Wien: Turia + Kant, S. 29, 40; Rancière, Jacques (2002): Das Unvernehmen. Politik und Philosophie. Übersetzt von Richard Steurer. Frankfurt a.M.: Suhrkamp Verlag, S. 30, 35, 38.

6 Převrátil, Rudolf/Puar Jasbir K. (2007): Terrorist Assemblages. Homonationalism in Queer Times. Durham \& London: Duke University Press, S. 24. Für Widerstandskorrespondenz und namentlich diesen Hinweis danke ich herzlich Sebastian Köthe. von Gewalt genutzt werden könnten, sind ebenso wenig denkbar, wie solche, die nicht zugleich von dissidenten Kräften in Frage gestellt würden, zumindest in Frage gestellt werden könnten, auf Seiten derer, die isoliert, markiert, unterworfen, versklavt, animalisiert, gefoltert, gedemütigt, rechtlos gemacht und vernichtet werden (sollen). Andernfalls handelte es sich um absolute, totale, ganz und gar erfolgreiche Macht- und Gewaltsysteme, in denen nichts Menschliches mehr im Spiel wäre. Menschliche Handlungen und menschliches Leiden müssen die Dimension des Aushandelnkönnens und des Außerordentlichen, der Passivierung, des "Eigensinns"7 und des Ereignisses behalten, selbst in Extremsituationen: Der (nicht nur) philosophische Einsatzpunkt eines "politischen Humanismus"8 zielt daher auf die Untersuchung der Frage, inwiefern sich Menschen in Gewalt- und Machträumen nicht rest- und widerstandslos menschlicher Gewalt fügen. Es geht nicht um Frontstellungen, sondern um Gewichtsund Akzentverschiebungen zwischen Gewalt- und Widerstandsforschung und um die Aufkündigung ihrer bisherigen Arbeitsteilung. Das eine kann nicht ohne das andere unternommen werden. Anstatt ausschließlich oder hauptsächlich die Effektivität von Macht und Gewalt zu untersuchen

7 Lüdtke, Alf (2007): Eigensinn. In: Jordan, Stefan (Hg.): Lexikon Geschichtswissenschaft. Hundert Grundbegriffe. Stuttgart: Reclam, S. 64-66, hier: S. 65f. „Der Gebrauch des Eigensinn-Begriffs steht im Zusammenhang mit zunehmender Kritik am bipolaren Konzept von ,Herrschaft' und ,Widerstehen' als Grundmatrix von Geschichte. [...] Die Beobachtung des Verhaltens von Individuen und von Gruppen zeigt, dass das Entweder-Oder von Zustimmen/ Mitmachen oder Widerstehen fehl geht. Das Mitmachen mit zusammengebissenen Zähnen, jene widerwillige Loyalität, [...] erforderte ein Gegengewicht, eine gehörige Dosis Eigensinn." Nach Einschätzung Lüdtkes sei die Verweigerung des ,Hitler-Grußes' zwar ein Zeichen von Eigensinn gewesen, habe sich jedoch "kaum je als Einstieg in gezielt-nachdrückliches Widerstehen" erwiesen. Lüdtke kontrastiert sein Eigensinn-Konzept mit einem starken und voraussetzungsreichen Widerstandsbegriff, den ich im Folgenden problematisieren möchte. Zugleich rege ich an, die Widerstandssituation und den spezifischen Gewalt(nicht nur den Herrschafts-)Kontext gleichermaßen in den Blick zu nehmen. Die Verweigerung eines anbefohlenen "Hitler-Grußes" im Folterraum der "Politischen Abteilung" ("Lager-Gestapo") in einem deutschen Konzentrationslager würde wohl von Widerstand, nicht nur von „Eigensinn" zeugen.

8 Mit herzlichem Dank an Andreas Gehrlach für diesen Begriff und unsere Widerstandsgespräche. 
und sie damit für „absolut" zu erklären, wie es die neuere Gewaltforschung sensu Wolfgang Sofsky, ${ }^{9}$ selbst wenn sie das Leiden der Opfer ins Zentrum rückt, ${ }^{10}$ tendenziell durchaus tut, ${ }^{11}$ geht es darum, gleichzeitig auch deren Grenzen im Modus einer punktuellen Schwächung durch Widerständigkeit und eine Gewaltenteilung in statu nascendi durch Gegengewalt aufzuzeigen.

In konkreter Perspektive handelt es sich darum, noch unterhalb von Attentaten, revolutionären Großereignissen, Klassenkämpfen, Massenaufständen, Protestbewegungen und deren medialen wie öffentlichen Verlautbarungsweisen einen radikal erweiterten Widerstandsbegriff zu skizzieren und flache Widerstandsformen in den

9 Siehe dazu das Kapitel "Absolute Macht" von Sofsky, Wolfgang (1993): Die Ordnung des Terrors. Das Konzentrationslager. 4. Auflage. Frankfurt a.M.: S. Fischer Verlag, S. 27-40. Ich widerspreche nicht der organisationssoziologisch orientierten Beobachtung und Charakterisierung Sofskys, dass das "Machtsystem der Konzentrationslager" als "die extremste Form von Macht und moderner Organisation" von unvergleichlicher, "eigener Art" war, dass es sich um eine "organisierte", ,etikettierende', "gestaffelte", "auf sich selbst gründende", ,bar jeder Legitimationsideologie' operierende, den Sinn menschlicher Arbeit pervertierende Macht gehandelt habe, wohl aber, dass es sich um eine "absolute Aktionsmacht, befreit von allen Hemmungen" und Grausamkeit entgrenzende Macht gehandelt habe. Denn dies ist die reproduzierende Perspektive der Macht, die wähnt, absolut, nämlich ohne mögliche Gegengewalt und Widerständigkeit und das heißt restlos "erfolgreich" im Sinne ihrer eigenen Kriterien zu sein.

$10 \mathrm{Vgl}$. Nedelmann, Birgit (1997): Gewaltsoziologie am Scheideweg. Die Auseinandersetzungen in der gegenwärtigen und Wege der künftigen Gewaltforschung. In: Trotha, Trutz von (Hg.): Soziologie der Gewalt, Opladen/Wiesbaden: Westdeutscher Verlag, S. 59-85, hier: S. 63. Für die Hinwendung zum Leiden der Opfer war die Untersuchung der Geschichte des körperlichen Schmerzes von Scarry, Elaine (1985): The Body in Pain. The Making and Unmaking of the World, New York: Oxford University Press von entscheidender Bedeutung.

11 Heinrich Popitz räumt mit Verweis auf Georg Simmel ein, dass sich die „absolute Gewalt, die ein Machthaber ausübt, [...] sich durch die Tat des Attentäters auch gegen ihn wenden [kann]". Die Möglichkeit der "Tötung des Machthabers" und dessen eigene "Verletzungsoffenheit" „entlarvt den Vollkommenheitsanspruch nicht nur dieses Machthabers, sondern aller Macht." Mit der Figur des Attentäters und Märtyrers bringt Popitz heroische Formen aktiven bzw. "radikal passiven Widerstands" ins Spiel, die ich im Folgenden mittels flacher, aisthetischer und passivierender Widerstandsformate erweitern möchte. Popitz, Heinrich (1986): Phänomene der Macht. Autorität - Herrschaft - Gewalt Technik. Tübingen: Mohr Siebeck, S. 83-87.
Blick zu nehmen, die sich in der Spanne und Spannung zwischen vita activa und vita passiva, Überleben und Freitod, Entgegentreten und Entziehen, öffentlicher Sichtbarkeit und Verborgenheit, Präsenz und historischer Nachträglichkeit, Intention und Effekt, Singularität und Kollektivität bewegen, in ihren Eskalationskräften einerseits, in ihren Spurenbereichen und geringfügigen Resten andererseits. Wer oder was insistiert im Widerstehen? Wie verlaufen Mikrophysiken von Gewalt und Widerstand? Wo werden wir philosophisch, ideengeschichtlich, theoretisch, historisch und praktisch überhaupt fündig? Werden wir?

\section{Traditionsstränge}

Im westlichen Denken finden sich drei große Traditionsstränge, Widerstand und Widerstandserfahrungen betreffend, ein erkenntnistheoretischer bzw. psychoanalytischer, ein ästhetischer und ein politischer.

(1) Der eine, erkenntnistheoretisch orientierte Strang, der von Fichte über Maine de Biran, Wilhelm Dilthey bis hin zu Max Scheler, Nicolai Hartmann und Martin Heidegger reicht, ${ }^{12}$ setzt die Widerstandserfahrung als "Ursprung unseres Glaubens an die Realität der Außenwelt" an, wie zumindest der Titel des einschlägigen Aufsatzes Wilhelm Diltheys lautet: Die Bedeutung der "äußeren Erfahrung" liege im „Finden" und "Vorfinden", nicht aber im „Erfinden von Wirklichkeit": ${ }^{13}$ Jeder Erfahrungszusammenhang, in dem etwas Hemmendes, Drückendes, Unerwartetes, Affizierendes oder Gewaltsames den eigenen Willensvollzügen und Intentionen widerstreite, ${ }^{14}$ in der uns also etwas „Fremd-Selbständiges ent-

12 Vgl. Kaiser, Ulrich (1997): Das Motiv der Hemmung in Husserls Phänomenologie. München: Fink Verlag, S. 37. 13 Dilthey, Wilhelm (ca. 1880-1890/1982): Ausarbeitung zum zweiten Band der Einleitung in die Geisteswissenschaften. Viertes bis sechstes Buch. In: Johach, Helmut/ Rodi, Frithjof (Hgg): Gesammelte Schriften, Bd. XIX. Göttingen: Vandenhoeck \& Ruprecht, S. 58-295, hier: S. 80. 14 Vgl. Dilthey, Wilhelm (1957): Beiträge zur Lösung der Frage vom Ursprung unseres Glaubens an die Realität der Aussenwelt und seinem Recht. In: Georg Misch (Hg.): Gesammelte Schriften, Bd. V. 2. Auflage. Stuttgart: B. G. Teubner Verlagsgesellschaft, S. 90-138, hier: S. 116, 131, 137. 
gegentritt", das „nicht in uns selber gelegen ist" ${ }^{15}$ sei eine Grenz- und Widerstandserfahrung mit unkonstruierbarem Realitätsgehalt. Wirklichkeit mache sich durch Wirksamkeiten, Widerfahrnisse und bezwingende Gegenkräfte bemerkbar: "Nur was auf uns wirkt, ist für uns da." 16

Ausgehend von der Psychologie Johann Friedrich Herbarts haben Edmund Husserl und Sigmund Freud demgegenüber komplexere Kraft-Sinn-Konstellationen ausgearbeitet. Für Husserl setzen Widerstands- und nicht zuletzt Widerstreitserfahrungen, die die "Einstimmigkeit"17 von Erfahrungsverläufen in der Konstitution von Wirklichkeit irritieren, Modifikationen von Welt und Modalisierungen von Wirklichkeit in Gang; Affektionen, die von widerständiger "Kraft", "Intensität", „Auffälligkeit", „Aufdringlichkeit" und "Entgegendrängen" herrührten, ${ }^{18}$ weckten an der Schwelle des Bewusstseins Antworttendenzen und "antwortende Tätigkeiten" des Ich wie Zuwendung, Aufmerksamkeit, Erfassung. ${ }^{19}$ Freud erkannte in den Widerständen, die er freilich nicht als reale Ereignisse in der Welt und als faktische Veranlassungen, sondern vielmehr als „psychische Mächte gegen sich" wusste, sofern sie den Fortlauf der analytischen Arbeit "stören",20 dieselben Kräfte am Werk, die auch bei Abwehr und Verdrängung im Spiel sind. ${ }^{21}$ Bevor er sich jedoch von der Unbeugsamkeit

15 Dilthey, Wilhelm (1957): Beiträge zur Lösung der Frage vom Ursprung unseres Glaubens an die Realität der Aussenwelt und seinem Recht, S. 116.

16 Dilthey, Wilhelm (WS 1888/89/1997): Psychologie als Erfahrungswissenschaft. In: Kerckhoven, Guy van/Lessing, Hans-Ulrich (Hgg.): Gesammelte Schriften, Bd. XXI, Göttingen: Vandenhoeck \& Ruprecht, S. 275-327, hier: S. 325. 17 Husserl, Edmund (1966): Analysen zur passiven Synthesis. Aus Vorlesungs- und Forschungsmanuskripten 1918-1926. In: Margot Fleischer (Hg.): Husserliana, Bd. XI. Den Haag: Nijhoff, S. 364, 432.

18 Husserl, Edmund (1976): Erfahrung und Urteil. Untersuchungen zur Genealogie der Logik. Redigiert und herausgegeben von Ludwig Landgrebe. 5. Auflage. Hamburg: Felix Meiner Verlag, S. 79f.

19 Husserl, Edmund (1966): Analysen zur passiven Synthesis, S. 151.

20 "Was immer den Fortgang der Arbeit stört, ist ein Widerstand." Freud, Sigmund (1942): Die Traumdeutung. In: Gesammelte Werke, Bd. II/III, herausgegeben von Anna Freud u.a. Frankfurt a.M./London: S. Fischer Verlag, S. 521. 21 Vgl. Freud, Sigmund (1940): Jenseits des Lustprinzips. In: Gesammelte Werke, Bd. XIII, S. 3-69, hier: S. 17. der „inneren Widerstände" gegenüber suggestiv-hypnotischer und diskursiv-deutender Gewalt überzeugt hatte und stattdessen Sprech- und Hörallianzen mit widerständigen Patientinnen zu schließen verstand ${ }^{22}$ sowie Prozesse des Wiederholens, Erinnerns und Durcharbeitens in den Mittelpunkt der analytischen Arbeit stellte, nahm er durchaus an, dass es nötig sei, den Widerständen "den Herrn [zu] zeigen". ${ }^{23}$ Freuds Sprache despotischer Machtdemonstration ruft die Frage nach einem analytischen Widerstandsrecht wach: Muss man der Psychoanalyse in der Analyse widerstehen, ${ }^{24}$ gegen die Regeln verstoßen, nicht alles sagen und preisgeben, um das Nichtwollen selbst, die Verneinung, das Zurückweisen und Widerstehen, vor allem freilich das mutige "Wahrsprechen"25 im geschützten Raum der Analyse zu erproben und zu kultivieren? "Man könnte es sogar wagen und behaupten, dass gewissermaßen in jeder Analysesitzung eine Art Mikro-Revolution" der freien Rede und befreiten Sprache stattfindet. ${ }^{26}$ Zweifellos wird immer mehr Scharfsinn, Fintenreichtum, List, Mut und affektive Kraft erforderlich sein, um zu widerstehen, als es nicht zu tun, vor allem aber, als Befehle zu erteilen und Gewalt auszuüben. Es gibt keine Schule des organisierten Widerstands, in der Widerstandsproben abgegeben und Widerstandskünste eingeübt würden. Vermutlich können nur institutionengeschichtlich bzw. organisationssoziologisch

22 In Hemmung, Symptom und Angst unterscheidet Freud fünf Modi des Widerstands, die vom Ich, Es und Über-Ich ausgingen, darunter drei, bei denen das Ich die Quelle sei, und zwar im Modus des Verdrängungs-, Übertragungsund Ichwiderstands. Vgl. Freud, Sigmund (1948): Hemmung, Symptom und Angst. In: Gesammelte Werke, Bd. XIV, S. 113-205, hier: 191-193; siehe auch Freud, Sigmund (1955): Die Widerstände gegen die Psychoanalyse. In: Gesammelte Werke, Bd. XIV, S. 97-110.

23 Freud, Sigmund (1942): Die Traumdeutung, S. 529.

24 Vgl. Derrida, Jacques (1980): Widerstände. In: Ders.: Vergessen wir nicht - die Psychoanalyse. Übersetzt von Hans-Dieter Gondek. Frankfurt a.M.: Suhrkamp Verlag, S. $128-180$, hier: S. $128,141 \mathrm{ff}$.

25 Foucault, Michel (2009): Die Regierung des Selbst und der anderen. Übersetzt von Jürgen Schröder. Frankfurt a.M.: Suhrkamp Verlag, S. 436, 259.

26 Derrida, Jacques (2002): Seelenstände der Psychoanalyse. Die Unmöglichkeit jenseits einer souveränen Grausamkeit. Übersetzt von Hans-Dieter Gondek, Frankfurt a.M.: Suhrkamp Verlag, S. 39. 
bewanderte Untersuchungen von Fall zu Fall das Rätsel lösen, ${ }^{27}$ warum Widerstand in Institutionen und Organisationen ungleich seltener auftritt und unwahrscheinlicher erscheint als die mehrheitsfähigeren und willfährigen Praktiken des Zuschauens, Nachgebens, Einwilligens und Mitmachens. ${ }^{28}$ Zweifellos ist Widerstand eine riskante Praxis der gefährlichen Improvisation und des bedrängenden Augenblicks in ihrer ganzen Aktivitäts- und Passivitätsfülle. Umso mehr bedarf es heute der Schulen und Künste des Widerstands.

(2) Vom Widerstand geht, je nach Perspektive, eine teils politische Anziehungskraft, teils bedrohliche Macht aus, die auf die zweite europäische Traditionslinie, die des Widerstandsrechts führt. Hobbes schließt diese Traditionslinie in seiner Schrift Leviathan (1651) warnend mit der Lektüre griechischer und römischer Klassiker kurz, die zur "Nachahmung" verleiteten, indem sie das destabilisierende "Gift" der "Tyrannophobie" selbst in absolute Monarchien einführten und im Namen demokratischer Freiheit Rebellionen und Tyrannenmord Vorschub leisteten. ${ }^{29}$ In der Tat ist die Frage des Widerstands seit der Antike mit der Tyrannislehre und der Bestimmung normativer Kriterien für die kritische Beurteilungs-

27 Siehe dazu das Special Issue: Resistance, Resisting, and Resisters in and around Organizations der Organization Studies Vol. 38, Issue 9 von Martí, Ignasi/Mumby, Dennis K. /Thomas, Robyn et al. (Hgg.) (2017a), insbesondere den Artikel von Martí, Ignasi/Mumby, Dennis K./ Thomas, Robyn et al (2017b): Resistance Redux, S. 11571183, in dem sich die Autoren ebenfalls dafür aussprechen, niedrigschwellige Widerstandspraktiken in Organisationen in den Blick zu nehmen. Mit herzlichem Dank an Günther Ortmann für diesen Hinweis und weiteres Geleit.

28 Einen analytischen Zugang eröffnet Jan Philipp Reemtsma mit dem von ihm untersuchten "Delegationen" und "Dynamiken der Entmonopolisierung" von Gewalt sowie dem Zusammenhang von "Partizipationsmacht und Gewalt". Reemtsma, Jan Philipp (2008): Vertrauen und Gewalt. Versuch über eine besondere Konstellation der Moderne. Hamburg: Hamburger Edition, S. 170-182.

29 Hobbes, Thomas (1996): Leviathan. Mit einer Einführung und herausgegeben von Hermann Klenner, übersetzt von Jutta Schlösser. Darmstadt: Felix Meiner Verlag, S. 277ff. Zu den englischen Widerstandslehren des 17. Jahrhunderts siehe Wolzendorff, Kurt (1968): Staatsrecht und Naturrecht in der Lehre vom Widerstandsrecht des Volkes. Zugleich ein Beitrag zur Entwicklungsgeschichte des modernen Staatsgedankens. 2. Neudruck der Ausgabe Breslau 1916, Aalen: Scientia Verlag, S. $262 \mathrm{ff}$. und Unterscheidungsfähigkeit von gerechten und ungerechten Herrschaftsformen verknüpft. ${ }^{30}$

Das Widerstandsrecht stützt sich auf den Grundsatz, dass die freie und gleiche Bürgerschaft respektive das "Volk" berechtigt sei, sich eines unrechtmäßigen Usurpators oder ungerechten Herrschers zu entledigen, um seiner illegitimen Herrschaft bzw. seinem Amtsmissbrauch Einhalt zu gebieten, nötigenfalls durch Umsturz und Anschlag auf sein Leben. Zweifellos bildet der Tyrannismord das alteuropäische Passepartout für das neuzeitliche und moderne Widerstandsrecht gegen staatliches Unrecht und Gewaltherrschaft, bei Montesquieu durch die Ausarbeitung des Despotie-Begriffs aus liberaler Begründungsperspektive, bei Rousseau „in radikal-demokratischer Fassung des Despotie-Begriffs"31 und unter Berufung auf die natürliche Freiheit der Bürger, die wiederzuerlangen diese das Recht hätten, für den Fall, dass der Souverän die künstlichen Freiheitsrechte lädierte. ${ }^{32}$ Seit der Enthauptung Ludwig XIV. und der Erklärung der Menschenrechte eröffnete sich, neben dem Despotenmord als ein politisches, dem Allgemeinwohl dienendes Rechtsinstitut, eine zweite, gewissermaßen individualrechtliche bzw. subjektive Begründungsmöglichkeit für das Widerstandsrecht, das zur Verteidigung der Menschenrechte in Anspruch

30 Aristoteles (1981): Politik 1319b 33 ff., 1311a ff. Mit einer Einleitung von Günther Bien übersetzt und mit erklärenden Anmerkungen versehen von Eugen Rolfes. Hamburg: Felix Meiner Verlag: „Der König soll ein Wächter darüber sein, daß die Vermögenden kein Unrecht leiden und das Volk keine Gewalttat erfährt. Die Tyrannis dagegen verfolgt, wie wiederholt gesagt, keinerlei gemeinnützigen Zweck, es sei denn des eigenen Vorteils wegen." Zu den Motiven (Furcht, Hass, Verachtung) und Möglichkeiten des Sturzes und Endes der Tyrannis (von außen, durch sich selbst, durch Mordanschlag und Umsturz) siehe: Politik 1312b 10 ff., 1311a 26 ff.

31 Mandt, Hella (1974): Tyrannislehre und Widerstandsrecht. Studien zur deutschen politischen Theorie des 19. Jahrhunderts. Darmstadt/Neuwied: Luchterhand, S. 81. 32 Die Maximalhandlung einer gewaltsamen Rebellion als Wahrnehmung eines kollektiven Widerstandsrechts bindet Rousseau indes an Zwischenschritte wie die Einsetzung eines "Tribunats", dem der Schutz des Souveräns namens "Volk" vor der Regierung obliegt. Jdanoff, Denis: (2006): Gehorsam und Widerstand in Hobbes' "Leviathan" und Rousseaus "Gesellschaftsvertrag" - Ein Vergleich, Berlin: Wissenschaftlicher Verlag, S. 140, 154f. 
genommen werden konnte. ${ }^{33}$ Kraft Erklärung der "Rechte der Menschen und der Bürger" sprach die Constituante am 26. August 1789 "den Menschen" die Grundrechte von „Freiheit, Eigentum, Sicherheit und das Recht auf Widerstand gegen Unterdrückung" zu. Allerdings eröffnete sie damit einen menschenrechtlichen Konflikt: als Menschen waren Sklaven frei, als Eigentum jedoch gehörten sie zum „unveräußerlichen Recht" ihrer "Eigentümer". ${ }^{34}$ Mit Beginn der Revolution auf Saint-Domingue im August 1791 „[setzten] die Abgeordneten" der Nationalversammlung die

33 Zur "doppelten Wurzel" des Widerstandsrechts siehe Scheidle, Günther (1969): Das Widerstandsrecht. Entwicklung anhand der höchstrichterlichen Rechtsprechung der Bundesrepublik Deutschland, Berlin: Duncker \& Humblot, S. 114; Arndt, Adolf (1962): Agraphoi Nomoi (Widerstand und Aufstand). In: Neue Juristische Wochenschrift S. 430-433, hier: S. 430. Hinweise und entsprechende Überlegungen bei Missling, Bodo (1999): Widerstand und Menschenrechte. Das völkerrechtlich begründete Individualrecht gegen Menschenrechtsverletzungen. Tübingen: Köhler, S. 12ff. Als Notwehrrecht zur Verteidigung individueller Rechtspositionen könnte es auf Grundlage von Absatz 3 der Präambel der Allgemeinen Erklärung der Menschenrechte (Resolution 217 A [II] vom 10.12.1948, beschlossen von den Vereinten Nationen) als ein "völkerrechtlich begründete[s] Individualwiderstandsrecht gegen Menschenrechtsverletzungen" zum Tragen gebracht werden, wie Bodo Missling geltend macht, um dem unsicheren Rekurs auf ein überpositives Naturrecht zu entgehen, auf das sich die Brüder Stauffenberg, die Widerstandsgruppe Die Weiße Rose und nicht wenige andere Widerstandskämpferinnen und -kämpfer berufen haben. Frauke Höntzsch verortet das kollektive Widerstandsrecht mit seiner Anbindung an das Naturrecht in der Schwellenzeit zwischen Neuzeit und Moderne. Mit der Herausbildung des modernen Rechtsstaats sei es angesichts einer "konsequent individualistischen Argumentation" obsolet geworden. Höntzsch, Frauke (2017): Das kollektive Widerstandsrecht - Hybrid zwischen Tradition und Moderne. In: Zehnpfennig, Barbara (Hg.): Politischer Widerstand. Allgemeine theoretische Grundlagen und praktische Erscheinungsformen in Nationalsozialismus und Kommunismus, Baden-Baden: Nomos Verlag, S. 61-81. Rolf Gröschner untersucht „Das Widerstandsrecht im Grundgesetz" (Art. 20 IV GG), das die "Verteidigungswürdigkeit der freiheitlichen Ordnung" symbolisiere und in seinem die Freiheitsordnung bewahrenden Charakter "das Gegenbild der Revolution" darstelle. Gröschner, Rolf (2017): Das Widerstandsrecht im Grundgesetz. In: Zehnpfennig, Barbara (Hg.): Politischer Widerstand, S. 83-95, hier: S. 89.

34 Gliech, Oliver (2011): Saint-Domingue und die Französische Revolution. Das Ende der weißen Herrschaft in einer karibischen Plantagenwirtschaft. Köln/Weimar/Wien: Böhlau Verlag, S. 288.
"Erklärung der Menschenrechte für die Kolonien außer Kraft" und sprachen "den Kolonialversammlungen das Recht zu [...], für die gens de couleur eigene Rassegesetze zu erlassen." 35 Die Tür, die mit der Erklärung der Menschenrechte weit aufgestoßen worden war, dass nämlich das Widerstandsrecht sich nicht ausschließlich gegen einen ungerechten Herrscher und illegitimen Despoten richten müsse, sondern gerade auch zur Verteidigung unveräußerlicher Menschenrechte und gegen Unterdrückung eingesetzt werden könne, wurde im Hinblick auf die vielen Millionen rechtlos gemachter, gewaltsam versklavter Menschen in Frankreich und in den französischen Kolonien - allein 500.000 verrichteten 1790/1791 Zwangsarbeit auf den Kaffee- und Zuckerrohrplantagen Saint-Domingues ${ }^{36}$ - wieder verriegelt. Das aus der Französischen Revolution hervorgegangene Recht auf Widerstand gegen Unterdrückung wurde halbiert und zwischen Europa und den Kolonien aufgeteilt.

Doch "die Revolution" war kein exklusives europäisches Privileg. Das für weiße Zeitgenossen "undenkbare" Ereignis, als welches der Historiker Michel-Rolph Trouillot ${ }^{37}$ die Haitianische Revolution bezeichnet hat, sandte Schockwellen nach Europa und ein Leuchtfeuer der Selbstbefreiung in die übrigen Kolonien. ${ }^{38}$ Im August 1791 begann im Norden der Halbinsel der erste Aufstand und leitete einen revolutionären Prozess ein, der 1804 zur Gründung des ersten unabhängigen schwarzen Nationalstaates Haiti führte. Von Historiographen der Revolutionsgeschichte wurde die Haitianische Revolution indes ebenso "unver-

35 Gliech, Oliver (2011): Saint-Domingue und die Französische Revolution, S. 310.

36 Vgl. Gliech, Oliver (2011): Saint-Domingue und die Französische Revolution, S. 1, 50, 55.

37 Trouillot, Michel-Rolph (1995): An Unthinkable History: The Haitian Revolution as a Non-Event. In: Ders.: Silencing the Past: Power and the Production of History. Boston: Beacon Press, S. 70-107.

38 „Von Kuba bis South Carolina, von Bahia bis Louisiana beklagten sich Sklavenhalter über die ,Unverschämtheiten', die ihre Sklaven an den Tag legten, seitdem sie von der erfolgreichen schwarzen Revolution gehört hatten." Geggus, David Patrick (1989): The French and Haitian Revolutions, and Resistance to Slavery in the Americas: An Overview. In: Revue française d'histoire d'outre-mer 76/ Nr. 282-283, S. 107-124, hier: S. 111. Wirz, Albert (1984): Sklaverei und kapitalistisches Weltsystem. Frankfurt a.M.: Suhrkamp Verlag, S. 177ff. 
nehmlich"39 gemacht wie von europäischen politischen Denkern und Revolutionstheoretikerinnen. Anders als die Amerikanische und Französische Revolution erschien die Revolution in der Karibik noch weit bis ins 20. Jahrhundert hinein wie ausgelöscht und spurenlos gemacht. In Hannah Arendts Schrift Über die Revolution findet sich kein einziger Hinweis darauf, stattdessen die fehlerhafte Einlassung, "daß es weder im Altertum noch in der Neuzeit je zu wirklichen, geschichtlich ernstzunehmenden Sklavenaufständen gekommen ist". ${ }^{40}$

Wie Hegel ${ }^{41}$ so hatten auch Marx und Engels Kenntnis von den revolutionären Ereignissen in Haiti. In Die Deutsche Ideologie bot Max Stirners Der Einzige und sein Eigentum (1845) eine Angriffsfläche: Stirner, so heißt es dort, bildete sich ein, dass "die revolutionierenden Neger von Haiti und die weglaufenden Neger aller Kolonien [...] nicht sich, sondern , den Menschen' befreien wollen." 42 Marx und Engels bestritten jedoch energisch, dass der massenweisen Flucht von den kolonialen Plantagen und zumal der Haitianischen Revolution ein anderer als ein selbstbezüglicher Sinn, ein über die eigene Gegenwart hinausweisender Befreiungsanspruch für "den Menschen" zukomme, ${ }^{43} \mathrm{im}$ großen Unterschied zum Klassenkampf zwischen Proletariat und Bourgeoisie, der "auf seinen höchsten Ausdruck gebracht, eine totale Revolution bedeutet." 44 Sie wehrten das für Europäer und Sklavenhalter gleichermaßen ungeheuerliche, zutiefst schockierende Ereignis $a b$ : das einer schwarzen Revolution mit immen-

39 Rancière, Jacques (2002): Das Unvernehmen, S. 40-43. 40 Arendt, Hannah (1963): Über die Revolution. München: R. Piper Verlag, S. 273.

$41 \mathrm{Vgl}$. die erhellende historisierende Lektüre von Hegels Phänomenologie von Buck-Morss, Susan (2011): Hegel und Haiti. Für eine neue Universalgeschichte. Übersetzt von Laurent Faasch-Ibrahim, Berlin: Suhrkamp Verlag.

42 Marx, Karl/Engels, Friedrich (1978): Die deutsche Ideologie. Kritik der neuesten deutschen Philosophie in ihren Repräsentanten Feuerbach, B. Bauer und Stirner, und des deutschen Sozialismus in seinen verschiedenen Propheten. In: MEW, Bd. 3, Berlin: Dietz Verlag, S. 290.

43 Dazu von der Verfasserin ",Schwarze' und ,weiße Sklaverei'" in Karl Marx' Kritik des Amerikanischen Bürgerkrieges und der Politischen Ökonomie". In: Därmann, Iris (2020): Undienlichkeit. Gewaltgeschichte und politische Philosophie. Erscheint Berlin: Matthes \& Seitz.

44 Marx, Karl (1977): Das Elend der Philosophie. Antwort auf Proudhons „Philosophie des Elends". In: MEW, Bd. 4, Berlin: Dietz Verlag, S. 63-182, hier: S. 182. ser Ausstrahlungskraft für jede weitere Revolte. Von einem multiethnischen Verständnis des Proletariats und Vorstellungen eines revolutionären Transatlantik mit vielgestaltigen Formen aktiven und passiven Widerstands waren Marx und Engels denkbar weit entfernt. ${ }^{45}$ "Widerstand" war ein in der marxistischen Revolutionstheorie selten positiv besetzter Begriff. ${ }^{46} \mathrm{Er}$ diente vor allem dazu, die repressive Gegenwehr der Stände, der Fabrikanten, der Bourgeoisie, von Regierung, der Gendarmerie und Polizei gegen das aufbegehrende "Volk" bzw. gegen die revolutionäre Arbeiterklasse zu bezeichnen. ${ }^{47}$

Henry David Thoreau, der 1849 die Praxis des "zivilen Ungehorsams" begründen sollte, berief sich in seinem berühmten Essay On the Duty of Civil Disobedience unter Rekurs auf die Amerikanische und die Französische Revolution demgegenüber auf das Recht eines "Volkes", einer Regierung "Widerstand zu leisten, wenn ihre Tyrannei oder ihre Inkompetenz übergroß und unerträglich werden". ${ }^{48}$ Doch zu dieser Zeit - der Bürgerkrieg (1861-1865), in dem befreite Afroamerikaner in der repräsentativen Uniform der United States Colored Troops gegen die Südstaaten kämpfen sollten, lag ebenso in weiter Ferne wie Abraham

45 Ohne eine in dieser Hinsicht explizite Marx-Kritik untersuchen Peter Linebaugh und Marcus Rediker multiethnische Fallgeschichten eines "revolutionären Atlantiks". Linebaugh, Peter/Rediker, Marcus (2000): Die vielköpfige Hydra. Die verborgene Geschichte des Revolutionären Atlantiks. Übersetzt von Sabine Bartel. Berlin/Hamburg: Assoziation A, S. 351.

46 Eine Ausnahme findet sich in Engels, Friedrich (1977a): Revolution in Paris. In: MEW, Bd. 4, Berlin: Dietz Verlag, S. 528-530, hier: S. 529. "Gegen Abend fing das Volk an, Widerstand zu leisten."

47 Engels, Friedrich (1977b): Die preußische Verfassung. In: MEW, Bd. 4, Berlin: Dietz Verlag, S. 30-36, hier: S. 34; Marx, Karl (1977): Das Elend der Philosophie. Antwort auf Proudhons "Philosophie des Elends", S. 104; Engels, Friedrich (1977c): Die Kommunisten und Karl Heinzen. In: MEW, Bd. 4, Berlin: Dietz Verlag, S. 309-324, hier: S. 310; Engels, Friedrich (1977d): Die Reformbewegung in Frankreich. In: MEW, Bd. 4, Berlin: Dietz Verlag, S. 399-406, hier: S. 406; Marx, Karl/Engels, Friedrich (1977): Manifest der Kommunistischen Partei. In: MEW, Bd. 4, Berlin: Dietz Verlag, S. 459-493, hier: S. 473.

48 Thoreau, Henry David (2017): Ziviler Ungehorsam. Übersetzt von Ulrich Bossier. In: Braune, Andreas (Hg.): Ziviler Ungehorsam. Texte von Thoreau bis Occupy. Stuttgart: Reclam, S. 42-55, hier: S. 45. 
Lincolns Emancipation Proclamation -49 wähnte er kein "Volk" hinter sich. Daher begründete er seine Weigerung, Wahlsteuer an den Staat Massachusetts zu bezahlen, einschließlich seiner Bereitschaft, die Folgen seiner Handlung zu übernehmen und sich von eben jenem Staat mit Gefängnis bestrafen zu lassen, dem er solchermaBen die Gefolgschaft aufgekündigt hatte, mit seinem Gewissen: ${ }^{50}$ Es gebiete ihm als freiem Bürger, gegen die Sklaverei der Südstaaten und gegen den Expansionskrieg gegen Mexiko (1846-1848) zu protestieren, man ist versucht zu sagen, im Namen einer "kommenden Demokratie", ${ }^{51}$ in der die Anerkennung und formale Ausgestaltung der Menschenrechte für jedes Individuum "als höchsten und eigenständigen Souverän" Richtschnur allen staatlich-rechtlichen Handels sei. ${ }^{52}$ Der von inm selbst gewählte gewaltfreie Protest ${ }^{53}$ hinderte inn indes nicht daran, sich auf die Seite des weiBen Abolitionisten John Brown zu schlagen, der 1859 vergeblich versucht hatte, in der Nähe von Washington Sklaven aus den umliegenden Plantagen mit Waffen aus einem Waffenlager der Unionstruppen zu versorgen und sie zu einem Aufstand zu bewegen. ${ }^{54}$ John Brown wurde zum Tode

49 Siehe freilich Abraham Lincolns berühmt-berüchtigten Brief an Horace Greeley vom 22. August 1862, kurz vor der Schlacht am Antietam: "My paramount object in this struggle is to save the Union, and is not either to save or to destroy slavery. If I could save the Union without freeing any slave I would do it, and if I could save it by freeing all the slaves I would do it; and if I could save it by freeing some and leaving others alone I would also do that. What I do about slavery, and the colored race, I do because I believe it helps to save the Union; and what I forbear, I forbear because I do not believe it would help to save the Union." Lincoln, Abraham (1953): The Collected Works of Abraham Lincoln, Vol. 5, herausgegeben von Roy P. Basler, New Brunswick, N.J: Rutgers University Press, S. 389.

50 Arendt kritisiert Thoreaus Berufung auf das Gewissen, das ganz und gar "unpolitisch" und "subjektiv" sei. Arendt, Hannah (2017): Ziviler Ungehorsam. In: Braune, Andreas (Hg.): Ziviler Ungehorsam, S. 132-161, hier: S. 138.

51 Derrida, Jacques (2003): Das Recht des Stärkeren (Gibt es Schurkenstaaten)? In: Ders.: Schurken. Zwei Essays über die Vernunft. Übersetzt von Horst Brühmann, Frankfurt a.M.: Suhrkamp Verlag, S. 60.

52 Thoreau, Henry David (2017): Ziviler Ungehorsam, S. 55. 53 Vgl. Thoreau, Henry David (2017): Ziviler Ungehorsam, S. 52 .

54 Vgl. Marx, Karl (1980): Die amerikanische Frage in England (New York Daily Tribune, Nr. 6403 vom 11.Oktober 1861). In: MEW, Bd. 15, Berlin: Dietz Verlag, S. 304-314, hier: S. 310. verurteilt und hingerichtet, wie auch die aufständischen Sklaven. Doch Henry David Thoreau verteidigte in seinem Vortrag A Plea for Captain John Brown, den er am Samstagabend des 30. Oktobers 1859 vor den Bürgern von Concord, Massachusetts verlesen hatte, ${ }^{55}$ den Bürger John Brown, nicht aber die Afroamerikaner, die in diesen und vielen weiteren blutig niedergeschlagenen Aufständen im Gefolge der Haitianischen Revolution versucht hatten, sich selbst aus ihrer unrechtmäBigen Versklavung zu befreien. Die normativen Kriterien, die an die Handlungsform des zivilen Ungehorsams bis heute angelegt werden - öffentliche Sichtbarkeit, Gewaltlosigkeit in Form passiven und symbolischen Widerstands, politisch-moralische Motive, vernünftige Rechtfertigung und die Bereitschaft, die rechtlichen Sanktionen, mit denen die Ungehorsamsakte staatlicherseits geahndet werden, auf sich zu nehmen, nachdem alle anderen legalen Mittel erfolglos ausgeschöpft worden sind ${ }^{56}$ - schließt rechtlos gemachte und gewaltsam unterworfene Personen von den rechtlich eingehegten Formen zivilen Ungehorsams aus und richtet sich stattdessen einzig an (mehr oder minder anerkannte respektive potentielle) Bürger. Ziviler Ungehorsam wie auch das Widerstandsrecht sind von der Vorstellung getragen, dass sich die betreffenden Handlungen gegen einen illegitimen Souverän, einen unrechtmäßigen Staat bzw. gegen das ungerechte Verhalten von Staatsorgangen richtet: "Ziviler Ungehorsam entsteht", so Hannah Arendt, in ihrem gleichlautenden Vortrag von 1969,

wenn eine bedeutende Anzahl von Staatsbürgern zu der Überzeugung gelangt ist, daß entweder die herkömmlichen Wege der Veränderung nicht mehr offenstehen beziehungsweise auf Beschwerden nicht gehört und eingegangen wird oder daß im Gegenteil

55 Vgl. Thoreau, Henry David (30.10.1859): A Plea for Captain John Brown. http://avalon.law.yale.edu/19th_century/thoreau_001.asp, (Zugriff am 28.12.2018). Thoreau, Henry David (1973): Die letzten Tage des John Brown. In: Ders.: Über die Pflicht zum Ungehorsam gegen den Staat und andere Essays. Übersetzt von Walter E. Richartz, Zürich: Diogenes, S. 71-83.

56 Dreier, Ralf (1983): Widerstandsrecht und ziviler Ungehorsam im Rechtsstaat. In: Glotz, Peter (Hg.): Ziviler Ungehorsam im Rechtsstaat, Frankfurt a.M.: Suhrkamp, S. 54-75, hier: S. 60f.; sowie Schüler-Springorum, Horst (1983): Strafrechtliche Aspekte zivilen Ungehorsams. In: Glotz, Peter (Hg.): Ziviler Ungehorsam im Rechtsstaat, S. 76-98, hier: S. 79. 
die Regierung dabei ist, ihrerseits Änderungen anzustreben, und dann beharrlich auf einem Kurs bleibt, dessen Gesetz- und Verfassungsmäßigkeit schwerwiegende Zweifel aufwirft. ${ }^{57}$

Im Hintergrund standen die Proteste gegen den nicht-erklärten Krieg der USA gegen Vietnam und die Bürgerrechtsbewegung gegen die Rassendiskriminierungsgesetze, ${ }^{58}$ die Arendt gegenüber militanten Studenten- und Bürgerrechtsbewegungen wie der Organization of Afro-American Unity und den Black Panther Party for Self Defense abzugrenzen suchte. Die Legitimitätsformate des Widerstandsrechts und des zivilen Ungehorsams, so zentral sie für die Geschichte menschlicher Selbstbefreiung und zivilen Protests waren (und auch heute noch sind), erweisen sich als hoch voraussetzungsreich. Als politische Handlungsformen leiden sie an etatistischen Verengungen und zivilgesellschaftlichen Exklusionen. In jedem Fall beruhen sie auf den Institutionen des Oikos und der Polis, auf Konzepten von Privatheit und Öffentlichkeit, die all jene flachen Widerstandsaktivitäten und -passivierungen zum Verschwinden bringen, die sich im Modus eines unzivilen Ungehorsams gegen Machthaber im ökonomischen und häuslichen Bereich richten, gegen sexualisierte Gewalt und rassistische Folter in extraterritorialen Lagern und Gefängnissen, in Gewalt-, Folter- und Machträumen, neben oder jenseits öffentlicher Sichtbarkeit und Vernehmbarkeit. Die Aufmerksamkeit für kleine und große Konfrontationen, für aisthetische, symbolische, informelle, passive Widerstandsformen, die sich im Verborgenen abspielen müssen, steht und fällt mit der Frage, ob und, wenn ja, inwiefern diese politisch zu nennen sind, was unter dem Politischen in Extremsituationen der Gewalt überhaupt zu verstehen ist.

(3) Auch die dritte Traditionslinie, die mit der Reflexion über den autonomen Status von Kunst, mit Poietiken und "Ästhetiken des Widerstands" 59

57 Arendt, Hannah (2017): Ziviler Ungehorsam, S. $144 \mathrm{f}$. $58 \mathrm{Vgl}$. Arendt, Hannah (2017): Ziviler Ungehorsam, S. $145,149$.

59 Zur Rolle des proletarischen Lesens und Schreibens, zur literarischen Evokation des Leidens am Faschismus und des Widerstands der geeinten Arbeiterbewegung gegen den Faschismus, nicht zuletzt zu den Widerstandsgruppen der "Roten Kapelle" in Berlin um den Luftwaffenoffizier Harro Schulze-Boysen und Dr. Arvid Harnack siehe und gegenwärtig mit der ausdrücklichen Frage verbunden ist, ob "Kunst widerständig"60 sei, führt in dieser Hinsicht nicht unmittelbar weiter. Seit dem 18. Jahrhundert gründete sich Ästhetik auf die Grenzziehung zwischen Privatheit und Öffentlichkeit. Ästhetik war ein philosophisches Projekt, das auf rassistischen Aufteilungen des Sinnlichen und auf einer kapitalistischen "Lebensund Wirtschaftsform" beruhte, von der das aufsteigende Bürgertum als dessen Trägerschicht maximal profitieren konnte, wie Ruth Sonderegger zu Recht hervorhebt: ${ }^{61}$ Mit dem Strukturwandel der Öffentlichkeit in den Metropolen Europas wurden in den neuen bürgerlichen Salons, Teeund Kaffeehäusern jene Sucht- und Aufputschmittel, Zucker, Tee, Tabak, Kaffee, konsumiert, die auf den kolonialen Plantagen von versklavten Afrikanerinnen und Afrikaner produziert wurden. ${ }^{62}$ Die Erfindung des Körpers fand statt im Dispositiv der Sklaverei. In den Machträumen der Sklaverei wurden die versklavten Menschen mit extremer Gewalt und wie ,Vieh' behandelt. Das galt für die Lager, die baracoons und slave dungeons ${ }^{63}$ an den afrikanischen Küsten, in denen Afrikanerinnen und Afrikaner oft monatelang festgehalten wurden. Das galt für die Sklavenschiffe mit ihrer tödlichen Enge für die unter Deck "gestapelten" Menschen ${ }^{64}$ genauso wie für die Sklavenmärkte

Weiss, Peter (1983): Ästhetik des Widerstands. Roman, 3 Bde. Frankfurt a.M.: Suhrkamp Verlag.

60 Rancière, Jacques (2008): Ist Kunst widerständig? Übersetzt von Frank Ruda und Jan Völker. Berlin: Merve Verlag.

61 Siehe dazu und zum Folgenden die erhellende Analyse von Sonderegger, Ruth (2018): Kants Ästhetik im Kontext des kolonial gestützten Kapitalismus. In: Zeitschrift für Ästhetik und Allgemeine Kunstwissenschaft: Sensibilität der Gegenwart, herausgegeben von Burkhard Liebsch, Sonderheft 17, S. 109-129.

62 Vgl. Gikandi, Simon (2011): Slavery and the Culture of Taste, Princeton/Oxford: Princeton University Press, S. 5, S. 32. Siehe jetzt auch die Dissertation von Zandt, Stephan (2019): Die Kultivierung des Geschmacks. Eine Transformationsgeschichte der kulinarischen Sinnlichkeit. Erscheint Berlin: De Gruyter Verlag.

63 Dazu Saidiya V. Hartmans Schilderung eines slave dungeon in der Nähe der Küste von Accra mit meterdicken Schichten menschlicher Rückstände, die Archäologen 1972 freigelegt und als Blut, Fäkalien und Haut identifiziert hatten. Hartman, Saidiya V. (2007): Lose your mother. A Journey along the Trans Atlantic Slave Route, New York: Farrar, Straus and Giroux, S. 115.

64 Meissner, Jochen/Mücke, Ulrich/Weber, Klaus (2008): Schwarzes Amerika. Eine Geschichte der Sklaverei, Mün- 
bei Ankunft in der ,Neuen Welt'65 sowie für die kolonialen Plantagen, für die Bergwerke und Zuckermühlen, wo sie zur Zwangsarbeit eingesetzt wurden. ${ }^{66}$

Es war Teil des Kalküls der Sklavenhändler, der Kapitäne und Besatzungsmitglieder, der Schiffseigner, Aktionäre und Sklavenhalter, versklavte Menschen auf bloße ,pieces' bzw. ,hands' herabzuwürdigen und maximal dienstbar zu machen. Die europäische Ästhetik und Imagination von Blackness, kraft deren europäische Philosophen wie David Hume ${ }^{67}$ und Kant $^{68}$ den Versklavten

chen C.H. Beck, S. 70f.; Rediker, Marcus (2007): The Slave Ship. A Human History, Chicago: Viking Penguin.

65 Bailey, Anne C. (2017): The Weeping Time: Memory and the Largest Slave Auction in American History, New York: Cambridge University Press.

66 Die kolonialen Plantagen waren "factories in the field" so Pares, Richard (1960): Merchants and planters, Cambridge: University Press, S. 23; vgl. auch Wirtz, Albert (1984): Sklaverei und kapitalistisches Weltsystem, Frankfurt a.M.: Suhrkamp Verlag, S. 107.

67 Siehe dazu die berüchtigte Fußnote in Hume, David (1828): Essay of National Characters. In: The Philosophical Works of David Hume, Vol. III, Edinburgh: Adam Black and William Tait, S. 224-244, hier: S. 236, Anm. 2. „I am apt to suspect the negroes and in general all other species of men (for there are four or five different kinds) to be naturally inferior to the whites. There never was a civilized nation of any other complexion than white, nor even any individual eminent either in action or speculation. No ingenious manufactures amongst them, no arts, no sciences. On the other hand, the most rude and barbarous of the whites, such as the ancient GERMANS, the present TARTARS, have still something eminent about them in their valour, form of government, or some other particular. Such a uniform and constant differences could not happen in so many countries and ages, if nature had not made an original distinction betwixt these breeds of men. Not to mention our colonies, there are Negroe slaves dispersed all over Europe, of which none ever discovered any symptoms of ingenuity, tho'low people, without education, will start up amonst us, and distinguish themselves in every profession. In JAMAICA indeed they talk of one negroe as a man of parts and learning; but 'tis likely he is admired for very slender accomplishments like a parrot, who speaks a few words plainly." Bei dem von Hume erwähnten, namenlosen afroamerikanischen Mann handelt es sich um Francis Wallis, wie Gates Jr., Henry Louis (1987): Figures in Black: Words, Signs and the "Racial Self", Oxford: University Press, S. 13, 18, 43, herausgefunden hat. Siehe auch Ronnick, Michel Valerie (1998): Francis Williams. An Eighteenth-Century Tertium Quid. In: Negro History Bulletin 61, S. 19-29.

$68 \mathrm{Vgl}$. Kant, Immanuel (1983a): Über das Gefühl des Schönen und Erhabenen. In: Kant. Werke, Bd. 2, S. 825884, hier: S. 880. „Die Negers von Amerika haben von der jedes intellektuelle Talent und jede ästhetische Fähigkeit absprachen, wirkten an der Reduktion von Menschen auf bloße Körper zu Kommodifizierungs- und Ausbeutungszwecken maßgeblich mit.

Was Europa betraf, so formulierten Kant und Schiller zumal ein "ästhetisches Versprechen", das auf einem Bruch mit der sinnlich-gemeinschaftlichen Welt beruhte und der Bildung einer neuen Gemeinschaft galt. ${ }^{69}$ Die Briefe über die ästhetische Erziehung von 1795 standen erklärtermaßen unter dem Bann der "Kantischen Grundsätze", ${ }^{70}$ zugleich unter dem Eindruck des Terrors der Französischen Revolution, den Schiller auf eine ungleiche, nämlich klassenspezifische "Aufteilung" von Sinnlichkeit (auf die „niedern und zahlreichern Klassen") und Verstand (auf die "zivilisierten Klassen") ${ }^{71}$ zurückführte: Wer "von der Herrschaft bloßer Kräfte zu der Herrschaft der Gesetze" einen "Übergang"72 bahnen möge, der müsse das Pfand auf das "freie Spiel der Erkenntniskräfte" angesichts des Kunstschönen und auf Spielformen von Gesellschaft setzen. Von innen versprach sich Schiller die Errichtung eines "ästhetischen Staats", der "sich durch sich

Natur kein Gefühl, welches über das Läppische stiege. Herr Hume fordert jedermann auf, ein einziges Beispiel anzuführen, da ein Neger Talente gewiesen habe, und behauptet: daß unter den Hunterttausenden von Schwarzen, die aus ihren Ländern andernwärts verführt werden, obgleich deren sehr viele auch in Freiheit gesetzt werden, dennoch nicht ein einziger jemals gefunden worden, der entweder Kunst oder Wissenschaft, oder irgend einer anderen rühmlichen Eigenschaft etwas Großes vorgestellt habe, obgleich unter den Weißen sich beständig welche aus dem niedrigen Pöbel empor schwingen, und durch vorzügliche Gaben in der Welt ein Ansehen erwerben. So wesentlich ist der Unterschied zwischen den zwei Menschengeschlechtern, und er scheint eben so groß in Ansehung der Gemütsfähigkeiten, als der Farbe nach zu sein."

69 Rancière, Jacques (2006a): Schiller und das ästhetische Versprechen. In: Felix Ensslin (Hg.): Spieltrieb. Was bringt die Klassik auf die Bühne. Schillers Ästhetik heute. Berlin: Theater der Zeit, S. 39-55, hier: S. 40.

70 Schiller, Friedrich (1993): Über die ästhetische Erziehung des Menschen in einer Reihe von Briefen. In: Sämtliche Werke, Bd. V, herausgegeben von Gerhard Fricke/ Herbert G. Göpfert. 9. Auflage. München/Darmstadt: Wissenschaftliche Buchgesellschaft, S. 570.

71 Schiller, Friedrich (1993): Über die ästhetische Erziehung des Menschen in einer Reihe von Briefen, S. 580.

72 Schiller, Friedrich (1993): Über die ästhetische Erziehung des Menschen in einer Reihe von Briefen, S. 576. 
selbst und für sich selbst bildet": ${ }^{73}$ "Der Mensch spielt nur, wo er in voller Bedeutung des Worts Mensch ist, und er ist nur da ganz Mensch, wo er spielt." ${ }^{174}$ Die Bestimmung des Menschen freilich sei gerade seine äußerste "Bestimmungslosigkeit": Im „ästhetischen Zustand ist der Mensch also Null", „in Rücksicht auf Erkenntnis und Gesinnung [...] völlig indifferent und unfruchtbar", im Hinblick auf Wahrheit und Pflicht gleichermaßen "ungeschickt". Diesen ästhetischen Nullzustand nannte Schiller Freiheit. Mit anderen Worten: Das Spiel ist eine abgründige Erfahrung ohne Telos, auch und gerade in Bezug auf den Menschen, "der Grund der Möglichkeit von allem ist", weil er selbst grundlos, kein Grund für nichts ist. ${ }^{75}$

Noch Antonin Artauds "organloser Körper", ${ }^{76}$ Georges Batailles Heterologien ${ }^{77}$ und weitere Spieltheorien $^{78}$ des 20. Jahrhunderts korrespondieren mit solch' ästhetischen Konzepten der Zwecklosigkeit, haben jedoch konsequenterweise die Orientierung an ästhetischer Staatlichkeit und subjektiver Vermögenslehre aufgegeben. Deleuze und Guattari weisen in Milles Plateaux auf Antonin Artauds seltsame Idee eines organlosen Körpers hin. ${ }^{79}$ Mit dieser Idee weist Artaud nicht etwa

73 Schiller, Friedrich (1993): Über die ästhetische Erziehung des Menschen in einer Reihe von Briefen, S. 578.

74 Schiller, Friedrich (1993): Über die ästhetische Erziehung des Menschen in einer Reihe von Briefen, S. 618.

75 Schiller, Friedrich (1993): Über die ästhetische Erziehung des Menschen in einer Reihe von Briefen, S. 635. Vgl. dazu die instruktive Analyse von Menke, Christoph (2006): Vom Schicksal ästhetischer Erziehung. Rancière, Posa und die Polizei. In: Felix Ensslin (Hg.): Spieltrieb, S. 58-70, hier: S. 62f., 64.

$76 \mathrm{Zu}$ Antonin Artauds „le corps sans organes" siehe Artauds, Antonin (1974): Fuvres complètes. Bd. XIII. Paris: Éditions Gallimard, S. 34, 114, 287.

77 Die "Heterologie" bzw. "Skatologie" ist bekanntlich bloßes Projekt geblieben, das Bataille nur bruchstückhaft skizziert hat. Vgl. Bataille, Georges (1970a): Dossier "Hétérologie". In: Euvres complètes, Bd. II. Paris: Éditions Gallimard, S. 167-205; vgl. auch Bataille, Georges (1970b): Dossier de la polémique avec André Breton. In: Fuvres complètes, Bd. II, S. 51-109, hier: S. 61-65. Siehe dazu Mattheus, Bernd (1984): George Bataille. Eine Tanatographie, Bd. I. München: Matthes \& Seitz, S. 206.

78 Vgl. Caillois, Roger (1982): Die Spiele und die Menschen. Maske und Rausch, übersetzt von Sigrid von Massenbach, Frankfurt a.M./Berlin/Wien: Ullstein; Huizinga, Johan (1956): Homo Ludens. Vom Ursprung der Kultur im Spiel, Reinbek bei Hamburg: Rowohlt Taschenbuch Verlag. 79 Deleuze, Gilles/Guattari, Félix (1992): 28. November 1947 - Wie schafft man sich einen organlosen Körper? In: die Organe des Körpers zurück, sondern vielmehr ihre je bestimmte Organisation, um daraus eine "nützliche Arbeit" und Funktionalität zu „extrahieren". Deleuze und Guattari halten dafür, den Organismus zu demontieren und den Körper (der Klassen) stattdessen für die Desartikulation seiner Organe, für Intensitätsverteilungen, Schwellenerfahrungen und Konnexionen zu öffnen.

Hume, Kant und Schiller hatten bürgerliche Künstler und Rezipienten, nicht jedoch "Irokesen", ${ }^{80}$ Frauen, versklavte, recht- und eigentumslose Menschen im Sinn, die gerade nicht zwecklos spielen oder ausschweifend schlafen, sondern die Drecksarbeit verrichten sollten. Marx und Engels selbst arbeiteten bekanntlich daran, den Körper der proletarischen Klasse zu spalten und zu homogenisieren, indem sie dem "durchtrieben", "ordinär", buntscheckig und politisch wankelmütig erscheinenden "Lumpenproletariat" die Zugehörigkeit zur proletarischen Klasse absprachen und den Zugang zum Klassenkampf verwehrten. So in der Schrift Der achtzehnte Brumaire des Louis Bonaparte (1852), in der Marx seinen Unmut ergoss über die

Vagabunden, entlassene[n] Soldaten, entlassene[n]
Zuchthaussträflinge, entlaufene[n] Galeerensklaven,
Gauner, Gaukler, Lazzaroni, Taschendiebe, Taschen-
spieler, Spieler, Maquereaus, Bordellhalter, Lastträger,
Literaten, Orgeldreher, Lumpensammler, Scheren-
schleifer, Kesselflicker, Bettler, ${ }^{81}$

die er zum reaktionären "Lumpenproletariat" zählte, zu einer "ganz unbestimmte[n], aufgelöste[n], hin- und hergeworfe[n] Masse" ohne eigenes Bewusstsein als "Klasse für sich". Marx erklärte das infame, hungernde und kreative "Lumpenproletariat" zum unproduktiven "Auswurf, Abfall, Abhub aller Klassen",82 die versklavten und sich selbst befreienden Afroamerikaner hingegen zum schlechthin Anderen jeder Klasse.

Doch es gab eine "Poesie der Klasse”, wie namentlich Jacques Rancière und Patrick Eiden-

Dies.: Tausend Plateaus. Kapitalismus und Schizophrenie 2. Übersetzt von Gabriel Ricke und Ronald Voullié. Berlin: Suhrkamp Verlag, S. 205-227.

80 Kant, Immanuel (1983b): Kritik der Urteilskraft. In: Kant. Werke, Bd. 8, herausgegeben von Wilhelm Weischedel. Darmstadt: Wissenschaftliche Buchgesellschaft, S. 280. 81 Marx, Karl (1960): Der achtzehnte Brumaire des Louis Bonaparte. In: MEW, Bd. 8, Berlin: Dietz Verlag, S. 161.

82 Marx, Karl (1960): Der achtzehnte Brumaire des Louis Bonaparte, S. 161. 
Offe gezeigt haben. Die Erfindung und Hervorbringung des Proletariats waren mit einem literarisch-poetischen Imaginären verknüpft, so Eiden-Offe: Das Vormärz-Proletariat ist gerade auch auf dem Feld des Romantischen Antikapitalismus entstanden, hat in Ludwig-Tieck-Novellen, in Gesellengedichten oder Kolportageromanen Gestalt angenommen. ${ }^{83} \mathrm{Im}$ Anschluss an die Julirevolution von 1830 folgt Jacques Rancière Arbeiterliteraten in deren schlaflose Nächte, die sie nicht zur Reproduktion ihrer Arbeitskraft nutzten, sondern um sich zu verausgaben: an das Schreiben, an den Opium-, Alkohol- oder Liebesrausch, an die Einsamkeit oder an politische Debatten und Streitigkeiten. ${ }^{84}$ Der Kampf der englischen Arbeiterbewegung gegen die Kinderarbeit und um den Zehnstundentag, der dem "vampiristischen" Hunger des Kapitals nach lebendiger Mehrarbeit und der "Aussaugung" von nächtlicher Überarbeit einen gesetzlichen Riegel vorschieben sollte, ${ }^{85}$ verwandelte sich unter den Saint-Simonisten, Fourieristen und Ikariern gerade auch in einen poietischen Kampf um die eigene Nacht und den Widerstand gegen "illegitime Arbeitsdienste [...], die die Ausbeuter in den Momenten fordern, die völlig uns gehören müssten". ${ }^{86}$ Hier wie dort war es ein zäher Kampf um einen Fetzen Freiheit und um Selbstbestimmung über Tag und Nacht, Wachen und Schlafen. In den englischen Textilfabriken und Maschinenbauwerkstätten wurde er durch Enteignungen und Wiederaneignungen des Wissens um Uhrzeit und Minuten ausgefochten, wie betroffene Arbeiterinnen und Arbeiter bezeugten. ${ }^{87}$

83 Eiden-Offe, Patrick (2017): Die Poesie der Klasse. Romantischer Antikapitalismus und die Erfindung des Proletariats. Berlin: Matthes \& Seitz.

84 Vgl. Rancière, Jacques (2013): Die Nacht der Proletarier. Archive des Arbeitertraums. Übersetzt von Brita Pohl, Wien/Berlin: Turia + Kant.

85 Marx, Karl (1962): Das Kapital. In: MEW, Bd. 23, Berlin: Dietz Verlag,S. 247, 271, 280.

86 Gauny an Ponty, 4. Mai 1838, Fonds Gauny, Ms. 168, zitiert nach Rancière, Jacques (2013): Die Nacht der Proletarier. Archive des Arbeitertraums, S. 100.

87 Vgl. Kydd, Alfred S. (1857): History of the Factory Movement. The Year 1802, to the Enactment of the Ten Hours' Bill in 1847. Vol. 1, London: Simpkin, Marshall, amd Co., S. 283f.; Holloway, John/Thompson, Edward P. (2007): Blauer Montag. Über Zeit und Arbeitsdisziplin. Übersetzt von Lars Stubbe. Hamburg: Nautilus, S. 56; Thompson, Edward P. (1979): Wahrnehmungsformen und Protestverhalten. Stu-
Die Möglichkeiten für Flucht- und Ausbruchversuche aus dem Zyklus minimaler Reproduktion und extensiver Arbeitsdisziplin waren unter dem englischen „Fabrikregime" 88 eingeschränkter als unter den prekären, postrevolutionären Lebensund Arbeitsbedingungen der Pariser Handwerker, Näherinnen, Schildermaler, Wäscherinnen, Dienstleister, Kleingewerbetreiberinnen, Schriftsetzern und Tagelöhnern, die nachts ins intellektuelle Ungewisse aufbrachen, kurzlebige Arbeiterzeitschriften wie La Phalange, La Ruche populaire oder L'Atelier herausgaben, literarische Zirkel gründeten, sich in mehr oder minder konkreten Utopien von universalen Assoziationen ergingen oder sich während der Arbeit ziellosen Träumereien hingaben. Reicht es hin, sich die Nächte um die Ohren zu schlagen, die Fabrikglocke zu überhören, blau zu machen, wegzulaufen und davon zu träumen, Dichter in einem unerreichbaren Reich der Freiheit zu sein, um widerständig zu sein? Oder muss sich Widerstand nicht vielmehr in kollektiver Weise formieren und nicht zuletzt wirkungsvoll artikulieren, um einen genuin politischen Richtungssinn anzuzeigen?

\section{2 "Wo Macht ist, ist auch Gegenmacht"}

Widerstand ist, Edmund Husserl und Sigmund Freud zufolge, eine gemischte Praxis aus Sinn und Kraft. Sie richtet sich gegen eine andere, gegenstrebige Kraft, stemmt sich gegen eine unterwerfende Macht, steht quer zu einer bezwingenden Gewalt und ist damit stets eine Frage ungleicher Kräfteverhältnisse. Damit bestreitet sie zugleich die Vollständigkeit und Gewissheit eines vorherrschenden Sinnsystems, widersetzt sich seiner Gewaltgeschichte, rassistischen Moral, politi-

die zur Lage der Unterschichten im 18. und 19. Jahrhundert. Übersetzt von Detlev Puls. Frankfurt a.M.: Suhrkamp Verlag; Thompson, Edward P. (1987): Die Entstehung der englischen Arbeiterklasse, 2 Bde. Übersetzt von Lotte Eidenbenz u.a., Frankfurt a.M.: Suhrkamp Verlag. Zur globalgeschichtlichen Erforschung der Geschichte der Arbeit und Arbeiterbewegung; Linden, Marcel von der (2003): Transnational Labour History. Explorations. Ashgate: Aldershot; Linden, Marcel von der (2008): Workers of the World. Essays toward a Global Labor History. Leiden: Brill.

88 Marx, Karl (1962): Das Kapital, S. 316. 
schen Zoologie, kolonialen Ökonomie und fordert diese mit einem Gegensinn heraus. "Wo Macht ist, ist auch Gegenmacht", 89 skandierte Michel Foucault unter dem Eindruck der Hypothese Nietzsches vom Willen zur Macht, der stets mit differentiellen Machtverhältnissen, mit mehr als nur einer einzigen Macht rechnet. ${ }^{90}$ Dieses Wogegen kann als ein punktuelles Ereignis auftreten, in Form eines kurzfristigen Aufbegehrens, vielleicht als herausforderndes Lachen aufflammen, sich als offene Befehlsverweigerung ereignen, einen fortwährenden Kampf bis zur Erschöpfung aller widerständigen Kräfte bezeichnen, ohne Frage auch heißen, siegreich zu widerstehen, mit Erfolg anzuklagen und zu fordern. In repressiven und destruktiven Gewalt- und Machträumen der Dienstbarmachung entfaltet nicht so sehr die Macht als vielmehr die Gegenmacht eine erfinderische Produktivität. ${ }^{91} \mathrm{Im}$ Verhältnis zu Macht und Gewalt ereignen sich Widerstand und Gegengewalt nicht zuerst im Brennpunkt einer großen Revolution und eruptiven Weigerung,

sondern es gibt einzelne Widerstände: mögliche, notwendige, unwahrscheinliche, spontane, wilde, einsame, abgestimmte, kriecherische, gewalttätige, unversöhnliche, kompromißbereite, interessierte oder opferbereite Widerstände [...], die Widerstandspunkte, -knoten und -herde sind mit größerer oder geringerer Dichte in Raum und Zeit verteilt, gelegentlich kristallisieren sie sich dauerhaft in Gruppen oder Individuen, ${ }^{92}$

an bestimmten Zonen des menschlichen Körpers, seiner potentia passiva $a^{93}$ und potentia activa, an "transitorischen Widerstandspunkten." 94 "Wo es

89 Foucault, Michel (1994): Das Subjekt und die Macht. In: Dreyfus, Hubert L./Rabinow, Paul (Hgg.): Michel Foucault. Jenseits von Strukturalismus und Hermeneutik. Weinheim: Beltz Athenäum, S. 241-261, hier: S. 254.

$90 \mathrm{Vgl}$. Nietzsche, Friedrich (1967-77/88a): Zur Genealogie der Moral. Eine Streitschrift. In: Kritische Studienausgabe, Bd. 5, herausgegeben von Giorgio Colli und Mazzino Montinari. Berlin/New York/München: De Gruyter Verlag/ dtv, 2. Abhandlung, 12., S. 313-316; siehe auch Deleuze, Gilles (2002): Nietzsche und die Philosophie. Übersetzt von Bernd Schwibs. Hamburg: Europäische Verlagsanstalt, S. $69 \mathrm{ff}$.

91 Vgl. Foucault, Michel (1983): Sexualität und Wahrheit. Der Wille zum Wissen. Übersetzt von Ulrich Raulf und Walter Seitter, Frankfurt a.M.: Suhrkamp Verlag, S. $27 f f$.

92 Foucault, Michel (1983): Sexualität und Wahrheit, S. 117. 93 Vgl. Agamben, Giorgio (2005): Nymphae, herausgegeben und übersetzt von Andreas Hiepko. Berlin: Merve, S. 78. 94 Foucault, Michel (1983): Sexualität und Wahrheit, S. 117.
Macht gibt, gibt es Widerstand." 95 Zu widerstehen ist der Beginn aller "Erfindsamkeit", der "Kunst der nuances, d[er] feine[n] Fingerfertigkeit in der Handhabe von nuances", ${ }^{96}$ sich undienlich zu machen. An allen Ereignissen und Formen des Widerstandes ist das wohl Unerklärlichste, dass und wie überhaupt aus dem unerträglichen Leid, das mit Ohnmacht, mit gewaltsamer Ausbeutung, Versklavung, Misshandlung, Demütigung, Unterwerfung, Kraftlosigkeit, Auszehrung, Erschöpfung und Ausweglosigkeit verbunden ist, die Kraft der Zurückweisung, des Widerstehens und Sich-Entziehens hervorgehen kann.

In Gewalt- und Machträumen, die auf destruktive Überarbeit und Vernichtung ausgerichtet sind, müssen sich Widerstände vielfach im Verborgenen, unter der Maske der Unterwürfigkeit und des vermeintlichen Einverständnisses abspielen, um Raum und Zeit zu schaffen für geheime Aufzeichnungen, Fluchtvorbereitungen, nächtliches Tanzen, Sabotage, Diebstahl, Tagträume, Freundschaftsgespräche, Gebete, Trauer und Scheitern. Zwischen „Eigensinn", Mitmachen und Verweigern einerseits, ${ }^{97}$ Aufstand, Subversion und Revolte andererseits, bewegt sich Widerstand selbst in einem Kräftefeld eines Mehr oder Weniger und lässt sich nur schwer in einer Form oder Bedeutung hypostasieren. Als gegenwendige Praxis, die nicht bei sich selbst beginnt, erscheint sie selbst renitent gegenüber begrifflichen Festlegungen.

95 Foucault, Michel (1983): Sexualität und Wahrheit, S. 116. 96 Nietzsche, Friedrich (1967-77/88b): Nachlass Oktober - November 1888. In: Kritische Studienausgabe, Bd. 13. 24[1], S. 618.

97 Unter dem Hegel entlehnten Leitbegriff des Eigen-Sinns hat Alf Lüdtke den beruflichen Alltag von Fabrikarbeiterinnen und -arbeitern untersucht: „Eigensinn wird in aller Regel als ein Unterfall von Widerstand oder Widerständigkeit begriffen. Im vorherrschenden Blick pendeln Verhaltensweisen zwischen zwei Polen: Gehorsamkeit und Folgsamkeit auf der einen, Widerständigkeit und offener Widerstand auf der anderen Seite. Im Unterschied dazu zielt die Frage nach dem Eigensinn auf ein Verhalten jenseits solcher Entweder-Oder-Fixierung. " Lüdtke, Alf (1993): Eigen-Sinn: Fabrikalltag, Arbeitererfahrungen und Politik vom Kaiserreich bis in den Faschismus, Hamburg: Ergebnisse, S. 380; zu Hegels Verwendung des Begriffs im "Herr-Knecht-Kapitel" der Phänomenologie des Geistes siehe auch Lüdtke, Alf (1994): Geschichte und Eigensinn. In: Berliner Geschichtswerkstätten (Hg.): Alltagskultur, Subjektivität und Geschichte. Zur Theorie und Praxis von Alltagsgeschichte. Münster: Westfälisches Dampfboot, S. 139-153, hier: S. $149 f$. 
Als Re-Aktion bleibt sie irreduzibel gebunden an ein Wogegen und spielt sich nicht selten in einer „Undeutlichkeits-, Ununterscheidbarkeitsund Ambiguitätszone" ${ }^{198} \mathrm{ab}$, in der die Grenzlinien zwischen Tätern und Opfern, Gewalthabern und Gewaltunterworfenen sich verstricken und diffus bleiben. Das gilt gerade auch für Figuren des Dritten, ${ }^{99}$ die gezwungen werden, Zwang auszuüben, und selbst mit Gewalt dazu gebracht werden, gewalttätig zu sein. Ist Überleben in einer Situation extremer Gewalt ein Widerstandsakt? Kann er unter solchen Umständen eine politische Dimension entfalten? Wer oder was verleiht dem Akt des Aufbegehrens gegen eine feindliche Macht und vernichtende Gewalt eine politische Signatur? Wollte man ihn am Erfolg messen, am effektiven Schaden, den er den Gewalthabern zufügt, am Sturz des Gewaltregimes, gegen den er sich richtet, machte man die zahllosen gescheiterten, im Sande verlaufenden und beinahe spurenlos verlaufenden Widerstandsakte terrorisierter, anteilsloser, ausgezehrter und erniedrigter Menschen einmal mehr unsichtbar. Stattdessen ist es angemessen, den politischen Richtungssinn von Widerständen am Selbstverständnis derer zu orientieren, die sie praktizieren. Das zumindest eröffnet einen Zugang zu Widerstandspraktiken der Aisthesis, der Passivierung, des sich Undienlichmachens und des Undienlichwerdens und öffnet den Blick für augenblickliche Wirklichkeiten, punktuelle Wirkungen und ephemere Wirksamkeiten: Noch der unscheinbarste und geringste Widerstand hat eine diagnostische Wirkung in Bezug auf die Ungebrochenheit und Absolutheit von Macht. Er führt, zumindest für die Dauer seines Auftretens und Ereignisses, eine diágnosis, ${ }^{100}$ eine Unterscheidung und Entschei-

98 Deleuze, Gilles (1994): Bartleby oder die Formel. Übersetzt von Bernhard Dieckmann. Berlin: Merve, S. 31.

$99 \mathrm{Vgl}$. Koschorke, Albrecht (2010): Institutionentheorie. In: Esslinger, Eva/Schlechtriemen, Tobias/Schweitzer, Doris et al. (Hgg.): Die Figur des Dritten. Ein kulturwissenschaftliches Paradigma. Berlin: Suhrkamp Verlag, S. 49-64, hier: S. 49. Koschorke erkennt in der "Figur des Dritten" die sich ausschließenden Möglichkeiten der „Irritation" oder der "Institution" (der Macht und Gewalt), wie ich hinzufügen möchte. Diese beiden Möglichkeiten vereinen sich in Gewalt- und Machträumen nicht selten in ein und derselben (Kipp-)Figur des Dritten, des "Aufsehers", "Treibers", "Kapos".

100 Zum "diagnostischen" Aspekt von Widerstand siehe Hartman, Saidiya V. (1997): Scenes of Subjection. Terror, dung zwischen Macht und Gegenmacht, mithin eine Gewaltenteilung in statu nascendi herbei. Widerstand zerteilt je von Neuem die Gewaltfülle und Machtvollkommenheit derer, die sie ausüben und verkörpern, auch dann, wenn er sich nicht auf öffentlicher Bühne abspielen kann, sondern als fintenreiches, geheimes Manöver, mit heimtückischer Präsenz an den Rändern und in den Ritzen der Macht, das heißt in jenen Räumen und an Orten vollzogen wird, die die europäische politische Philosophie als präpolitisch deklassiert hat. Widerstand nimmt sich durch sich selbst sein Recht auf Widerstand, er durchkreuzt eine herrschende Absicht und bestreitet eine öffentlich anerkannte Macht, ohne damit selbst unmittelbar in die Öffentlichkeit zu treten. Das gelingt inm nicht selten überhaupt erst mit historischer Verspätung und Nachträglichkeit, im Modus einer verité à faire. ${ }^{101}$ Die Grenzziehung zwischen Oikos und Polis, zwischen präpolitischer Privatheit und politischer Öffentlichkeit, macht nur aus der Perspektive von Sklavenhaltern, Gewalthabern, Hausherren und Bürgern ,Sinn'. ${ }^{102}$ Sie verbrämt und verdunkelt die sexuelle und sexualisierte Gewalt des Hauses, die Zwangsarbeit auf den Plantagen, die "destruktive Arbeit"103 auf Kriegsschauplätzen

Slavers, and Self-Making in Nineteenth-Century America. New York: Oxford University Press, S. 42, 56; sowie Abu-Lughod, Lila (1990): The Romance of Resistance: Tracing Transformations of Power through Bedouin Women. In: American Ethnologist Vol. 17, No. I (1990), S. 41-55, hier: S. 42, 53.

101 Vgl. Merleau-Ponty, Maurice (1955): Les aventures de la dialectique. Paris: Éditions Gallimard, S. 269.

102 Arendt, Hannah (2007): Vita activa oder Vom tätigen Leben. 6. Auflage. München: Serie Piper, S. 39, 42, 45.

103 Clausen, Lars (1988): Produktive Arbeit, destruktive Arbeit. Soziologische Grundlagen. Berlin/New York: De Gruyter. Clausen räumt mit mehr als nur einem Vorurteil über die „Produktivität" von Arbeit auf. Er unterscheidet zwischen der "spektakulär am Militärischen nachgeprüfte[n] Destruktion in der Arbeit" und der "Vernichtungsarbeit" in deutschen Konzentrations- und Vernichtungslagern sowie der Zwangsarbeit, ferner der völlig sinnlosen, ausschließlich zur Quälerei und Tötung von Menschen eingesetzten "Arbeit" (S. 70f., 72ff.). Philosophisch gedacht: jede Arbeit, die nicht zugleich auch Trauerarbeit ist und damit den für sie konstitutiven Bezug zum Aufschub des Todes anderer gekappt hat, ist und wird destruktiv. "Die Trauerarbeit [ist] keine Arbeit unter anderen", sondern "die Arbeit selbst, die Arbeit im allgemeinen." Derrida, Jacques (1995): Marx' Gespenster. Der verschuldete Staat, die Trauerarbeit und die neue Internationale. Übersetzt von Susanne Lüdemann. Frankfurt a.M.: S. Fischer Verlag, 
und in Vernichtungslagern, und damit jene nichtoder halb-öffentlichen Räume, in denen sich mitunter nur "zerstreute Widerstände" 104 ereignen können, ohne eine deutliche diskursive Spur zu hinterlassen.

Die Sprache der politischen Philosophie war und ist die Sprache der Handlung und der Aktion. Die Denker des Staates, der Herrschaft und der Macht waren stets auf der Seite der Souveränität, der Aktivität und der Versklavung, nicht aber auf der Seite der Ohnmacht, des Leidens und der Heteronomie, ${ }^{105}$ an deren kolonialer Legitimation und öffentlicher Verhehlung sie vielmehr selbst mitgewirkt haben. Leid und Passivität haben aber auch unter den Denkern der "Anteilslosen" und der revolutionären Selbstbefreiung einen schlechten Ruf. ${ }^{106}$ Gilt es doch gerade, Ohnmacht und Ausbeutung zu überwinden und in einen offenen Kampf mit denjenigen einzutreten, die den Anteilslosen ihren Zugang zum Sagbaren und Sichtbaren, zu Gleichheit und Freiheit verwehren. Wie aber sind Makrophysiken revolutionärer Gegengewalt und Mikrophysiken des Widerstands miteinander verwoben? Eine politische Theorie, die darauf antworten könnte, müsste das Politische von einer passiven Synthesis, ${ }^{107}$ von der "Passivität als Widerstand"108 und von Praktiken der Passivierung ausgehend denken. Widerständigkeit in Extremsituationen der Gewalt ist gerade auch bestimmt von buchstäblichen body politics

S. 26, 157. Siehe dazu von der Verfasserin (2020): Dienstgemeinschaft und "Arbeitsstaat". Martin Heideggers und Ernst Jüngers Konzepte "destruktiver Arbeit". In: Dies.: Undienlichkeit.

104 Hartman, Saidiya V. (1997): Scenes of Subjection, S. 65. 105 Das ist die in das Feld der politischen Philosophie übersetzte Beobachtung von Kathrin Busch: „In der abendländischen Philosophie gehört der Begriff der Passivität' sicherlich zu den am stärksten marginalisierten Konzepten." Busch, Kathrin (2012): P - „Passivität”. Hamburg/Lüneburg: Textem Verlag, S. 10f., 15, 20. Buschs Analysen sind wegweisend für die zeitgenössischen Passivitätsdebatten, nicht zuletzt auf dem Kunstfeld. Siehe auch Busch, Kathrin/Draxler, Helmut (Hgg.) (2013): Theorien der Passivität. München: Fink Verlag.

106 Rancière, Jacques (2006b): Das ästhetische Unbewußte. Übersetzt von Ronald Vouillé. Berlin/Zürich: diaphanes, S. 17, 33.

$107 \mathrm{Vgl}$. Husserl, Edmund (1966): Analysen zur passiven Synthesis.

108 Kathrin Busch spricht nicht von "passivem Widerstand", sondern von "Passivität als Widerstandsform". Busch, Kathrin (2012): P - „Passivität”, S. 15-19. des Überlebens und Gesten des Sich-Entziehens, des Fliehens und Verschwindens, um sich für den Zugriff der Macht unverfügbar zu machen.

Die neuere Gewaltsoziologie, die sich nicht mehr primär mit Gewaltursachen, Gewaltmotiven und gar Gewaltrationalitäten auseinandergesetzt, ${ }^{109}$ sondern vielmehr eine dynamisch-prozesshafte, situative, verlaufs- und vollzugsorientierte „Phänomenologie der Gewalt"110 entwickelt hat, hat mit ihrer Aufmerksamkeit für die "physische Gewalt"111 als „Inbegriff sinnlicher Erfahrung infolge ihrer Körperbezogenheit"112 zu Recht das Leiden, den Schmerz, die Verletzung und Beschämung von Gewaltopfern in den Blick genommen und die Täterzentrierung früherer Gewaltsoziologien hinter sich gelassen. ${ }^{113}$ Prominente Vertreter wie Wolfgang Sofsky, der in der Gewaltausübung (wie im Gewaltverzicht) eine irreduzible menschliche Freiheitsdimension erkennt, ${ }^{114}$ hebt in seiner an Elias Canetti orientierten Beschreibung „absoluter Gewalt"115 mit George Bataille auf die "Gewaltökonomie der Ver-

$109 \mathrm{Vgl}$. Birgit Nedelmann (1997): Gewaltsoziologie am Scheideweg, S. 64.

110 Mit der von Edmund Husserl entwickelten, von Maurice Merleau Ponty, Emmanuel Lévinas, Bernhard Waldenfels u.a. akzentuierten Methode der Phänomenologie hat die "Phänomenologie der Gewalt" auf den ersten Blick wenig gemein, allerdings ist in Vergessenheit geraten, dass der entscheidende, gerade auch soziologisch relevante, Beitrag der Phänomenologie in ihren elaborierten Untersuchungen von „Interkulturalität”, "Intersubjektivität”, "Leiblichkeit”, „Fremderfahrung", „Passsivität”, „Affekt" und „Affizierung”, "Bildlichkeit”, „Wahrnehmung", „Erinnerung”, „Phantasie”, "Zeitbewusstsein", „alltäglicher Lebenswelt" (allesamt von Husserl geprägte Begriffe) liegt. Hier eröffnet sich ein breites interdisziplinäres Arbeitsfeld, das mit den Arbeiten von Alfred Schütz, Thomas Luckmann, Thomas L. Berger noch lange nicht ausgeschöpft ist.

111 Lindenberger, Thomas/Lüdtke, Alf (1995): Einleitung. Physische Gewalt - eine Kontinuität der Moderne. In: Dies. (Hgg.): Physische Gewalt. Studien zur Geschichte der Neuzeit. Frankfurt a.M.: Suhrkamp Verlag, S. 7-30.

112 Imbusch, Peter (2000): Gewalt - Stochern in unübersichtlichem Gelände. In: Mittelweg 36/2, S. 24-40, hier: S. 27.

113 Zur Gegenüberstellung von alter und neuer soziologischer Gewaltforschung siehe Nedelmann, Birgit (1997): Gewaltsoziologie am Scheideweg., S. 66.

114 Vgl. Sofsky, Wolfgang (2002): Zeiten des Terrors. Amok. Terror. Krieg. Frankfurt a.M.: S. Fischer Verlag, S. $13 f .$, S. 27.

115 Sofsky, Wolfgang (1996): Traktat über die Gewalt. Frankfurt a.M.: S. Fischer Verlag, S. 178. 
ausgabung"116 und den Selbstzweck von Gewalt $a b$, die sich durch sich selbst nährt: Im Exzess nämlich des Massakers, der sich entlädt, nachdem Jagd und Kampf abgeschlossen, die Gejagten umzingelt und jeder "Greueltat ausgeliefert" sind. Noch den "handfesten Widerstand", der sich auf Seiten der Opfer der "absoluten Gewalt" entgegensetzt, speist er als rekursive Verstärkung in die Eigendynamik und "reine Praxis" des blutigen Gemetzels ein. ${ }^{117}$ Jan Philipp Reemtsma sieht in seiner "Phänomenologie körperlicher Gewalt" und Analyse "lozierender", "raptiver" und "autotelischer Gewalt", die den Körper als "Masse" und zu beseitigendes Hindernis im Raum, als (sexuelles) Verfügungsobjekt respektive als Beschädigungs- und gar Zerstörungsobjekt behandelt, ${ }^{118}$ gleichfalls von der Auseinandersetzung mit der (un-)möglichen Gegengewalt und Widerständigkeit von Gewalterleidenden ab.

Eine anspruchsvolle Gewaltforschung freilich, die auf die Transformationen, ${ }^{119}$ die Eigen- und Entgrenzungsdynamiken von Gewalt abhebt,

116 Sofsky, Wolfgang (1996): Traktat über die Gewalt, S. 181 .

117 Sofsky, Wolfgang (1996): Traktat über die Gewalt, S. 178-181. Im Kapitel "Absolute Gewalt" seiner intensiv rezipierten Habilitationsschrift Die Ordnung des Terrors schenkt Wolfgang Sofsky, wie schon angemerkt, der Frage der Gegengewalt ebenfalls keine Beachtung. Sofsky, Wolfgang (1993): Die Ordnung des Terrors, S. 27-40. Das trifft im Übrigen auch auf Elias Canettis (2010) anthropologischen Roman Masse und Macht (31. Auflage, Frankfurt a.M.: S. Fischer Verlag) zu, nicht zuletzt auf Hannah Arendt (s.u.).

118 Reemtsma, Jan Philipp (2008): Vertrauen und Gewalt, S. 104, 106, 108-112, 113-116, 116-124. In Bezug auf die "autotelische Gewalt" macht Reemtsma die "individuelle Chance" ausfindig, "absolute Macht auszuüben: die schlechthin unbeschränkte Macht, die keinem Ziel mehr dient als ihr selbst" (S. 133); er akzentuiert sie mit der Leidwahrnehmung des Opfers: "- die Reduktion der gesamten Person auf das Leid - kann sich als so dramatisch erweisen, dass jede Gewalt als autotelisch wahrgenommen wird." (S. 132)

119 Zur Transformation von "Gewaltarbeit" in "sanfte Gewalt" siehe Bourdieu, Pierre (1979): Entwurf einer Theorie der Praxis. Übersetzt von Cordula Pialoux und Bernd Schwibs. Frankfurt a.M.: Suhrkamp Verlag, S. 357-371. Zur "kleinen Gewalt" wie der alltäglichen Ohrfeige in ihrer Verknüpfung mit den "Codes gewaltsamer Herrschaft" und mit "Gewalt-Exzessen"” siehe Lüdtke, Alf (2003): Gewalt und Alltag im 20. Jahrhundert. In: Bergsdorf, Wolfgang/Herz, Dietmar/Hoffmeister, Hans (Hgg.): Gewalt und Terror. 11 Vorlesungen. Weimar: Rhino-Verlag, S. 35-52, hier: S. 43. dabei nicht zuletzt die Rolle Dritter untersucht, die als Organisationen, Institutionen, Medien, Zuschauer und Mitwirkende auf Gewalthandlungen einwirken (sie neutralisieren, choreographieren, inszenieren, legitimieren, ermöglichen, verschärfen) und die konkreten Interaktionen und Wahrnehmungen zwischen Tätern und Opfern vielgestaltig verändern können, müsste, vom Leid der Opfer ausgehend, Handlungsspielräume der Gegengewalt und des Widerstands, auch die ihrer Abwesenheit ernst nehmen.120 Gewaltforschung sollte Nachdruck legen auf Mikrophysiken der Gegengewalt, und zwar in allen Spielarten widerständiger und reaktiver Gewalt, als psychische, symbolische, visuelle, kulturelle, informelle, verdeckte, sexuelle Gegengewalt. Denn Mikrophysiken der Gegengewalt können Gewalträume und Gewaltdynamiken verändern, sie punktuell schwächen und begrenzen, kurz: Gegengewalt kann eine Gewalt, die wähnt, absolut zu sein, und sich als totale ausgibt, in nuce treffen, punktieren, erschüttern und angreifbar machen. Und selbst wenn sie das nicht schafft, ist sie doch nicht nichts. Und ob sie, es schafft', kann im Vorhinein nicht gewusst und im Nachhinein allzu leicht mit Rückschaufehlern beurteilt werden.

Es gibt bislang keine ausgearbeitete politische Theorie des Widerstands und des unzivilen Ungehorsams, in der das Politische unter Gesichtspunkten seiner Verborgenheit und Ortlosigkeit, seiner vita passiva und Aisthesis in Extremsituationen der Gewalt, der Verfolgung und Entrechtung im Mittelpunkt steht, auch keine moderne Soziologie der Gewalt, in der Gegengewalt als reaktive Praxis des Widerstands aus der Perspektive der Leidtragenden und der Opfer eine Rolle spielt. Allerdings weisen die frühen African American Studies und die jüdische Holocaust-Forschung nicht nur programmatische Berührungspunkte auf, ihre Protagonisten haben gerade auch wegweisende alltagshistorische Verfahren und soziologische Untersuchungen realisiert, in denen Gewaltund Widerstandsforschung auf bemerkenswerte

120 Christian Gudehus und Michaela Christ räumen zumindest ein, dass "Notwehr und Selbstverteidigung, gewaltfreier Widerstand und Nötigung, Suizid und Naturgewalten" zu den „Rändern" bzw. "Grenzbereiche[n]" der Gewaltforschung zählen. Gudehus, Christian/Christ, Michaela (2013): Gewalt - Begriffe und Forschungsprogramme. In: Dies. (Hgg.): Gewalt. Ein interdisziplinäres Handbuch. Stuttgart: J.B. Metzler, S. 1-15, hier: S. 12 f. 
Weise verschränkt sind. Wir stoßen hier auf theoretische Skizzen, die eine Assemblage des politischen Denkens bilden.

\section{Widerstands- und Gewaltforschung avant la lettre}

Zwischen 1936 und 1938 wurden im Rahmen des ersten Federal Writers' Project, das Präsident Franklin Delano Roosevelt im Rahmen des New Deal ins Leben gerufen hatte, in siebzehn Bundesstaaten der USA mehr als 2000 Interviews mit ehemals versklavten Afroamerikanerinnen und Afroamerikanern geführt. ${ }^{121}$ John A. Lomax, der National Advisor on Folklore and Folkways, der im April 1937 spezifizierte Guidelines für die Interviewer ("workers") entwickelt hatte, beabsichtigte, die Ex-Slave-Narratives, insbesondere jene, welche die Antebellum-Periode betrafen, in abolitionistischen Zeitschriften zu veröffentlichen, um Sklavereibefürworter und den Ku Klux Klan herauszufordern. ${ }^{122}$ Daher dramatisierten wohl die Antebellum-Narrative die Selbstbefreiungserfahrungen und die Folgen der Flucht aus der Sklaverei, ${ }^{123}$ nicht zuletzt die Selbstbehauptung jener Frauen und Männer, die sich nach misslungener Flucht ihrer Auspeitschung widersetzten und ihren Widerstand als Wahrung menschlicher Würde verstanden. ${ }^{124}$ Für die Zeit nach dem Bürgerkrieg und der Reconstruction Era schien dieser Gesichtspunkt in den Hintergrund zu treten

121 Vgl. Yetman, Norman R. (1984): Ex-Slaves Interviews and the Historiography of Slavery. In: American Quaterly 36.2, S. 181-210, hier: S. 181.

122 Vgl. Lomax, John A. (1941): Supplementary Instructions \#9-E to The American Guide Manual. In: Slave Narratives. A Folk History of Slavery in the United States from Interviews with Former Slaves, by the Library of Congress Project Work Project Administration. Washington, S. xxxxii, hier: S. xxii.

123 Vgl. Esten, Emily (2015): A Peculiar Project. Ethics and Analysis of the WPA Slave Narrative Collection of Oklahoma (UMass Amherst), S. 2f. http://scua.library.umass. edu/umarmot/wp-content/uploads/FLURA-doc-2016-04. pdf (Zugriff am 4.3.2019).

124 Vgl. Clift, Arlene L. (1980): If Trees Would Talk: The Communication of Resistance in Ex-Slave-Narratives. Working Paper. Cambridge, MA. The Mary Ingraham Bunting Institute of Radcliff College. https://files.eric.ed.gov/fulltext/ED221443.pdf (Zugriff am 4.3.2019). zugunsten der Dokumentation des "daily life in a plantation" und der retrospektiven Einschätzungen der Sklaverei, die die zum Zeitpunkt des Gesprächs hochbetagten Zeitzeugen als "Sklavenkinder" noch selbst erlebt hatten. ${ }^{125}$ Lomax wies die Interviewer diesbezüglich an, keine Äußerungen zu zensieren. ${ }^{126}$ Was das 20. Jahrhundert betraf, so überwog vor dem Hintergrund der Harlem Renaissance der 1920er Jahre das Interesse an Afrikanisch-Amerikanischer Kultur, an Kunst und Künstlern wie Langston Hughes oder Zora Neal Hurston. John und Ruby Lomax, Zora Neal Hurston, ${ }^{127}$ Roscoe Lewis, John Henry Faulk und andere hatten auf dem Gebiet der Oral History und der Ex-Slaves-Narratives Pionierarbeit geleistet. Mit einfachen Aufzeichnungsgeräten reisten sie Ende der 1920er Jahre durch den Süden der USA, um Songs und Erzählungen aufzunehmen, "trying to capture the voices of men and women who had experienced slavery." 128

Die Work Progress Administration's Slave Narrative Collection konnte von der bahnbrechenden Arbeit ähnlich gelagerter, lokaler Projekte profitieren, die seit 1927 bereits an schwarzen Universitäten, an der Southern University und an der Fisk University, unter der Leitung der Historiker Ophelia Settle Egypt, John B. Cade und des Soziologen Charles S. Johnson in kleinerem Umfang durchgeführt worden sind. ${ }^{129}$ Wichtige Stationen einer eigenen, selbstbewussten afroamerikanischen Geschichtsschreibung, ${ }^{130}$ im Widerstand gegen die rassistische und sklavereifreundliche Historiographie, für die Ulrich Bonnell Philipps'

125 Botkin, Benjamin (1941): Vorwort zu Slave Narratives. A Folk History of Slavery in the United States from Interviews with Former Slaves, S. v-x, hier: S. viii-ix; Esten, Emily (2015): A Peculiar Project, S. 2.

126 Vgl. Lomax, John A. (1941): Supplementary Instructions \#9-E to The American Guide Manual, S. xx.

127 Vgl. Hurston, Zora Neal (2018): Barracoon. The Story of the Last ,Black Cargo' (1931). London: Amistad.

128 Berlin, Ira/Favreau, Marc/Miller, Steven F. (2007): Introduction. Slavery as Memory and History. In: Dies. (Hgg.): Remembering Slavery. African Americans talk about their personal experiences of slavery and emancipation, New York: The New Press, S. xv-xlix, hier: S. xviii. 129 Vgl. Spindel, Donna J. (1996): Assessing Memory: Twentieth-Century Slave Narratives Reconsideres. In: The Journal of Interdisciplinary History 27, No. 2, S. 247-261. $130 \mathrm{Vgl}$. Bruce, Jr., Dickson B. (2014): Slave Narratives and Historical Understanding. In: Ernest, John (Hg.): The Oxford Handbook of the African American Slave Narrative. Oxford: Oxford University Press, S. 54-66, hier: S. 60. 
American Negro Slavery ${ }^{131}$ Pate gestanden hatte, bezeichneten William Du Bois' Untersuchung über den transatlantischen Sklavenhandel, mit der er als erster Afroamerikaner 1896 an der Harvard University die Doktorwürde erlangte, die Gründung der Association for the Study of Negro Life and History, 1915 durch Carter G. Woodson, Sohn der ehemaligen Sklaven James Woodson und Ann Eliza Riddle Woodson, und nicht zuletzt das von ihm ein Jahr später gegründete Journal of Negro History.

Die mehr als 2000 Interviews der Work Progress Administration wurden 1941 unter dem Titel Slave Narratives: A Folk History of Slavery in the United States from Interviews with Former Slaves als siebzehn Bände umfassender Mikrofilm veröffentlicht. Heute sind sie in digitalisierter Form auf der Library of Congress's American Memory website und durch verschiedene Buchpublikationen zugänglich. Bis in die 1970er Jahre äußerten Historiker wie John Blassingame ${ }^{132}$ und C. Vann Woodward ${ }^{133}$ immer wieder Bedenken hinsichtlich des objektiven historischen Aussagegehalts der Interviews und sprachen Autobiographien wie denjenigen von Solomon Northup und Frederick Douglass demgegenüber authentischen Wert zu: „WPA field agents interviewed more urban slaves than rural slaves, more men than women, and more house servants than field hands." 134 Ein entscheidender Einwand aber war, dass die Interviews in der Hauptsache von unausgebildeten "white Southerners" durchgeführt worden waren. Terri L. Snyder weist unter Rekurs auf Rhys Isaac zu Recht darauf hin, dass sie im "negro dialect" erstellt worden sind, in dem von Weißen erson-

131 Vgl. Bonnell Philipps, Ulrich (1929): American Negro Slavery. A Survey of the Supply, Employment and Control of Negro Labor as determined by the Plantation Régime, New York/London: D. Appleton and Company.

132 Vgl. Blassingame, John (1977): Slave Testimony. Baton Rouge: Louisiana State Univ. Press 1977; Blassingame, John (1979): Slave Community. New York: Oxford University Press.

133 Vgl. Woodward, C. Vann (1979): History From Slave Sources. In: American Historical Review 79, No. 2, S. 470481.

134 Strickland, Jeff (2014): Teaching the History of Slavery in the United States with Interviews: Born in Slavery: Slaves Narratives from the Federal Writers' Project 19361938. In: Journal of American Ethnic History 33, No. 4, S. 41-48, hier: S. 42. nenen Idiom der minstrel shows. ${ }^{135}$ In der Tat gibt es schriftliche Belege dafür, dass Interviewte ein "exzellentes Englisch" sprachen. ${ }^{136}$

Former slaves tended to defer and avoid conflict during the inerview. When African Americans interviewers were present, the ex-slaves were more candid and often expressed resentment about the slavery experience. ${ }^{137}$

Diejenigen, die von schwarzen Interviewern befragt wurden, waren freimütiger und offensiver, was Auskünfte über "black restistance to white", ihre Bewunderung für Nat Turner und seinen blutig niedergeschlagenen Sklavenaufstand, was grausame Bestrafungen durch Sklavenhalter, Familientrennungen durch Verkauf und sexuelle Gewalt anging. Das belegen die 900 Interviews, die zwischen 1929 bis 1938 von "black Scholars" am Hampton Institute, an der Fisk University und der Southern University durchgeführt worden sind. 138 So angreifbar die Rahmenbedingungen der Interviews und deren historische Bedeutung als Sklavenzeugnisse auch sind, vermitteln sie jedoch einen Eindruck von eben jenen Bedingungen selbst, unter denen sie stattgefunden haben, und tragen jene Stimmen, Klangfarben, Erzählungen, Erlebnisse, Schmerzen und Widerstände über die color line, von der sie zugleich tiefgreifend bestimmt sind. Sie verzeichnen ein Spektrum an Erzähl- und Gesprächsstrategien, mittels derer sich viele der Beantwortung des Fragenkatalogs entzogen und sich weigerten, ihre persönliche Geschichte geradewegs mit den weißen Interviewern zu teilen. Andere verwoben fantastisch erscheinende Details in ihre Erinnerungen an das tägliche Leben in der Sklaverei wie die Intervention von Geistern oder eine

135 Snyder, Terri L. (2010): Suicide, Slavery, and Memory in North America. In: Journal of American History Vol. 97/1, S. 39-62, hier: S. 39; Isaac, Rhys (2004): Landon Carter's Uneasy Kingdom: Revolution and Rebellion on a Virginia Plantation. New York: Oxford University Press, S. 193.

136 Blassingame, John (1985): Using the Testimony of Ex-Slaves. In: Davis, Charles T./Gates Jr., Henry Louis (Hgg.): The Slave's Narratives. New York: Oxford University Press, S. 78-98, hier: S. 87 mit Hinweis auf J. Jones, Ralph (1967): Portrait of Georgia Slaves. In: Georgia Review 21, S. 268-273, hier: S. 271.

137 Strickland, Jeff (2014): Teaching the History of Slavery in the United States with Interviews, S. 43.

138 Vgl. dazu Blassingame, John (1985): Using the Testimony of Ex-Slaves, S. 91. 
persönliche Begegnung mit Abraham Lincoln, die je nach Kontext eine Verspottung der "workers", ein Ablenkungsmanöver, ein Scherz, eine symbolische Markierung oder etwas ganz anderes gewesen sein dürfte. ${ }^{139}$ Um die Hoheit über ihre eigene Geschichte zu wahren, fügten andere inrem Narrativ korrigierende Fußnoten hinzu oder beschwerten sich mit Memos, vielfach erfolgreich, bei den Vorgesetzten des jeweiligen Interviewers, wenn er eigenmächtig in ihre Narration eingegriffen hatte. Wieder andere setzten ihre Furcht vor Vergeltung hintan und warnten die Interviewer zu Beginn, dass innen nicht gefallen würde, was sie zu sagen hätten, aber sie wollten ihre Meinung sagen. ${ }^{140}$

Die Narrationen sind schlaflose historische Zeugnisse trotz allem, diskursive Spuren jener Interviewereignisse selbst, die sich in ihrer Singularität einer vollständigen Überführung in Geschichte und Geschichtsschreibung widersetzen. "[F]or the first and last time, a large number of surviving slaves [...] habe been permitted to tell their own story, in their own way", ${ }^{141}$ wie Benjamin Botkin, Nachfolger von John A. Lomax, 1941 in leicht gönnerhaftem Duktus betonte.

1937 begann der jüdische Historiker Herbert Aptheker damit, der innerhalb der offiziellen amerikanischen Historiografie bis dahin völlig marginalisierten Frage des sklavischen Widerstandes aus marxistischer Perspektive nachzugehen. ${ }^{142}$ Dabei unterschied er zwischen acht Widerstandsformen: Freikauf, Streik, Sabotage, Suizid und Selbstverstümmelung, Flucht - zu den communities der runaways - und Überlaufen zu den Armeen der Franzosen, der First Nations, Kana-

$139 \mathrm{Zu}$ all dem siehe Jenkins Schwartz, Marie (2014): The WPA Narratives as Historical Sources. In: Ernest, John (Hg.), The Oxford Handbook of the African American Slave Narrative, S. 89-100, hier: S. 98.

140 Siehe dazu Berlin, Ira/Favreau, Marc/Miller, Steven F. (2007): Introduction. Slavery as Memory and History, S. xxii.

141 Botkin, Benjamin (1941): Vorwort zu Slave Narratives: A Folk History of Slavery in the United States from Interviews with Former Slaves, by the Library of CongressProject Work Project Adminstration, Washington, S. viii-ix. 142 Vgl. Meier, August/Rudwick, Elliott (1986): Black History and the Historical Profession, 1915-1980. Urbana/Chicago: University of Illinois Press, S. 29f.; Finkelman, Paul (Hg.) (1989): Rebellions, Resistance, and Runaways within the Slave South. New York/London: Garland Publishing, Inc. dier, Holländer, Spanier, Mexikaner und Briten, Anti-Sklaverei-Agitation, schließlich: Revolten. ${ }^{143}$ Als erster nicht-rassistischer Historiker überhaupt untersuchte er 1931 Nat Turner's slave rebellion von 1831. ${ }^{144}$ In seiner Dissertation American Negro Slave Revolts folgte er 1943 der Erkenntnis, dass es sich nicht um ein einzelnes Ereignis handeln konnte. ${ }^{145}$ Das Zeitalter der Revolution war in den USA gerade auch eine Epoche der Sklavenrevolutionen und -rebellionen, etwa unter der Führung Catos 1739, Gabriels 1800 und Denmark Veseys 1822. ${ }^{146}$ Allein im Süden konnte Herbert Aptheker 250 Sklaven-Revolten namhaft ${ }^{147}$ machen; 1951 edierte er den ersten Band der siebenbändigen Documentary History of the Negro People in the United States. ${ }^{148}$ Zeitgenössische Historiker, darunter zumal jüdische und sozialistische, wie Harvey Wish, ${ }^{149}$ Joseph C. Caroll ${ }^{150}$ und Kenneth

143 Vgl. Aptheker, Herbert (1937): American Negro Slave Revolts. Part 1. In: Science and Society 1, S. 512-538, hier: S. 512; Aptheker, Herbert (1938): American Negro Slave Revolts. Part 2. In: Science and Society 1, S. 386-392.

144 Vgl. Aptheker, Herbert (1943): American Negro Slave Revolts. New York: Columbia University Press, S. 303.

$145 \mathrm{Vgl}$. Aptheker, Herbert (1943): American Negro Slave Revolts, S. 11.

146 Vgl. Aptheker, Herbert (1943): American Negro Slave Revolts, S. 11, 187, 161, 69, 111 u.ö.

$147 \mathrm{Vgl}$. Aptheker, Herbert (1939: Negro Revolts in the United States, 1526-1860. New York: International Publishers; Donnan, Elizabeth (Hg.) (1930-1935): Documents IIlustrative of the Slave Trade. 4 vols., Washington, D.C.: Carnegie Institution; Catterall, Helen T. (Hg.) (1936): Judicial Cases Concerning American Slavery and the Negro. 5 vols. Washington, D.C.: Carnegie Institution.

148 Vgl. Kailin, Julie (1998): Toward Nonracist Historiography: The Early Work of Herbert Aptheker. In: Shapiro, Herbert (Hg.): African American History and Radical Historiography. Essays in Honor of Herbert Aptheker. Minneapolis: MEP Publications 1998, S. 19-38, hier: S. 29.

149 "The struggle of the Negro for his liberty, beginning with those dark days on the slave-ship, was far from sporadic in nature, but an ever-recurrent battle waged everywhere with desperate courage against the bonds of his master." Wish, Harvey (1937): American Slave Insurrections before 1861. In: The journal of Negro History 22/3, S. 299-320, hier: S. 320, 301f. der Autor weist nicht zuletzt auf Hungerstreiks, Melancholie und Suizide als Widerstandspassivierungen bereits auf den Sklavenschiffen hin. Dazu von der Verfasserin: "Sich Undienlichmachen/ Undienlichwerden im transatlantischen Sklavenhandel". In: Därmann, Iris (2020): Undienlichkeit.

150 Vgl. Carroll, Joseph Cephas (1938): Slave Insurrections in the United States, 1800-1856. Boston: Chapman \& Grimes. 
W. Porter ${ }^{151}$, setzten sich zur gleichen Zeit mit den verschiedenen aktiven und pathischen Formen des slave resistance auseinander. Der von Franz Boas promovierte jüdische Anthropologe Melville J. Herskovits, ${ }^{152}$ der erste Lehrstuhlinhaber für African Studies, widmete sich 1941 in The Myth of the Negro Past den survival studies, dem lebenswichtigen Austausch von kulturellem Wissen, von Ethos und diasporischen Erfahrungen zwischen den in die Kolonien deportierten Afrikanern, den bereits in die Plantagensklaverei "Assimilierten"" und den Neuankömmlingen, mithin dem Überleben des westafrikanisch-transatlantischen Erbes, das eng mit der Geschichte des Widerstands gegen die Sklaverei verbunden war. ${ }^{153}$ Das "fighting back" bedurfte indes vielfältiger kultureller Ressourcen, die sich nicht unidirektional aus der europäischen Sklavenhalterkultur und dem Widerstand gegen sie speisten. ${ }^{154}$

Wie bei den afroamerikanischen Soziologen und Bürgerrechtsrechtaktivisten William Du Bois und E. Franklin Frazier ${ }^{155}$ oder dem Historiker Frederic Bancroft ${ }^{156}$ standen Selbstzeugnisse ehemaliger Sklavinnen und Sklaven auch im Zentrum der Analysen ${ }^{157}$ der beiden jüdisch-österreichischen Soziologen Alice H. Bauer und Raymond A. Bauer. In den 1940er Jahren lenkten sie wohl erstmals den Blick auf die alltäglichen Widerstandspraktiken gegen die Sklaverei, die sich, halb und halb, im Verborgenen abspielen mussten. Dabei hatten sie nicht zuletzt - wie im Falle Solomon Northups - auch doppelbödige Künste

151 Vgl. Porter, Kenneth W. (1943): Florida Slaves and Free Negroes in the Seminole War, 1825-1842. In: The journal of Negro History 28.4, S. 390-421.

152 Vgl. Herskovits, Melville J. (1926): The Cattle Complex in East Africa. In: American Anthropologist. Vol. 28, No. 1, S. 230-272.

153 Vgl. Herskovits, Melville J. (1941): The Myth of the Negro Past. London/New York: Harper \& Brothers. Gershenhorn, Jerry (2007): Melville J. Herskovits and the Racial Politics of Knowledge. Lincoln/London: University of $\mathrm{Ne}$ braska Press.

154 Siehe dazu French, Scot (2004): The Rebellious Slave. Nat Turner in American Memory. Boston/New York: Oxford University Press, S. 208.

155 Vgl. Frazier, Franklin (1932): The Free Negro Family: A Study of Family Origins Before the Civil War. Nashville: Fisk University Press.

$156 \mathrm{Vgl}$. Bancroft, Frederic (1931): Slave Trading in the Old South. Baltimore: J. H. Furst Company.

157 Vgl. Bruce, Jr., Dickson B. (2014): Slave Narratives and Historical Understanding, S. $60 f$. des Handelns im Blick. ${ }^{158}$ Ignoranz, sich dumm stellen gegenüber dem "Master", gehörte auch aus Sicht des Abolitionisten Frederick Douglass, dem 1838 die Flucht aus der Sklaverei gelang, zu den "gerissensten Tugenden", um sich dem Gewalt- und Zwangsarbeitssystem zu entziehen. ${ }^{159}$ Die beiden Bauers, beide Studenten von Melville J. Herskovits an der Northwestern University, gehörten auch zu den ersten, die die aktiven und passiven Widerstandspraktiken gegen die Sklaverei untersucht haben, und zwar konsequent from the slaves' point of view. ${ }^{160} \mathrm{Zu}$ den alltäglichen Passivierungen als Widerstandsform zählten sie Suizide, Kindstötungen, Abtreibungen und Selbstverstümmelungen. ${ }^{161}$ In ihrer dichten Beschreibung der Day to Day Resistance to Slavery verliehen sie ferner den, wie sie es nannten,

158 Vgl. Northup, Solomon (2014): Zwölf Jahre ein Sklave. Altenmünster: Jazzybee Verlag, S. 396, 102, 120. Als schwarzer "Treiber" war es Northups Aufgabe, die anderen Sklaven bei der Baumwollernte zu überwachen und zu strafen. Doch er hatte die Peitsche zum Schutz seiner Fellows gekapert: "Ich bekam eine Peitsche und die Anweisung, sie jedem zu geben, der untätig herum stand. Sollte ich dies nicht beherzigen, gab es eine zweite, die für meinen Rücken bestimmt war. [...] [W]ährend meiner acht Jahre als Treiber habe ich gelernt, die Peitsche mit wundersamer Fingerfertigkeit und Genauigkeit zu gebrauchen. Ich konnte sie in Haaresbreite eines Rückens, eines Ohrs und einer Nase schlagen, ohne mein Ziel auch nur zu berühren. Wenn ich Epps aus der Entfernung sehen konnte, oder wir Grund zu der Annahme hatten, daß er irgendwo in der Nähe herumschlich, ließ ich die Peitsche energisch fliegen und die Sklaven schrien und wanden sich - wie vorher besprochen -, obwohl keinem von ihnen auch nur ein Haar gekrümmt worden war."

159 Douglass, Frederick (1845): Narrative of the Life of Frederick Douglass, 1817-1895. Boston: Bedford Books of St. Martin's Press, S. 8; Bauer, Raymond A./Bauer, Alice H. (1942): Day to Day Resistance to Slavery. In: The Journal of Negro History, Vol. 27, No 4, S. 388-419, hier: S. 391.

160 Die beiden Bauers hatten ihr Papier Day to Day Resistance to Slavery erstmals im Seminar von Herskovits vorgestellt: "Herskovits encouraged students and colleagues to analyze slavery in the United States from the slave's perspective." Gershenhorn, Jerry (2007): Melville J. Herskovits and the Racial Politics of Knowledge, S. 141f.

161 Siehe dazu auch Wirz, Albert (1984): Sklaverei und kapitalistisches Weltsystem, S. 165; Terri L. Snyder hat dem Suizid ein eigenes und historisch höchst ertragreiches Buch gewidmet, sie steht einer Deutung des Suizids als Widerstandshandlung jedoch reserviert gegenüber: Snyder, Terri L. (2015): The Power to Die. Slavery and Suicide in British North America, Chicago/London: University of Chicago Press, S. 18. 
„praktischen Streiks", 162 ein politisches Gewicht, noch diesseits von Revolten und revolutionären Bewegungen. Dazu zählten sie Flucht, Blaumachen, Krankfeiern, ,Faulheit', ,Inkompetenz', verlangsamte Arbeitsrhythmen, nächtliches Tanzen bis zur Erschöpfung, Zerstörung von Arbeitsgerät und Arbeitstieren, Diebstahl, Sich-Lustigmachen über die Pflanzer, so tun als ob, Maskierung der eigenen Gefühle, Brandstiftung, Vergiftung von Sklavenhaltern und Hexerei. In ihrer Studie findet sich das gesamte Repertoire der Arbeitsverweigerung, wie es sich auch im proletarischen Widerstand entwickeln sollte, freilich mit dem großen Unterschied, dass die Arbeiterbewegung schriftliche Diskursivierungen ihres Kampfes gegen die Despotie der Fabrik und "System der Lohnsklaverei"163 hervorgebracht hat. Sie konnte dies in einem Umfang tun, wie es den weitgehend in Schrift- und Mittellosigkeit gehaltenen Sklavinnen und Sklaven gerade nicht möglich war, die auf orale Praktiken setzen mussten.

Die Pionierleistung der beiden Bauers bestand nicht nur darin, dass sie die praxeologische Wende und damit Michel de Certeaus poietisch-politisches Verständnis von Alltagspraktiken, nicht zuletzt Alf Lüdtkes Alltagsgeschichte des Eigensinns vorwegnahmen. Mit ihrer antirassistischen Alltagsgeschichte afroamerikanischer Widerstandspraktiken machten die beiden jüdisch-österreichischen Wissenschaftler, die sich in den 1960er Jahren mit Untersuchungen zu Massenmedien hervortun sollten, ${ }^{164}$ eine soziologische Auffassung von Geschichte jenseits von Staatlichkeit und Territorialität geltend, wie sie gerade auch Simon Dubnow im Hinblick auf die jüdische Geschichte entwickelt hatte.

Dubnow hatte 1925 gefordert, dass das jüdische Volk in allen Zeiten und in allen Ländern, immer und überall, [als] ein Subjekt, [ein] Schöpfer seiner Geschichte, nicht nur auf dem geistigen, sondern auch auf dem Gebiete des sozialen Lebens überhaupt ${ }^{165}$

162 Bauer, Raymond A./Bauer, Alice H. (1942): Day to Day Resistance to Slavery, S. 404.

163 Marx, Karl (1962): Das Kapital, S. 399.

164 Vgl. Bauer, Raymond A./Bauer, Alice H. (1960): America, Mass Society, and Mass Media. In: Journal of Social Issues 16, No. 3, S. 3-66.

165 Dubnow, Simon (1925): Weltgeschichte des jüdischen Volkes von seinen Uranfängen bis zur Gegenwart. Band. 1: Die älteste Geschichte des jüdischen Volkes. Orientalische Periode. Von der Entstehung des Volkes Israel bis zum in Betracht zu ziehen sei. Sein „Diasporanationalismus"166 ermöglichte, so Elisabeth Gallas, "eine geschichtsbewusste, säkularisierte und autonome Form jüdischer kollektiver Zugehörigkeit, die die jiddisch-sprechenden Massen zwischen Baltikum und Schwarzem Meer unter den Herausforderungen der Moderne zu einigen suchte." 167 Dubnows „Aufruf zur Arbeit am nationalen Gedächtnis", ${ }^{168}$ den er, nach den russischen Pogromen 1881-1884, 1891 an die in Russland und Polen lebenden Juden ${ }^{169}$ gerichtet hatte, und seine programmatische Gewissheit, dass die Geschichte des Judentums nicht allein als die seiner Rabbiner und Philosophen, sondern vielmehr als die Geschichte des jüdischen Volkes, seiner jiddischen Sprache und Kultur zu schreiben sei, legten die intellektuellen Grundsteine für das YIVO (Jidischer Wisnschaftlecher Institut). Es wurde zwischen 1924 und 1925 in drei Zentren jiddischer Bildungs- und Kulturarbeit in Berlin, Wilna und Warschau gegründet, wie Cecile Esther Kuznitz in ihrer brillanten Studie YIVO and the Making of Modern Jewish Culture sorgfältig nachgezeichnet

Ende der persischen Herrschaft in Judäa. Berlin: Jüdischer Verlag, S. XV.

166 Kuznitz, Cecile Esther (2014): YIVO and the Making of Modern Jewish Culture: Scholarship for the Yiddish Nation. Cambridge: Cambridge University Press, S. 27.

167 Gallas, Elisabeth (2015): Rezension von Cecile E. Kurnitz: YIVO and the Making of Modern Jewish Culture. Schorlarship fort he Yiddish Nation (New York 2014). In: Medaon 9, Heft 16, S. 1-4, hier: S. 1f.

168 Hilbrenner, Anke (2004): Simon Dubnow war eine Art intellektueller Pate. Das YIVO in Wilnar und Dubnows Aufruf zur Arbeit am nationalen Gedächtnis. In: Dmitrieva, Marina/ Petersen, Heidemarie (Hgg.): Jüdische Kultur(en) im Neuen Europa, Wilna 1918-1939. Wiesbaden: Harrassowitz Verlag, S. 147-162, siehe dazu Wagner, Birgitt (2011): Jüdische Gesellschaft im Mittelpunkt. „Ghetto" und "Judenrat" als Themen der frühen englischsprachigen Holocaustforschung. In: PaRDeS. Zeitschrift der Vereinigung für Jüdische Studien e.V. 17, S. 53-70, hier: S. 61. Der Artikel von Birgitt Wagner basiert auf ihrer Diplomarbeit: Der Holocaust vor der Bezeichnung ,Holocaust'. Wege zur wissenschaftlichen Auseinandersetzung mit der Vernichtung der europäischen Jüdinnen und Juden in der englischsprachigen Forschung 1940-1960 (Universität Wien, 2010). https://core.ac.uk/download/pdf/11589235.pdf (Zugriff am 27.02.2019).

169 Vgl. Web, Marek (2013): The Story of YIVO's Polish Jewish Archive. YIVO Institute for Jewish Reearch, S. 6. http://polishjews.yivoarchives.org/YIVO-GL-Story-of-YIVOs-Polish-Jewish-Archive.pdf (Zugriff am 19.3.2019). 
hat ${ }^{170}$ : Erst 1929 wurde beschlossen, Wilna zum Hauptsitz des YIVO zu machen. Im Oktober 1925 konstituierte sich Die Gesellschaft der Freunde des Jiddischen Wissenschaftsinstitut, zur selben Zeit wurde auch in New York die amerikanische Dependance Amopteyl (Amerikaner Opteyl or American Section) unter der Leitung des Historikers Yankev (Jacob) Shatzky eröffnet. ${ }^{171}$ Mit dem Aufbau der vier Forschungssektionen Philologie, Pädagogik, Ökonomie/Demographie und Geschichte verbanden Nokhem Shtif, Max Weinreich, Zelig Kalmanovitch, Zalman Reisen, Elias Tcherikower und weitere Mitbegründer des YIVO das Konzept einer "Geschichte von unten". Wegweisend war dabei auch die von Baron Vladimir de Guenzburg geförderte "Ansky-Expedition", die von 1912 bis 1914 Städte und Dörfer in Volhynia und Podolia bereiste, um jüdische Gebräuche, Volkslieder und Volkskunst aufzuzeichnen. ${ }^{172}$ Das aus dieser Feldforschung hervorgehende Jahrbuch Der pinkes (1912/13) war die erste wissenschaftliche Publikation in jiddischer Sprache. ${ }^{173}$ Jüdische Wissenschaft sei keine historische Disziplin, sondern „ein lebendes, weiterschaffendes Element der Gegenwart", proklamierte Max Weinreich. ${ }^{174}$ Das jüdische Kollektiv, das Volk, sollte selbst zentral an der Archivierung und Erforschung seiner eigenen Geschichte und Kultur mitwirken. Realisiert wurde dies mit einer wachsenden Zahl freiwilliger Helfer, den Samlers, die Interviews führten und vielfältiges Material, Dokumente, Daten, Bücher, Poster, Zeitungen, Fotografien, Kinderspiele, Kunst und Dinge der Alltagskultur

$170 \mathrm{Vgl}$. Kuznitz, Cecile Esther (2014): YIVO and the Making of Modern Jewish Culture, S. 71-99.

$171 \mathrm{Vgl}$. Kuznitz, Cecile Esther (2014): YIVO and the Making of Modern Jewish Culture, S. 69.

172 Vgl. Kuznitz, Cecile Esther (2014): YIVO and the Making of Modern Jewish Culture, S. 77.

$173 \mathrm{Vgl}$. Der pinkes. Yohrbukh far der geshikhte fun der yudisher literatur un shprakh, far folklor, kritik un biblyografye. Wilna 1912/13. Kuznitz, Cecile Ester (10. November 2010): YIVO. In: YIVO Encyclopedia of Jews in Eastern Europe. http://www.yivoencyclopedia.org/article.aspx/YIVO (Zugriff am 23.02.2019).

174 Weinreich, Max (1926/2002): Ein Jiddisches Wissenschaftliches Institut. In: Zeitschrift der Deutschen Morgenländischen Gesellschaft. Neue Folge, Bd. 5 (Bd. 80), Leipzig, S. 68-70; wiederabgedruckt in: Jüdisches Museum Frankfurt (2002): SCHTARKER FUN AJSN. Konzert- und Theaterplakate aus dem Wilnaer Getto 1941-1943. Frankfurt a.M.: Jüdisches Museum Ffm, S. 117-119. in ihren jeweiligen Gemeinden zusammentrugen: "Mitglieder in 163 Samlerkrajsn (Sammlergruppen) hatten bereits 1929 mehr als 50.000 Niederschriften von Sprichwörtern, Volkserzählungen und Volksliedern an das YIVO geschickt." ${ }^{175}$ Die Ökonomische Abteilung des YIVO untersuchte wiederum die "Wirkungen des Krieges und der Nachkriegszeit auf das jüdische Leben, insbesondere die Umschichtung der jüdischen Bevölkerung in Osteuropa". Die Historische Abteilung beschäftigte sich mit den "wirtschaftlichen, politischen und ideologischen Faktoren der jüdischen Emanzipation"176, auch mit der zeitgenössischen jüdischen Arbeiterbewegung, wie dem 1889 in Wilna gegründeten Bund (Algemeyner Yidisher Arbeyterbund in Poylin, Lite un Rusland), der sich für "die jüdisch-nationale Gleichberechtigung in der Diaspora"177 engagierte. 1926 regte der Historiker Emmanuel Ringelblum die Einrichtung einer Historischen Kommission des YIVO in Warschau an, um mit Hilfe von nicht-professionellen Interviewern und professionell ausgearbeiteten Fragebögen das Alltagsleben der polnischen Juden zu erforschen, wie Kuznitz berichtet. ${ }^{178}$

Am 19. September 1939 besetzen die Sowjets Wilna. Das YIVO wurde als Institut für jüdische Kultur Teil der Wissenschaftlichen Akademie der Sowjetisch Sozialistischen Republik Litauen, bevor es nach der Besetzung Wilnas am 24. Juni 1941 durch die deutsche Wehrmacht im März 1942 für das sogenannte "Institut zur Erforschung der Judenfrage" in Frankfurt geplündert wurde. Der "Einsatzstab Reichsleiter Rosenberg" (ERR) ordnete an, dass jüdische Mitarbeiter des YIVO, darunter der Bibliothekar Herman Kruk, jüdisches Kulturgut und jüdische Buchbestände zur Zerstörung aussortieren sollten. Die sogenannten „Papierbrigaden" gingen, nach Einschätzung Kutznitz', ein hohes Risiko ein, um seltene Bücher, Briefe, Manuskripte und Zeichnungen aus den YIVO-Beständen ins Wilnaer Ghetto zu

175 Kuznitz, Cecile Ester (2010): "YIVO".

176 Weinreich, Max (1926/2002): Ein Jiddisches Wissenschaftliches Institut, S. $117 \mathrm{f}$.

177 Schroeter, Gudrun (2008): Worte aus einer zerstörten Welt: das Ghetto Wilna. St. Ingbert: Röhring, S. 40, Anm. 91.

178 Vgl. Kuznitz, Cecile Ester (2010): "YIVO”; siehe auch Roth, Markus/Löw, Andreas (2012): Das Warschauer Getto. Alltag und Widerstand im Angesicht der Vernichtung. München: Beck Verlag, S. 55. 
schmuggeln und vor der Zerstörung zu bewahren. ${ }^{179}$ Die Rettung von Leben und von Büchern, die Dokumentation der deutschen Vernichtung der europäischen Juden, nicht zuletzt die Aufzeichnung des jüdischen Lebens in den Ghettos wurde zu einer zentralen Aufgabe: "Ob im Wilnaer oder Warschauer Ghetto, in Todeslagern oder Lagern, wurden die überlieferten Worte des 1941 in Riga ermordeten Historikers Simon Dubnows shrayb un forshraybt [Schreibt alles auf!] zum Imperativ." 180 Der heimliche und lebensgefährliche Akt des Schreibens, des Erinnerns als einem Wahrnehmen des Rechts auf die eigene Geschichte sowie des Bezeugens ${ }^{181}$ und Dokumentierens der Verbrechen des NS-Regimes waren eminente Widerstandsakte und evozierten nicht selten eine eigene Überlebenskraft in einer organisierten Welt rassistischer Gewalt und Vernichtung. Der Prager Journalist Oskar Singer hielt im Frühjahr 1944 mit Blick auf das im November 1940 im Ghetto Litzmannstadt gegründete jüdische Archiv fest, dass dort „in aller Stille Material für eine künftige Schilderung (Geschichte) des Ghettos" gesammelt und "selbst entsprechende Aufzeichnungen"182 gemacht würden.

Im Rückblick auf die Anfangszeit der deutschen Besatzung von Warschau und der Terrorisierung der jüdischen Zivilbevölkerung notierte Emanuel Ringelblum im Januar 1943 in sein Tagebuch:

Alle schrieben: Journalisten, Literaten, Lehrer, die politisch Aktiven, die Jugend, sogar die Kinder. Die Mehrheit schrieb Tagebuch, in denen sie die tragischen Ereignisse durch das Prisma des eigenen Überlebens ausleuchteten. Es wurde viel geschrieben, aber die überwältigende Mehrzahl [der Texte] wurde in der

179 Kuznitz, Cecile Ester (2010): „YIVO”.

180 Schroeter, Gudrun (2008): Worte aus einer zerstörten Welt: das Ghetto Wilna, S. 38f.

181 Zur starken Besetzung des Bezeugens in der jüdischen Tradition siehe Krochmalnik, Daniel (2007): Pflicht Nr. 122. Das Zeugnisgebot (Mizwat Edut) in Geschichte und Gegenwart. In: Fritz-Bauer-Institut (Hg.): Zeugenschaft des Holocaust. Zwischen Trauma, Tradierung und Ermittlung. Frankfurt a.M./New York: Campus Verlag, S. 19-32.

182 Zitiert nach Löw, Andrea (2013): Chronisten der ,Lebenswelt Ghetto'. Dokumentationstätigkeit in den Ghettos Litzmannstadt und Warschau. In: Hansen, Imke/Steffen, Katrin/Tauber, Joachim (Hgg.): Lebenswelt Ghetto. Alltag und soziales Umfeld während der nationalsozialistischen Verfolgung. Wiesbaden: Harrassowitz Verlag, S. 310-329, hier: S. 313.
Zeit der Aussiedlung gemeinsam mit den Warschauer Juden vernichtet. Es blieb nur das Material, das im A[rchiv] des G[ettos] aufbewahrt wurde. ${ }^{183}$

Es war eine immense Herausforderung, von der akuten tödlichen Bedrohung, der man selbst mit den Nächsten hautnah ausgesetzt war, Tag für Tag ein klares Zeugnis abzugeben. Die jüdische Geschichtsschreibung des Holocaust begann in exakt der Gegenwart, in der die deutsche Enteignungs-, Ghettoisierungs-, Verfolgungs- und Vernichtungspolitik der europäischen Juden stattfand und exekutiert wurde, multiperspektivisch, in verschiedenen alltagshistorischen, subjektiven und objektivierenden Schreib- und Repräsentationsformen, ${ }^{184}$ mit äußerster Dringlichkeit, Disziplin, Selbstaufopferung, in Zuständen des Hungers und chronischer Auszehrung. Wie kann man schreiben und "vor-Augen-führen", 185 was man erleidet und wogegen man sich wehrt, für wen, für wessen Gegenwart und für welche Zeit danach?

Von Herman Kruk stammt die umfassendste Chronik des Wilnaer Ghettos in jiddischer Sprache. ${ }^{186}$ Als engagiertes Mitglied des Bundes sah er es als seine unabweisbare Aufgabe an, das Leben im Ghetto und den Kampf der Wilnaer Jüdinnen und Juden so detailliert und exakt wie möglich festzuhalten,wie Gudrun Schroeter betont. Fast täglich notierte er seine Beobachtungen auf der einzigen Schreibmaschine, die im Ghetto vorhan-

183 Ringelblum, Emanuel (1983): Kronika getta warszawskiego. Wrzesień 1939 - styczeń 1943, herausgegeben von Artur Eisenbach. Warszawa: Czytelnik, S. 471; zitiert nach Roth, Markus/Löw, Andrea (2012): Das Warschauer Getto, S. 53.

184 Vgl. Young, James E. (1997): Beschreiben des Holocaust. Darstellung und Folgen der Interpretation. Übersetzt von Christa Schuenke. Frankfurt a.M.: Suhrkamp Verlag, S. 33. Siehe auch Langer, Lawrence (1975): The Holocaust and the Literary Imagination. New Haven: Yale University Press; Langer, Lawrence (2010): Holocaust-Testimonies: The Ruin of Memory. New Haven: Yale University Press; Marcuse, Harold (2010): Holocaust Memorials: The Emergence of a Genre. In: The American Historical Review Vol. 115, No. 1, S. 53-89.

185 Didi-Huberman, Georges (2011): Wenn die Bilder Position beziehen. Das Auge der Geschichte I. Übersetzt von Markus Sedlaczek. München: Fink Verlag, S. 32.

186 Die Chronik Hermann Kruks umfasste insgesamt 757 Seiten, von denen 510 gerettet wurden. 380 Seiten erreichten 1948 das YIVO in New York, weitere 130 Seiten gelangten 1959 nach Yad Vashem. Dazu Schroeter, Gudrun (2008): Worte aus einer zerstörten Welt: das Ghetto Wilna, S. 39, Anm. 89. 
den war. Er sammelte schriftliche wie mündliche Erzählungen und erschuf mit der Ghettobibliothek, deren Nutzung und Leserschaft er im September 1942 einen eigenen Bericht in jiddischer Sprache widmete, ${ }^{187}$ "einen Raum für Aktivitäten, deren Bedeutung", nach Einschätzung Gudrun Schroeters, "vergleichbar ist mit der Gruppe um Emanuel Ringelblum." 188 Kruk verzeichnete jeweils die Zahl der ausgeliehenen Bücher im Anschluss an akute "Vernichtung und Verwüstung". "Am 1. Oktober (1941), am Jom-Kippur-Tag, wurden in mehreren ,Schüben' etwa 3000 Menschen aus dem Wilnaer Getto verschleppt, und schon am 2. Oktober bildeten sich vor der Bibliothek lange Warteschlangen." 189

Im Warschauer Ghetto hatte die von dem Historiker Emanuel Ringelblum geleitete Gruppe des Oyneg Shabes, "Freude am Sabbat", wie der Tarnname lautete, seit dem Sommer 1940 ein geheimes Untergrundarchiv angelegt, um das jüdische Leben, in seiner Widerständigkeit und erzwungenen Kooperation mit den Deutschen für die Nachwelt zu dokumentieren, im soziologischen und alltagsgeschichtlichen Geist des YIFO: darunter Untersuchungen über das Leben und Leiden der Kinder, den täglichen Hunger, Reportagen zu den über 100 Hauskomitees, dem allgegenwärtigen Sterben auf den Straßen des Ghettos, Tagebücher, statistische Erhebungen zu Typhus und Fleckfiebererkrankungen, Bilder aller Art, Plakate, Familienfotografien, Zeichnungen von Künstlerinnen wie Gela Sekstein, ${ }^{190}$ Abschiedspostkarten und -briefe, die Juden und Jüdinnen „in den Provinzen am Vorabend ihrer Deportation verfasst"191 und ins Ghetto geschickt hatten. Im Juni 1942 erstellte das Oyneg Shabes unter dem

187 Vgl. Kruk, Hermann (2002): Getto-Bibliothek und Getto-Leser (Wilnaer Getto, September 1942). Der Bericht befindet sich im Archiv des "Jidischer wisnschaftlecher Institut" (YIVO) in New York. Übersetzt von Maria Kühn-Ludewig. In: Jüdisches Museum Frankfurt: SCHTARKER FUN AJSN. Konzert- und Theaterplakate aus dem Wilnaer Getto 1941-1943, S. 222-238.

188 Schroeter, Gudrun (2008): Worte aus einer zerstörten Welt: das Ghetto Wilna, S. 41.

189 Kruk, Hermann (2002): Getto-Bibliothek und Getto-Leser, S. 230.

190 Vgl. Roth, Markus/Löw, Andreas (2012): Das Warschauer Getto, S. 52-64.

191 Kassow, Samuel D. (2010): Ringelblums Vermächtnis. Das geheime Archiv des Warschauer Ghettos. Reinbek bei Hamburg: Rowohlt Verlag, S. 468.
Titel Die Hölle des polnischen Judentums einen umfangreichen Bericht über die Eskalationsstufen der deutschen Entrechtungs- und Vernichtungspolitik seit 1939. Seit April 1942 brachte das Oyneg Shabes die Miteylungen heraus, um über die deutsche Deportations- und Vernichtungspolitik zu berichten. ${ }^{192}$ In Metallkästen und zwei großen Milchkannen vergraben, konnte ein Teil des Archivs 1946 in den Ruinen des ehemaligen Warschauer Ghettos, unter den Trümmern des Hauses Nowolipki-Straße 68 geborgen werden. ${ }^{193}$ Die war der Verdienst zweier Überlebender und Mitarbeiter Ringelblums, Hersz Wasser und der Schriftstellerin Rachel Aucherbach, die auch einen Essay über die Besucher der von ihr geleiteten Suppenküche in der ul. Leszno 40 verfasst hatte. ${ }^{194}$

Birgitt Wagner hat auf eine frühe Tagung zur Holocaust-Forschung hingewiesen, die von der New Yorker Zeitschrift Jewish Social Studies (JSS) aus Anlass ihres zehnjährigen Bestehens unter dem Titel Problems of Research in the Study of the Jewish Catastrophe, 1939-1945, 1949 in New York ausgerichtet wurde. Die Teilnehmenden u.a. traten Philip Friedman, Joshua Starr, Solomon Bloom, Hannah Arendt, Herbert Wechsler, Samuel Gringauz als Vortragende auf, während Zosa Szajkowski, Paul N. Neurath und Max Weinreich als Kommentatoren involviert waren - und insbesondere Samuel Gringauz und Solomon Bloom ${ }^{195}$ hatten bei dieser Gelegenheit mit ihren soziologischen Analysen der Ghettos dazu angeregt, die Leiden und das Handeln von Juden gleichermaßen, insbesondere die Organisation des täglichen und gesellschaftlichen Lebens, in den Blick zu nehmen: "From the sociological point of view the Ghetto was a unique social experience. [...] The Ghetto of the great catastrophe is the only instance of a full-fledged Jewish community outside the state of Israel."196

192 Vgl. Kassow, Samuel D. (2010): Ringelblums Vermächtnis, S. $472 \mathrm{f}$.

193 Vgl. Kassow, Samuel D. (2010): Ringelblums Vermächtnis, S. 15.

194 Vgl. Roth, Markus/Löw, Andrea (2012): Das Warschauer Getto, S. 61.

195 Vgl. Bloom, Solomon F. (1950): Toward the Ghetto Dictator. In: Jewish Social Studies 12, S. 73-78.

196 Gringauz, Samuel (1950): Some Methodological Problems in the Study of the Ghetto. In: Jewish Social Studies 12, S. 65-72, hier: S. 58. 
Diese bemerkenswerte Einschätzung erläuterte Samuel Gringauz, Nationalökonom und Jurist, Überlebender des Ghettos Kaunas und des Konzentrationslagers Dachaus sowie gewählter Vertreter der jüdischen Displaced Persons in der amerikanischen Besatzungszone in Deutschland, mit konkreten methodischen Vorschlägen für die Analyse erfolgreicher, gescheiterter und ausbleibender Widerstandsformate. Exemplarisch machte er dafür die Bildung sozialer und politischer Gruppen verantwortlich, die die Frage der Befehlsverweigerung bzw. der Kooperation, gerade in ihrem Verhältnis zur jüdischen Führung, zur jüdischen Polizei und zur Politik der Judenräte, jeweils unterschiedlich bewertet hätten. ${ }^{197}$ Samuel Gringauz stand mit seinen differenzierten Vorschlägen zur soziologischen Ghetto- und Widerstandsforschung nicht allein. Die Herausgeber und Beiträger der Jewish Social Studies hatten ihr Augenmerk seit 1939 ebenfalls auf die soziologische Untersuchung des Holocaust gerichtet. Desgleichen das YIVO. Nach der Plünderung und Zerstörung durch die Deutschen emigrierte es 1940 von Wilna nach New York, um sich unter der Leitung von Max Weinreich und weiteren Überlebenden der Erinnerung an die jüdische Kultur und Existenz in Osteuropa, der Erforschung der NS-Vernichtungspolitik, der jüdischen Alltags- und Widerstandsgeschichte und zumal der Sammlung von Augenzeugenberichten zu widmen: "At the end of the war, YIVO became the pioneer of Holocaust studies avant la lettre, immediately recruiting zamlers to collect survivors' testimonies and documents from displaced persons camps" allein an 500 Orten in Europa und konnte so das in dieser Zeit weltweit größte Holocaust-Archiv aufbauen. ${ }^{198}$ Später kollaborierte das YIVO mit „Israel's Yad Vashem Martyrs' and Heroes' Memorial Authority to produce 15 volumes of Holocaust bibliographies (1960-1978)."199

Wie Elisabeth Gallas in einem eindrücklichen Forschungsüberblick gezeigt hat, sind diese und viele weitere jüdische Initiativen der frühen Widerstands- und Holocaust-Forschung, die zunächst in jiddischer, hebräischer, polnischer und nach 1945

197 Siehe dazu Wagner, Birgitt (2011): Jüdische Gesellschaft im Mittelpunkt, S. 58, der ich hier folge.

198 Gallas, Elisabeth (2016): Frühe Holocaustforschung in Amerika. Dokumentation, Zeugenschaft und Begriffsbildung. In: Jahrbuch des Simon-Dubow-Instituts/Simon Dubnow Institute Yearbook 15, S. 535-569, hier: S. 554.

199 Kuznitz, Cecile Ester (2010): "YIVO". zunehmend in englischer Sprache verfasst wurden, sowie deren Schreib- und Repräsentationsformen erst in jüngerer Zeit wieder stärker in den Blickpunkt gerückt. ${ }^{200}$ Gallas verweist u.a. auf den von Jacob Robinson und Philip Friedman 1960 edierten Guide To Jewish History Under Nazi Impact: 201 Allein für die 1940er und 1950er Jahre sind darin mehrere tausend Publikationen von jüdischen Historikern, Überlebenden und Augenzeugen angeführt. ${ }^{202}$ In ihrer Einleitung betonten sie:

The Jews under Nazi domination were separated from their kin. ,The world closed around them'. Left to themselves, they struggled much more than people elsewhere believed they did. It was a peculiar kind of struggle, a hopeless and permanent one for the preservation of the human image. It was a drama in which millions participated, in which each moment in the lives of the persecuted, humiliated and condemned to death was saturated with action. ${ }^{203}$

200 Siehe dazu den instruktiven Sammelband von Rásky, Béla/Fritz, Regina/Kovács, Eva (Hgg.) (2016): Als der Holocaust noch keinen Namen hatte / Before the Holocaust had its Name: Zur frühen Aufarbeitung des NS-Massenmords an Jüdinnen und Juden. Wien: new academic press 2016, insbesondere den Artikel zur politischen Bedeutung des Holocaust für die Bürgerrechtsbewegung und die Sorge, dass sich dies in Amerika mit den Afroamerikanern wiederholen könnte, von Wiesen, S. Jonathan (2016): On Dachau and Jim Crow. Holocaust Memory in the Postwar African American Press. Wien: new academic press, S. 111-131. Jan Mollenhauer richtet in seinem Dissertationsvorhaben Spektrale Montagen (Humboldt-Universität zu Berlin/GK Konfigurationen des Films, Goethe Universität, Frankfurt am Main) das Augenmerk auf die "multidirektionale Erinnerungskultur" und erinnert in diesem Zusammenhang daran, dass W.E.B. Du Bois, der 1936 NS-Deutschland und 1949 die Ruinen des Warschauer Ghettos besuchte, dafür eine ebenso prominente Figur ist wie der afroamerikanische Fotograf William A. Scott, der die Befreiung des Konzentrationslagers Buchenwald durch die amerikanische Armee und die dort vorgefunden „Leichenberge" ermordeter Häftlinge fotografisch dokumentiert hat. Mollenhauer untersucht das "american dilemma”, demzufolge afroamerikanische Soldaten im II. Weltkrieg gegen das rassistische NS-Regime kämpften und zugleich selbst unter rassistischer Diskriminierung innerhalb der segregierten Armee und in den USA, zumal vor dem Hintergrund der Gewalt- und pornografischen Bildkultur des Lynchens, zu leiden hatten. 201 Vgl. Stauber, Roni (2010): Laying the Foundations for Holocaust Research - The Impact of Philip Friedman. Göttingen: Wallstein Verlag.

202 Vgl. Gallas, Elisabeth (2016): Frühe Holocaustforschung in Amerika, S. 541.

203 Robinson, Jacob/Friedman, Philip (1960): Guide To Jewish History Under Nazi Impact. Biographical Series No. 1, New York: Marstin Press, Inc., S. XVII. 
Lange hielt sich der "Mythos des Schweigens"204 einerseits, der des Fehlens jüdischen Widerstands andererseits, letzterer wohl Folge eines zu hoch angesetzten politischen Widerstandsbegriff, befördert auch durch umstrittene Äußerungen Hannah Arendts. 1948 hatte Arendt in ihrem Artikel Konzentrationsläger, bereits hier unter totalitarimustheoretischen Gesichtspunkten, bestritten, dass es überhaupt nennenswerten jüdischen Widerstand gegeben habe. ${ }^{205}$ "Widerstandslos" hätten sich "Millionen von Menschen [...] in den Gastod [...] abkommandieren lassen." Es habe "kaum ernsthafte Revolten gegeben", und "selbst im Moment der Befreiung" sei es „kaum zu irgendwelchen spontanen Metzeleien der SS gekommen."206 "Aller effektive Widerstand gegen die Nazis hatte gegen 1936 aufgehört," ${ }^{207}$ so ihr Diktum. Gewiss hat Hannah Arendt vom Warschauer Ghetto Aufstand (vom 19. April bis 16. Mai 1943) Kenntnis gehabt. Hat sie 1948 jedoch vom Aufstand des "Sonderkommandos" in Auschwitz-Birkenau am 7. Oktober 1944 gewusst und von den Häftlingsaufständen im Juni 1943 in den Ghettos von Lemberg, Tschenstochau (Juni 1943), in Będzin (3. August 1943) und in Białystok (August 1943) sowie in den Vernichtungslagern Treblinka (August 1943) und Sobibór (Oktober 1943)? Allerdings wollte auch der große Holocaust-Forscher Raul Hilberg, dessen Hauptwerk erst 1982 in deutscher Sprache erschien, kaum Möglichkeiten für jüdischen Widerstand gegen das NS-Regime gesehen haben. ${ }^{208}$

204 Diner, Hasia R. (2009): We Remember with Reverence and Love. American Jews and the Myth of Silence after the Holocaust 1945-1962, New York: New York University Press; sowie Diner, Hasia R. (2016): No Generation of Silence. American Jews and the Holocaust in the Post-War-Years. In: Rásky, Béla/Fritz, Regina/Kovács, Eva (Hgg.): Als der Holocaust noch keinen Namen hatte, S. 135-147.

205 Vgl. Arendt, Hannah (1948): Konzentrationsläger. In: Die Wandlung. Eine Monatsschrift. Dritter Jahrgang, Viertes Heft (1948). Unter Mitwirkung von Karl Jaspers, Marie Luise Kaschnitz und Alfred Weber herausgegeben von Dolf Sternberger, S. 309-330, hier: S. 327. Siehe auch Arendt, Hannah (2011): Elemente und Ursprünge totaler Herrschaft. Antisemitismus, Imperialismus, totale Herrschaft. Von der Autorin übersetzt und durchgesehen, 14. Auflage, München/Zürich: R. Piper Verlag, S. 907-943.

206 Arendt, Hannah (1948): Konzentrationsläger, S. 326. 207 Arendt, Hannah (1948): Konzentrationsläger, S. 326. 208 Vgl. Hilberg, Raul (1992): Die Vernichtung der europäischen Juden, Bd. 2. Übersetzt von Hans Günther Holl. 3. Auflage. Frankfurt a.M.: S. Fischer Verlag, S. 518ff. Zum schwierigen Verhältnis Hilbergs zu Arendt, deren unter-
Jedoch, so Yehuda Bauer:

Der bewaffnete Widerstand war nicht nur umfangreicher, als man gewöhnlich annimmt, sondern er war auch von großer symbolischer Bedeutung. Man muß jedoch erinnern, daß er erst begann, als die Juden realisierten, daß es keine Alternative gab, daß die Nazis planten, alle Juden umzubringen. ${ }^{209}$

Was die Erfindung des "Mythos des Schweigens" angeht, so macht Hasia R. Diner dafür in durchaus provokanter Weise die "jüdischen Aktivisten" der amerikanischen Counter-Culture der 1960er Jahre verantwortlich, die für sich reklamiert hätten, den verdrängten Holocaust „entdeckt” zu haben, freilich unter Missachtung der jüdischen Toten- und Gedenkbücher, der frühen jüdischen Erinnerungsarbeit und Geschichtsschreibung des Holocaust, einschließlich der Monographien zu den großen Ghettos aus den 1940er und 1950er Jahren, ohne die der "Boom" der Holocaust-Forschung seit den 1970er Jahren nicht denkbar gewesen wäre, wie sie unterstreicht. ${ }^{210}$

Dieser Vorwurf betrifft zumal "die deutsche Zeitgeschichtswissenschaft bei der Behandlung des Holocaust-Themas", wie Martin Broszat unter dem Eindruck der Ausstrahlung der vierteiligen Serie Holocaust - Die Geschichte der Familie Weiss von Marvin J. Chomsky 1979 im westdeutschen Fernsehen, freilich in einem anders gerichteten Sinne, höchst despektierlich hervorhebt. ${ }^{211}$

schiedliche Einschätzung Eichmanns einerseits, der Judenräte andererseits siehe Hilberg, Raul (1994): Unerbetene Erinnerung. Der Weg eines Holocaust-Forschers. Übersetzt von Hans-Günter Holl. Frankfurt a.M.: S. Fischer Verlag, S. 129ff.; sowie Ludz, Ursula (2011): In den Untiefen des Allzumenschlichen. In: HannahArendt.net. Zeitschrift für politisches Denken 1/2, Bd. 6. http://www.hannaharendt. net/index.php/han/article/view/17/86 (27.02.2019).

209 Bauer, Yehuda (2012): Jüdische Reaktionen auf den Holocaust. Berlin: LIT Verlag, S. 119-126, hier: S. 124.

210 Diner, Hasia R. (2009): We Remember with Reverence and Love, S. 309.

211 Broszat, Martin (1979): Holocaust und die Geschichtswissenschaft. In: Vierteljahrshefte für Zeitgeschichte 27, S. 285-298, hier: S. 289-293; siehe Gallas, Elisabeth (2016): Frühe Holocaustforschung in Amerika, S. 554, Anm. 17. Das perspektivisch und methodisch Trennende zwischen jüdischer Holocaust-Forschung, die die individuelle Erinnerung der Überlebenden und das Gedächtnis der Opfer nicht restlos in Geschichte übersetzt, und westdeutscher "Historisierung des Nationalsozialismus", die wähnt, durch ihre eigene "Zugehörigkeit zur Hitlerjugend" nicht kompromittiert und zu gewissermaßen sach- 
In seinem Artikel Holocaust und die Geschichtswissenschaft weist er darauf hin, dass

[d]ie Geschichte der jüdischen Katastrophe im Zweiten Weltkrieg [...] zunächst und vor allem jüdische Geschichte und Erinnerung gewesen [war]. Diese trat anfangs, vor allem in den Jahren 1945-1948, auch in der Form einer breiten, spontan entstandenen jüdischen Erinnerungs-,Trivialliteratur' hervor, rasch und oft unbeholfen in Displaced-Persons-Camps von Überlebenden der Katastrophe niedergeschrieben. ${ }^{212}$

Er verweist auf die "khurbn-Literatur", ${ }^{213}$ die in derselben Zeit entstanden sei wie "viele Tausende unveröffentlicht gebliebene jüdische Erlebnis-

licher Geschichtsschreibung befugt zu sein, wird in dem zwischen September und Dezember 1987 geführten Briefwechsel zwischen Saul Friedman und Martin Broszat plastisch. Broszat, Martin/Friedländer, Saul (1988): Diskussion um die "Historisierung des Nationalsozialismus". Ein Briefwechsel. In: Vierteljahresschrift für Zeitgeschichte Jg. 36, Heft 2, S. 339-372. Nicht zuletzt anhand der Ablehnung der Pionierarbeiten Joseph Wulfs und Léon Poliakovs hat Berg, Nicolas (2003): Der Holocaust und die westdeutschen Historiker, Göttingen: Wallstein Verlag, S. 343 - die Ausgrenzung der jüdischen Holocaust-Forscher durch prominente Akteure der bundesdeutschen Geschichtswissenschaft untersucht. Im Vorgehen Martin Broszats gegen Joseph Wulf, jüdischer Widerstandskämpfer und Auschwitz-Überlebender, "offenbart sich die Überzeugung Broszats, daß eine gerechte Darstellung der Judenvernichtung nicht jüdischen Überlebenden überlassen werden kann." Saul Friedländer hat demgegenüber das Konzept der "integrierten Holocaustgeschichte" entwickelt, die die "Komplexität und wechselseitige Verflochtenheit der gewaltigen Zahl von Komponenten" berücksichtigt: Die Holocaust-Forschung lasse sich nicht auf deutsche Maßnahmen und Entscheidungen beschränken, sondern müsse alle Akteure, Behörden und Institutionen sowie "unterschiedliche gesellschaftliche Gruppen der besetzten Länder und der Satellitenstaaten im von Deutschen besetzten Europa" berücksichtigen. Es sei zumal "offenkundig, dass in jedem Stadium jüdische Wahrnehmungen und Reaktionen (ob kollektiv oder individuell) ein untrennbarer Bestandteil dieser Geschichte waren und man sie somit im Hinblick auf eine allgemeine historische Darstellung nicht als separaten Teil ansehen kann." Friedländer, Saul (2007a): Eine integrierte Geschichte des Holocaust. In: Aus Politik und Zeitgeschichte 14-15, S. 7-14; Friedländer, Saul (2007b): Den Holocaust beschreiben. Auf dem Weg zu einer integrativen Geschichte. Göttingen: Wallstein Verlag, S. 7-27. Für den Hinweis auf Friedländers Konzept sowie für Gewalt- und Widerstandsgespräche danke ich herzlich Michael Wildt.

212 Broszat, Martin (1979): Holocaust und die Geschichtswissenschaft, S. 289.

213 Zur jüdischen Gattung der "khurbn", der "Literatur der Zerstörung" siehe Friedman, Philip (1959): Research and Literature on the recent Jewish tragedy. In: Jewish So- und Augenzeugenberichte", auf Tagebücher wie das der sechzehnjährigen Mary Berg, geschrieben im Warschauer Ghetto, ${ }^{214}$ nicht zuletzt auf das YIVO, seine großen Akten- und Materialbestände aus polnischen und litauischen Ghettos, sowie auf die wichtigen Primärquellen des Ringelblum-Archivs, nicht jedoch auf die Holocaust- und Widerstandsforschung des YIVO. ${ }^{215}$ An der auch im bundesdeutschen Fernsehen ausgestrahlten Holocaust-Serie monierte er insbesondere den Folklorismus, mit dem der Warschauer GhettoAufstand und "die jüdischen Partisanentätigkeit in der Ukraine weit über das Maß der nur minimalen jüdischen Widerstands-Aktivitäten hinaus in Szene gesetzt [sind], so proportioniert, wie junge Israelis sich wahrscheinlich wünschen, daß es gewesen sein möge." 216 In Einlassungen wie diesen, in denen Widerstand an Erfolgskriterien gemessen wird, verrät sich eine unheilvolle Tendenz, in den europäischen Juden und Jüdinnen nur Opfer sehen zu wollen, die NS-Vernichtungspolitik demgegenüber für beinahe restlos zu erklären. ${ }^{217}$

Anders der israelische Historiker Yehuda Bauer, der sowohl bewaffnete als auch unbewaffnete Formen jüdischen Widerstands untersucht hat. Letztere bezeichnete er in hebräischer Sprache als "amidah" - "aufrecht stehen", "stand halten", "sich gegen jemanden erheben". ${ }^{218} \mathrm{Er}$ nahm die sozialen, religiösen, kulturellen und politischen Widerstandspraktiken in den Blick, mit denen

cial Studies 12, S. 17-26, hier: S. $17 \mathrm{ff}$. sowie Gallas, Elisabeth (2016): Frühe Holocaustforschung in Amerika, S. $557 f$. $214 \mathrm{Vgl}$. Berg, Mary (Miriam Wattenberg) (1945): Warsaw Ghetto. A Diary. Übersetzt von Norbert Gutermann, herausgegeben von S.L. Schneidermann. New York: L.B. Fischer 1945.

215 Broszat, Martin (1979): Holocaust und die Geschichtswissenschaft, S. 291.

216 Broszat, Martin (1979): Holocaust und die Geschichtswissenschaft, S. 287.

217 Eine Ausnahme bildete die XXXI. Tagung der Forschungsgemeinschaft 20. Juli 1944 "Mit jedem Leben, das wir retteten, bekämpften wir Hitler!" - Jüdischer Widerstand und der Widerstand und die Juden, Bonn 16.02.18.02.2018.

218 Bauer, Yehuda (2001): Die dunkle Seite der Geschichte. Die Shoah aus historischer Sicht. Interpretationen und Re-Interpretationen. Frankfurt a.M.: Jüdischer Verlag im Suhrkamp Verlag, S. 153-181. Zum bewaffneten jüdischen Widerstand und seine "symbolische Bedeutung" siehe Bauer, Yehuda (2012): Jüdische Reaktionen auf den Holocaust, S. 119-126, hier: S. 124. 
jüdische Menschen in den Ghettos durch den verbotenen Aufbau von Schulen, Kindergärten, Waisenhäusern, Krankenhäusern, durch Beschaffung von Nahrungsmitteln, Kleidung, Medikamenten, durch die Veranstaltung von Konzerten, Theateraufführungen, Gedenkabenden für die von der SS Ermordeten der deutschen Vernichtungs- und Verfolgungspolitik begegneten. "Amidah" zielte auf die ",Heiligung des Lebens", auf die Bewahrung jüdischer Kultur und Würde, die Aufrechterhaltung einer elementaren Moral "in einer völlig unmoralischen Welt". ${ }^{219}$

"'Das Leben heiligen'. Dies bedeutete, daß alles dafür getan werden mußte, jüdisches Leben zu retten. Jüdisches Leben, dies wollte der Feind nehmen. Es folgten vielfältige Reaktionen, nicht alle organisiert, einige spontan."220 In seiner Holocaust-Studie von 1968 fasste Martin Gilbert nicht nur alles das als Widerstand, was Überleben ermöglichte, sondern gerade auch das Überleben selbst: "Thus, simply to survive was a victory of the human spirit." $221 \mathrm{Zu}$ überleben war „eine Form

219 Bauer, Yehuda (2001): Die dunkle Seite der Geschichte, S. 173, 164. Im Ghetto in Wilnar fand am 4.5.1942, begleitet von kontroversen Debatten darüber, ob ein Theater überhaupt, wie es hieß, auf einem Friedhof gegründet werden könne, das erste Konzert statt, so Schroeter, Gudrun (2010): Jüdischer Widerstand in Ghettos 1939-1944. In: Lernen aus der Geschichte, S. 6-7. „In Erinnerungen und Memoiren ist dokumentiert, dass viele Menschen, die den entmenschlichten und hoffnungslosen Bedingungen ausgesetzt waren, diese Ruhestunde des Konzerts als fast sakrales Erlebnis empfanden. Avrom Sutzkewer beschreibt die Stimmung des ersten Abends, dass jeder Klang der Ermordeten gemahnte, ,... MENTSHN SAYNEN GESHTANEN, WI ME SHTEYT LEBN AN OFENEM KEYWER.' In den ersten Monaten der Existenz des Theaters wurden Themen der jüdischen Literatur, Werke von Aleiychem, Perez oder Bialik gespielt, dann kamen eigene Produktionen aus dem Ghetto dazu." Schroeter, Gudrun: Konzert- und Theaterplakate aus dem Wilnaer Ghetto 1941 - 1943. http://www. juden-in-europa.de/baltikum/wilnaer-ghetto.htm (Zugriff am 9.4.2019).

220 Bauer, Yehuda (2012): Jüdische Reaktionen auf den Holocaust, S. 77.

221 Gilbert, Martin (1986): The Holocaust: The Jewish Tragedy. London: Collins, S. 174, dazu Gitman, Esther (2018): Courage to Resist. Jews of the Independent State of Croatia Fight back. In: Schoeps, Julius H./Bingen, Dieter/Botsch, Gideon (Hgg.): Jüdischer Widerstand in Europa (1933-1945). Formen und Facetten. Berlin/Boston: De Gruyter Oldenbourg, S. 106-125, hier: S. 108. des Widerstandes" 222, wie Ágnes Rózsa 1945 in ihrem Tagebuch festhielt.

Am 6.3.1964, dem 24. Verhandlungstag des ersten Frankfurter Auschwitz-Prozesses, vermittelte Hermann Langbein dem Gericht eine Vorstellung von den Möglichkeiten des "Rettungswiderstandes"223 im Konzentrations- und Vernichtungslager Auschwitz:

Der Hauptwiderstand in Auschwitz war natürlicherweise der, Leben zu retten. Denn die Haupttätigkeit der SS war, Leben zu vernichten. Begonnen hat es in sehr kleinem Maßstab. Es hat begonnen damit, daß man versucht hat, Essen zu ,organisieren'. Es hat begonnen damit, daß man versucht hat, Häftlinge auszutauschen mit Leichen. Das ist die Ursache gewesen, weshalb dann Häftlingsnummern tätowiert wurden: In Einzelfällen - in sehr wenigen Einzelfällen war das nur möglich - konnte man jemanden, von dem man annahm, daß er besonders gefährdet war von draußen, mit einem Toten auswechseln, konnte inm die Nummer des Toten geben und ihn als tot abschreiben, so daß er für die Politische Abteilung gestorben war und daher nicht mehr verfolgt werden konnte. ${ }^{224}$

Unter dem Eindruck rassistischer Vernichtungsgewalt zäh/ten ausnahmslos alle Praktiken, mochten sie auch noch so flach und unbedeutend erscheinen wie der Schlaf, wie "lazarenische" und "konzentrationäre[...] Träume", zum Widerstand in Gestalt des Sich-Entziehens, der es, so Jean Cayrol, „einigen erlaubte zu überleben":

222 Rózsa, Ágnes (2006): Solange ich lebe, hoffe ich. In: Diefenbach, Michael/Jochem, Gerhard (Hgg.): "Solange ich lebe, hoffe ich". Die Aufzeichnungen des ungarischen KZ-Häftlings Ágnes Rózsa. Nürnberg: Verlag testimon, S. 95-352, hier: S. 227. Zu den Handlungsspielräumen der Häftlinge siehe Wachsmann, Nikolaus: (2015): KL. Die Geschichte der nationalsozialistischen Konzentrationslager. Berlin: Siedler Verlag, S. 573ff.

223 Der treffende Begriff "Rettungswiderstand" geht auf Wolfram Wette zurück, der inn jedoch für "Helfer und Retter in der Uniform" der Wehrmacht, Polizei und der SS reserviert. Wette, Wolfram (2003): Helfer und Retter in der Wehrmacht als Problem der historischen Forschung. In: Ders. (Hg.): Retter in Uniform. Handlungsspielräume im Vernichtungskrieg der Wehrmacht. 3. Auflage. Frankfurt a.M.: S. Fischer Verlag, S. 11-31.

224 1. Frankfurter Auschwitz-Prozess. "Strafsache gegen Mulka u.a", 4 Ks 2/63, Landgericht Frankfurt am Main, 24. Verhandlungstag, 6.3.1964. Vernehmung des Zeugen Hermann Langbein, S. 49. Zum Widerstand und den Widerstandsmöglichkeiten in Auschwitz siehe Langbein, Hermann (1978): Menschen in Auschwitz. Wien: Europa Verlag, S. 276ff., 278, 291, 292. 
Der Gefangene war Herr seines Schlafes, über diese wenigen Stunden, wo alles Gelebte bis zum Paroxysmus in einer übernatürlichen Vision erschien, hatte die SS weder Gewalt noch Macht. Dieser Schlaf war zumeist kein kreatürliches Ausruhen; er wurde zu einer Art Reliquienschein einer vielleicht ersterbenden Vergangenheit, die sich jedoch umwandelte, wenn es einigen blitzartigen Bildern gelang, einen Steg der Rückkehr aufleuchten zu lassen. Dieser Schlaf bedeutete für jeden von uns die Aufhebung seiner Rechtlosigkeit, das Positive eines negativen Tageslebens. ${ }^{225}$

Jean Cayrol, der 1942 von der Gestapo in Paris festgenommen und in das KZ Gusen bei Mauthausen deportiert wurde, erzählt vom morgendlichen "'Einsammeln' der Träume bei seinen Kameraden" und umreißt in seinen Traumanalysen "die vollkommene innere Umwälzung, die dem Menschen ermöglicht, ohne alle Hilfsmittel und Reserve zu widerstehen." 226 In der Extremsituation der Konzentrationslager waren soziale Beziehungen, "stabile Paarbeziehungen" und Kleingruppenbildungen überlebenswichtig, wie Elmar Luchterhand, Nachrichtenoffizier der amerikanischen Armee, herausfand, der insgesamt 75 Überlebende der Lager Ohrdruf, Buchenwald, Gusen, Mauthausen, Dachau, Wanfried und Feldafing interviewte, auch österreichische und deutsche Zivilisten, die in der Nähe der befreiten Lager lebten. „Das Paar, die Dreier- oder Vierergruppe und, in seltenen Fällen, größere Einheiten waren sichere Organisationsformen. Verrat war weniger wahrscheinlich. Größere Gruppen waren in der Regel weniger erfolgreich im ,Organisieren"' und Teilen der organisierten Lebensmittel. $^{227}$ Mit seiner "genuin soziologi-

225 Cayrol, Jean (1995): Lazarus unter uns. Übersetzt von Sigrid von Massenbach. Stuttgart: Curt E. Schwaab, S. 18. Den Hinweis auf Jean Cayrol verdanke ich Holger Brohm und seiner "Kulturgeschichte des Träumens". Wichtige Anregungen zu den politischen Implikationen von "Schlaf und Schlaflosigkeit" verdanke ich wiederum dem gleichnamigen Masterseminar, das ich mit Zoë Herlinger und Waldermar Isak im Wintersemester 2018/19 ausgerichtet habe.

226 Cayrol, Jean (1995): Lazarus unter uns, S. 16, 10.

227 Luchterhand, Elmer (2018): Einsame Wölfe und stabile Paare. Verhalten und Sozialordnung in den Häftlingsgesellschaften nationalsozialistischer Konzentrationslager, herausgegeben und eingeleitet von Andreas Kranebitter und Christian Fleck. Wien: new academic press, S. 99. Bei der Publikation handelt es sich um die 1953 abgeschlossene Doktorarbeit Prisoners Behavior and Social System in Nazi Concentration Camps. Siehe dazu die Rezension von schen Perspektive" widersprach er ausdrücklich all jenen, die, wie Hannah Arendt, Bruno Bettelheim, ${ }^{228}$ später auch Wolfgang Sofsky oder Maja Suderland, ${ }^{229}$ allein "die Effizienz des Nazi-Terrors" herausgestellt hatten, ohne zugleich „die Grenzen der NS-Politik"230 durch Sozialitätsstiftung, durch Rettungs- und Überlebenswiderstand aufzuzeigen.

Sofern die "Reservate" und "Territorien des Selbst", ${ }^{231}$ die eigene Haut, die Kleidung, der intime Raum, körperliche Unverletzlichkeit, leibliche Selbstzugehörigkeit, die nackte Existenz, deren Schutz eine zentrale soziale und gesellschaftliche Aufgabe darstellt, im kalkulierten System des Terrors mit extremer Gewalt zerstört wurden, konnte der Freitod eine letzte, verzweifelte Chance auf Selbstaneignung durch Selbstentaneignung, einen Widerstandsakt radikaler Passivierung und des Sich-Undienlichmachens darstellen.

Das Politische in Extremsituationen muss nicht nur von der Natalität des widerständigen Überlebens, sondern auch von der Transitivität des Sterbens aus gedacht werden. Im Kontext der rassistischen NS-Tanathopolitik war nicht nur die Lebensrettung eine widerständige Praktik,

Götz Aly. In: Süddeutsche Zeitung, 14.12.2018. Mit herzlichem Dank an Lutz Fiedler.

228 Bruno Bettelheim wandte sich dem doppelten Problem des "Überlebens" zu. Das eine betraf die "persönlichkeitszersetzende" Erfahrung des "Gefangenseins in einem deutschen Konzentrationslager, das die soziale Existenz völlig zerstörte" und durch "schlimmste Mißhandlungen", Folter, Terror und ständige Lebensgefahr bestimmt war. Das andere bezog sich auf die „lebenslangen Nachwirkungen eines solchen Traumas, die ganz besondere Formen der Bewältigung erfordern, wenn man ihnen nicht erliegen soll." Bettelheim, Bruno (1980): Erziehung zum Überleben. Zur Psychologie der Extremsituation. Übersetzt von Edwin Ortmann, Rudolf Hermstein und Brigitte Weitbrecht. Stuttgart: DVA, S. 34.

229 Vgl. Suderland, Maja (2009): Ein Extremfall des Sozialen. Die Häftlingsgesellschaft in den nationalsozialistischen Konzentrationslagern, Frankfurt a.M./New York: Campus Verlag; vgl. hingegen Suderland, Maja (2004): Territorien des Selbst. Kulturelle Identität als Ressource für das tägliche Überleben im Konzentrationslager, Frankfurt a.M./New York: Campus Verlag.

230 Kranebitter, Andreas/Fleck, Christian (2018): Elmer Luchterhands Forschungen zu nationalsozialistischen Konzentrationslagern. Eine Einleitung. In: Luchterhand, Elmer: Einsame Wölfe und stabile Paare, S. 7-36, hier: S. 27.

231 Gofman, Erving (1982): Das Individuum im öffentlichen Austausch. Mikrostudien zur öffentlichen Ordnung. Übersetzt von R. und R. Wiggershaus. Frankfurt a.M.: Suhrkamp Verlag, S. 54-71. 
sondern auch der Freitod, erkennbar auch daran, dass missglückte Versuche hart bestraft wurden: Freitode wurden von der SS als Akte der Selbstbehauptung und Selbstbestimmung angesehen, die dem Anspruch auf totale Verfügungsgewalt "über Leben und Körper der Insassen" zuwiderliefen, ${ }^{232}$ wie Jean Améry, der Auschwitz überlebte und sich 1978 das Leben nahm, berichtet:

Es war bezeichnend für die Situation der Häftlinge, daß nur wenige sich entschlossen, , an den Draht' zu laufen, wie man sagte, das heißt: durch Berühren der mit Starkstrom geladener Stacheldrähte Suizid zu begehen. Der Draht war eine gute Sache, vielleicht aber wurde man noch vorher, beim Versuch, sich inm zu nähern, ertappt und in den Bunker geworfen, was zu einem schwierigen und peinvolleren Tode führte. ${ }^{233}$

Alle Widerstandspraktiken der Aktivierung und Passivierung und die buchstäblichen body politics des Undienlichwerdens zumal, die noch die konsequentesten Gewalt- und Machträume nicht total und restlos machen, müssen als Extremsituationen des Politischen ernst genommen werden, und das gerade auch mit irreduzibler Verspätung und historischer Nachträglichkeit, ausgehend von den singulären Zeugnissen, Berichten und der Erinnerungsliteratur der Überlebenden, deren Erfahrungen, Sprech- und Schreibweisen sich nicht vollständig in Geschichte auflösen und stillstellen lassen.

\section{Resümee}

Angesichts der alltagsgeschichtlich wie soziologisch orientierten Pionierleistungen der frühen African American Studies und der jüdischen Holocaustforschung avant la lettre zeigt sich die Voraussetzungshöhe gängiger Widerstandskonzepte und deren verengende Pointierung des Politischen. Das gilt für den Tyrannenmord und das Menschenrecht auf Widerstand gegen Unterdrückung genauso wie für Revolutionsprogrammatiken und Konzepte zivilen Ungehorsams in Rechtsstaaten, die sich jeweils auf die Abschaffung staatlicher Ungerechtigkeit, auf eine Zukunft der

232 Goeschel, Christian (2011): Selbstmord im Dritten Reich. Übersetzt von Klaus Bindner. Berlin: Suhrkamp Verlag, S. 179. 233 Améry, Jean (1966): Jenseits von Schuld und Sühne. Bewältigungsversuche eines Überwältigten. München: Szczesny, S. 34.
Menschheit und auf ein bürgerliches Verständnis von Öffentlichkeit und Sichtbarkeit berufen. Auch wenn deren Denker ihre Stimme im Namen des Gemeinwohls und gar menschenrechtlicher Universalität erhoben haben, so waren deren Widerstandskonzepte entstehungsgeschichtlich doch stets von Aufteilungen, hierarchischen Zugangsbeschränkungen und Exklusionen bestimmt. Als problematisch erweist sich im Hinblick auf Extremsituationen die Betonung von Sichtbarkeit und Öffentlichkeit, Aktivität und Handlung. Das betrifft selbst noch moderne Konzeptionen des passiven, gewaltfreien Widerstands wie Hungerstreik, Ankettung oder Blockade, für deren politische Bedeutung Öffentlichkeit und mediale Aufmerksamkeit geradezu konstitutiv sind. Praktiken der Passivierung als Widerstand, die sich im Verborgenen abspielen müssen, unterschreiten diese an Sichtbarkeit orientierten Protestformen und kommen daher für die Protestforschung bislang nicht recht in Betracht.

Es spricht viel dafür, Widerstand aisthetisch, von der empfindlichen Haut, vom verletzlichen, zwecklosen, undienlichen und sterblichen Körper aus zu denken, genauer: ausgehend von einem gewaltsam angetanen und schmerzlich empfundenen Erleiden und Leid, das zum Widerstand und zum Widerstehen drängt, zu body politics im buchstäblichen Sinne, zumal in Extremsituationen der Entrechtung und Verfolgung, des Terrors und Massenmords, der Folter, der Entmenschung, rassistischen Animalisierung, Verdinglichung und Kommodifizierung. Zum Widerstand als einer reaktiven Praxis, die ein Wogegen hat, gehören alle Formen der Selbstaneignung durch Selbstentaneignung, der Selbstzugehörigkeit, der Selbststabilisierung und Selbstaktivierung, mit denen sich das Selbst mit sich selbst in Berührung bringt und in sich zurückzieht, um sich dem Zugriff der Gewalt zu entziehen. Das ist ein mehr oder minder passiver Modus der Gewaltenschwächung. Wo Täter in organisierten Macht- und Gewalträumen darauf abzielen, Menschen zu vernichten, erweist sich jede Form des Weiterlebens als ein politischer Rettungs- und Überlebenswiderstand. Hier vor allem kommen Formen sozialer Beziehungen und kulturelle Praktiken ins Spiel, die menschliches Überleben tragen durch Fürsorge, Trauerarbeit, Teilen und Schenken, mithin als politische Praktiken humaner Resistenz. Aktiver Widerstand, sei er offen- 
siv oder verborgen, der eine absolute und totale Gewalt durch Gegengewalt und Befehlsverweigerung, heimliche List und Taktik, punktuell angreift oder teilt, erweist sich als eine Gewaltenteilung in statu nascendi. Die irreduzible Reaktivität jeden Widerstands macht die kontextsensible Kooperation einer angemessenen Widerstandsforschung mit der je spezifischen Gewaltforschung unhintergehbar. Sie bewahrt beide vor Überzeichnungen und Effizienzüberschätzungen in die eine wie in die andere Richtung.

\section{Literaturverzeichnis}

1. Frankfurter Auschwitz-Prozess. "Strafsache gegen Mulka u.a", 4 Ks 2/63, Landgericht Frankfurt a.M., 24. Verhandlungstag, 6.3.1964. Vernehmung des Zeugen Hermann Langbein.

Abu-Lughod, Lila (1990): The Romance of Resistance: Tracing Transformations of Power through Bedouin Women. In: American Ethnologist Vol. 17, No. I (1990), S. 41-55.

Agamben, Giorgio (2005): Nymphae, herausgegeben und übersetzt von Andreas Hiepko. Berlin: Merve.

Améry, Jean (1966): Jenseits von Schuld und Sühne. Bewältigungsversuche eines Überwältigten. München: Szczesny.

Aptheker, Herbert (1937): American Negro Slave Revolts. Part 1. In: Science and Society 1, S. 512-538.

Aptheker, Herbert (1938): American Negro Slave Revolts. Part 2. In: Science and Society 1, S. 386-392.

Aptheker, Herbert (1939: Negro Revolts in the United States, 1526-1860. New York: International Publishers.

Aptheker, Herbert (1943): American Negro Slave Revolts. New York: Columbia University Press.

Arendt, Hannah (1948): Konzentrationsläger. In: Die Wandlung. Eine Monatsschrift. Dritter Jahrgang, Viertes Heft (1948). Unter Mitwirkung von Karl Jaspers, Marie Luise Kaschnitz und Alfred Weber herausgegeben von Dolf Sternberger, S. 309-330.

Arendt, Hannah (1963): Über die Revolution München: R. Piper Verlag.

Arendt, Hannah (2007): Vita activa oder Vom tätigen Leben. 6. Auflage. München: Serie Piper.

Arendt, Hannah (2011): Elemente und Ursprünge totaler Herrschaft. Antisemitismus, Imperialismus, totale Herrschaft. Von der Autorin übersetzt und durchgesehen, 14. Auflage, München/Zürich: R. Piper Verlag.

Arendt, Hannah (2017): Ziviler Ungehorsam. In: Braune, Andreas (Hg.): Ziviler Ungehorsam, S. 132-161.

Aristoteles (1981): Politik. Mit einer Einleitung von Günther Bien übersetzt und mit erklärenden Anmerkungen versehen von Eugen Rolfes. Hamburg: Felix Meiner Verlag.
Arndt, Adolf (1962): Agraphoi Nomoi (Widerstand und Aufstand). In: Neue Juristische Wochenschrift, S. $430-433$.

Artauds, Antonin (1974): Fuvres complètes. Bd. XIII. Paris: Éditions Gallimard.

Bailey, Anne C. (2017): The Weeping Time: Memory and the Largest Slave Auction in American History, New York: Cambridge University Press.

Bancroft, Frederic (1931): Slave Trading in the Old South. Baltimore: J. H. Furst Company.

Bataille, Georges (1970a): Dossier "Hétérologie”. In: Fuvres complètes, Bd. II. Paris: Éditions Gallimard, S. 167-205.

Bataille, Georges (1970b): Dossier de la polémique avec André Breton. In: Fuvres complètes, Bd. II, S. 51-109.

Bauer, Raymond A./Bauer, Alice H. (1942): Day to Day Resistance to Slavery. In: The Journal of Negro History, Vol. 27, No 4, S. 388-419.

Bauer, Raymond A./Bauer, Alice H. (1960): America, Mass Society, and Mass Media. In: Journal of Social Issues 16, No. 3, S. 3-66.

Bauer, Yehuda (2001): Die dunkle Seite der Geschichte. Die Shoah aus historischer Sicht. Interpretationen und Re-Interpretationen. Frankfurt a.M.: Jüdischer Verlag im Suhrkamp Verlag.

Bauer, Yehuda (2012): Jüdische Reaktionen auf den Holocaust. Berlin: LIT Verlag.

Berg, Nicolas (2003): Der Holocaust und die westdeutschen Historiker, Göttingen: Wallstein Verlag.

Berg, Mary (Miriam Wattenberg) (1945): Warsaw Ghetto. A Diary. Übersetzt von Norbert Gutermann, herausgegeben von S.L. Schneidermann. New York: L.B. Fischer 1945.

Berlin, Ira/Favreau, Marc/Miller, Steven F. (2007): Introduction. Slavery as Memory and History. In: Dies. (Hgg.): Remembering Slavery. African Americans talk about their personal experiences of slavery and emancipation, New York: The New Press, S. xv-xlix.

Bettelheim, Bruno (1980): Erziehung zum Überleben. Zur Psychologie der Extremsituation. Übersetzt von Edwin Ortmann, Rudolf Hermstein und Brigitte Weitbrecht. Stuttgart: DVA.

Blassingame, John (1977): Slave Testimony. Baton Rouge: Louisiana State Univ. Press 1977.

Blassingame, John (1979): Slave Community. New York: Oxford University Press.

Blassingame, John (1985): Using the Testimony of Ex-Slaves. In: Davis, Charles T./Gates Jr., Henry Louis (Hgg.): The Slave's Narratives. New York: Oxford University Press, S. 78-98.

Bloom, Solomon F. (1950): Toward the Ghetto Dictator. In: Jewish Social Studies 12, S. 73-78.

Bonnell Philipps, Ulrich (1929): American Negro Slavery. A Survey of the Supply, Employment and Control of Negro Labor as determined by the Plantation Régime, New York/London: D. Appleton and Company.

Botkin, Benjamin (1941): Vorwort zu Slave Narratives: A Folk History of Slavery in the United States from Interviews with Former Slaves, by the Library 
of Congress Project Work Project Adminstration, Washington, S. v-x.

Bourdieu, Pierre (1979): Entwurf einer Theorie der Praxis. Übersetzt von Cordula Pialoux und Bernd Schwibs. Frankfurt a.M.: Suhrkamp Verlag.

Broszat, Martin (1979): Holocaust und die Geschichtswissenschaft. In: Vierteljahrshefte für Zeitgeschichte 27, S. 285-298.

Broszat, Martin/Friedländer, Saul (1988): Diskussion um die "Historisierung des Nationalsozialismus". Ein Briefwechsel. In: Vierteljahresschrift für Zeitgeschichte Jg. 36, Heft 2, S. 339-372.

Bruce, Jr., Dickson B. (2014): Slave Narratives and Historical Understanding. In: Ernest, John ( $\mathrm{Hg}$.$) :$ The Oxford Handbook of the African American Slave Narrative. Oxford: Oxford University Press, S. 54-66.

Buck-Morss, Susan (2011): Hegel und Haiti. Für eine neue Universalgeschichte. Übersetzt von Laurent FaaschIbrahim, Berlin: Suhrkamp Verlag.

Busch, Kathrin (2012): P - „Passivität". Hamburg/ Lüneburg: Textem Verlag.

Busch, Kathrin/Draxler, Helmut (Hgg.) (2013): Theorien der Passivität. München: Fink Verlag.

Caillois, Roger (1982): Die Spiele und die Menschen. Maske und Rausch, übersetzt von Sigrid von Massenbach, Frankfurt a.M./Berlin/Wien: Ullstein.

Carroll, Joseph Cephas (1938): Slave Insurrections in the United States, 1800-1856. Boston: Chapman \& Grimes.

Catterall, Helen T. (Hg.) (1936): Judicial Cases Concerning American Slavery and the Negro. 5 vols. Washington, D.C.: Carnegie Institution.

Cayrol, Jean (1995): Lazarus unter uns. Übersetzt von Sigrid von Massenbach. Stuttgart: Curt E. Schwaab.

Clausen, Lars (1988): Produktive Arbeit, destruktive Arbeit. Soziologische Grundlagen. Berlin/New York: De Gruyter.

Clift, Arlene L. (1980): If Trees Would Talk: The Communication of Resistance in Ex-Slave-Narratives. Working Paper. Cambridge, MA. The Mary Ingraham Bunting Institute of Radcliff College. https://files.eric. ed.gov/fulltext/ED221443.pdf (Zugriff am 4.3.2019).

Därmann, Iris (2020): Undienlichkeit. Gewaltgeschichte und politische Philosophie. Erscheint Berlin: Matthes \& Seitz.

Deleuze, Gilles (1994): Bartleby oder die Formel. Übersetzt von Bernhard Dieckmann. Berlin: Merve.

Deleuze, Gilles (2002): Nietzsche und die Philosophie. Übersetzt von Bernd Schwibs. Hamburg: Europäische Verlangsanstalt.

Deleuze, Gilles/Guattari, Félix (1992): 28. November 1947 - Wie schafft man sich einen organlosen Körper? In: Dies.: Tausend Plateaus. Kapitalismus und Schizophrenie 2. Übersetzt von Gabriel Ricke und Ronald Voullié. Berlin: Suhrkamp Verlag, S. 205-227.

Derrida, Jacques (1980): Widerstände. In: Ders.: Vergessen wir nicht - die Psychoanalyse. Übersetzt von Hans-Dieter Gondek. Frankfurt a.M.: Suhrkamp Verlag, S. $128-180$.
Derrida, Jacques (1995): Marx' Gespenster. Der verschuldete Staat, die Trauerarbeit und die neue Internationale. Übersetzt von Susanne Lüdemann. Frankfurt a.M.: S. Fischer Verlag.

Derrida, Jacques (2002): Seelenstände der Psychoanalyse. Die Unmöglichkeit jenseits einer souveränen Grausamkeit. Übersetzt von Hans-Dieter Gondek, Frankfurt a.M.: Suhrkamp Verlag.

Derrida, Jacques (2003): Das Recht des Stärkeren (Gibt es Schurkenstaaten)? In: Ders.: Schurken. Zwei Essays über die Vernunft. Übersetzt von Horst Brühmann, Frankfurt a.M.: Suhrkamp Verlag.

Didi-Huberman, Georges (2011): Wenn die Bilder Position beziehen. Das Auge der Geschichte I. Übersetzt von Markus Sedlaczek. München: Fink Verlag.

Dilthey, Wilhelm (ca. 1880-1890/1982): Ausarbeitung zum zweiten Band der Einleitung in die Geisteswissenschaften. Viertes bis sechstes Buch. In: Johach, Helmut/Rodi, Frithjof (Hgg): Gesammelte Schriften, Bd. XIX. Göttingen: Vandenhoeck \& Ruprecht, S. 58-295.

Dilthey, Wilhelm (WS 1888/89/1997): Psychologie als Erfahrungswissenschaft. In: Kerckhoven, Guy van/ Lessing, Hans-Ulrich (Hgg.): Gesammelte Schriften, Bd. XXI. Göttingen: Vandenhoeck \& Ruprecht, S. 275-327.

Dilthey, Wilhelm (1957): Beiträge zur Lösung der Frage vom Ursprung unseres Glaubens an die Realität der Aussenwelt und seinem Recht. In: Misch, Georg (Hg.): Gesammelte Schriften, Bd. V. 2. Auflage. Stuttgart: B. G. Teubner Verlagsgesellschaft, S. $90-138$.

Diner, Hasia R. (2009): We Remember with Reverence and Love. American Jews and the Myth of Silence after the Holocaust 1945-1962, New York: New York University Press.

Diner, Hasia R. (2016): No Generation of Silence. American Jews and the Holocaust in the Post-WarYears. In: Rásky, Béla/Fritz, Regina/Kovács, Eva (Hgg.): Als der Holocaust noch keinen Namen hatte. Wien: new academic press, S. 135-147.

Donnan, Elizabeth (Hg.) (1930-1935): Documents Illustrative of the Slave Trade. 4 vols., Washington, D.C.: Carnegie Institution.

Douglass, Frederick (1845): Narrative of the Life of Frederick Douglass, 1817-1895. Boston: Bedford Books of St. Martin's Press.

Dreier, Ralf (1983): Widerstandsrecht und ziviler Ungehorsam im Rechtsstaat. In: Glotz, Peter (Hg.): Ziviler Ungehorsam im Rechtsstaat, Frankfurt a.M.: Suhrkamp, S. 54-75.

Dubnow, Simon (1925): Weltgeschichte des jüdischen Volkes von seinen Uranfängen bis zur Gegenwart. Band. 1: Die älteste Geschichte des jüdischen Volkes. Orientalische Periode. Von der Entstehung des Volkes Israel bis zum Ende der persischen Herrschaft in Judäa. Berlin: Jüdischer Verlag.

Eiden-Offe, Patrick (2017): Die Poesie der Klasse. Romantischer Antikapitalismus und die Erfindung des Proletariats. Berlin: Matthes \& Seitz. 
Elias Canettis (2010) Masse und Macht. 31. Auflage. Frankfurt a.M.: S. Fischer Verlag.

Engels, Friedrich (1977a): Revolution in Paris. In: MEW, Bd. 4, Berlin: Dietz Verlag, S. 528-530.

Engels, Friedrich (1977b): Die preußische Verfassung. In: MEW, Bd. 4, Berlin: Dietz Verlag, S. 30-36.

Engels, Friedrich (1977c): Die Kommunisten und Karl Heinzen. In: MEW, Bd. 4, Berlin: Dietz Verlag, S. 309-324.

Engels, Friedrich (1977d): Die Reformbewegung in Frankreich. In: MEW, Bd. 4, Berlin: Dietz Verlag, S. 399-406.

Esten, Emily (2015): A Peculiar Project. Ethics and Analysis of the WPA Slave Narrative Collection of Oklahoma (UMass Amherst). http://scua.library. umass.edu/umarmot/wp-content/uploads/FLURAdoc-2016-04.pdf (Zugriff am 4.3.2019).

Finkelman, Paul (Hg.) (1989): Rebellions, Resistance, and Runaways within the Slave South. New York/London: Garland Publishing, Inc.

Foucault, Michel (1983): Sexualität und Wahrheit. Der Wille zum Wissen. Übersetzt von Ulrich Raulf und Walter Seitter, Frankfurt a.M.: Suhrkamp Verlag.

Foucault, Michel (1994): Das Subjekt und die Macht. In: Dreyfus, Hubert L./Rabinow, Paul (Hgg.): Michel Foucault. Jenseits von Strukturalismus und Hermeneutik. Weinheim: Beltz Athenäum, S. 241-261.

Foucault, Michel (2009): Die Regierung des Selbst und der anderen. Übersetzt von Jürgen Schröder. Frankfurt a.M.: Suhrkamp Verlag.

Frazier, Franklin (1932): The Free Negro Family: A Study of Family Origins Before the Civil War. Nashville: Fisk University Press.

French, Scot (2004): The Rebellious Slave. Nat Turner in American Memory. Boston/New York: Oxford University Press.

Freud, Sigmund (1940): Jenseits des Lustprinzips. In: Gesammelte Werke, Bd. XIII, S. 3-69.

Freud, Sigmund (1942): Die Traumdeutung. In: Gesammelte Werke, Bd. II/III, herausgegeben von Anna Freud u.a. Frankfurt a.M./London: S. Fischer Verlag.

Freud, Sigmund (1948): Hemmung, Symptom und Angst. In: Gesammelte Werke, Bd. XIV, S. 113-205.

Freud, Sigmund (1955): Die Widerstände gegen die Psychoanalyse. In: Gesammelte Werke, Bd. XIV, S. 97-110.

Friedman, Philip (1959): Research and Literature on the recent Jewish tragedy. In: Jewish Social Studies 12, S. 17-26.

Friedländer, Saul (2007a): Eine integrierte Geschichte des Holocaust. In: Aus Politik und Zeitgeschichte 14-15, S. 7-14.

Friedländer, Saul (2007b): Den Holocaust beschreiben. Auf dem Weg zu einer integrativen Geschichte. Göttingen: Wallstein Verlag.

Gallas, Elisabeth (2015): Rezension von Cecile E. Kurnitz: YIVO and the Making of Modern Jewish Culture. Schorlarship fort he Yiddish Nation (New York 2014). In: Medaon 9, Heft 16, S. 1-4.
Gallas, Elisabeth (2016): Frühe Holocaustforschung in Amerika. Dokumentation, Zeugenschaft und Begriffsbildung. In: Jahrbuch des Simon-DubowInstituts/Simon Dubnow Institute Yearbook 15, S. 535-569.

Gates Jr., Henry Louis (1987): Figures in Black: Words, Signs and the "Racial Self", Oxford: University Press.

Geggus, David Patrick (1989): The French and Haitian Revolutions, and Resistance to Slavery in the Americas: An Overview. In: Revue française d'histoire d'outre-mer 76/Nr. 282-283, S. 107-124.

Gershenhorn, Jerry (2007): Melville J. Herskovits and the Racial Politics of Knowledge. Lincoln/London: University of Nebraska Press.

Gikandi, Simon (2011): Slavery and the Culture of Taste, Princeton/Oxford: Princeton University Press.

Gilbert, Martin (1986): The Holocaust: The Jewish Tragedy. London: Collins.

Gitman, Esther (2018): Courage to Resist. Jews of the Independent State of Croatia Fight back. In: Schoeps, Julius H./Bingen, Dieter/Botsch, Gideon (Hgg.): Jüdischer Widerstand in Europa (1933-1945). Formen und Facetten. Berlin/Boston: De Gruyter Oldenbourg, S. 106-125.

Gliech, Oliver (2011): Saint-Domingue und die Französische Revolution. Das Ende der weißen Herrschaft in einer karibischen Plantagenwirtschaft. Köln/Weimar/Wien: Böhlau Verlag.

Goeschel, Christian (2011): Selbstmord im Dritten Reich. Übersetzt von Klaus Bindner. Berlin: Suhrkamp Verlag.

Gofman, Erving (1982): Das Individuum im öffentlichen Austausch. Mikrostudien zur öffentlichen Ordnung. Übersetzt von R. und R. Wiggershaus. Frankfurt a.M.: Suhrkamp Verlag.

Gröschner, Rolf (2017): Das Widerstandsrecht im Grundgesetz. In: Zehnpfennig, Barbara (Hg.): Politischer Widerstand, S. 83-95.

Gringauz, Samuel (1950): Some Methodological Problems in the Study of the Ghetto. In: Jewish Social Studies 12 , S. $65-72$.

Gudehus, Christian/Christ, Michaela (2013): Gewalt Begriffe und Forschungsprogramme. In: Dies. (Hgg.): Gewalt. Ein interdisziplinäres Handbuch. Stuttgart: J.B. Metzler, S. 1-15.

Hartman, Saidiya V. (1997): Scenes of Subjection. Terror, Slavers, and Self-Making in Nineteenth-Century America. New York: Oxford University Press.

Hartman, Saidiya V. (2007): Lose your mother. A Journey along the Trans Atlantic Slave Route, New York: Farrar, Straus and Giroux.

Herskovits, Melville J. (1926): The Cattle Complex in East Africa. In: American Anthropologist. Vol. 28, No. 1, S. 230-272.

Herskovits, Melville J. (1941): The Myth of the Negro Past. London/New York: Harper \& Brothers.

Hilberg, Raul (1992): Die Vernichtung der europäischen Juden, Bd. 2. Übersetzt von Hans Günther Holl. 3. Auflage. Frankfurt a.M.: S. Fischer Verlag. 
Hilberg, Raul (1994): Unerbetene Erinnerung. Der Weg eines Holocaust-Forschers. Übersetzt von HansGünter Holl. Frankfurt a.M.: S. Fischer Verlag.

Hilbrenner, Anke (2004): Simon Dubnow war eine Art intellektueller Pate. Das YIVO in Wilnar und Dubnows Aufruf zur Arbeit am nationalen Gedächtnis. In: Dmitrieva, Marina/ Petersen, Heidemarie (Hgg.): Jüdische Kultur(en) im Neuen Europa, Wilna 19181939. Wiesbaden: Harrassowitz Verlag, S. 147-162.

Hobbes, Thomas (1996): Leviathan. Mit einer Einführung und herausgegeben von Hermann Klenner, übersetzt von Jutta Schlösser. Darmstadt: Felix Meiner Verlag.

Holloway, John/Thompson, Edward P. (2007): Blauer Montag. Über Zeit und Arbeitsdisziplin. Übersetzt von Lars Stubbe. Hamburg: Nautilus.

Höntzsch, Frauke (2017): Das kollektive

Widerstandsrecht - Hybrid zwischen Tradition und Moderne. In: Zehnpfennig, Barbara (Hg.): Politischer Widerstand. Allgemeine theoretische Grundlagen und praktische Erscheinungsformen in Nationalsozialismus und Kommunismus, BadenBaden: Nomos Verlag.

Humboldt-Universität zu Berlin: Kulturwissenschaftliche Ästhetik und Kulturtheorie. URL: https://www. aesthetik.hu-berlin.de/ (Zugriff am: 24.9.2019).

Huizinga, Johan (1956): Homo Ludens. Vom Ursprung der Kultur im Spiel, Reinbek bei Hamburg: Rowohlt Taschenbuch Verlag.

Hume, David (1828): Essay of National Characters. In: The Philosophical Works of David Hume, Vol. III, Edinburgh: Adam Black and William Tait, S. 224-244.

Hurston, Zora Neal (2018): Barracoon. The Story of the Last ,Black Cargo' (1931). London: Amistad.

Husserl, Edmund (1966): Analysen zur passiven Synthesis. Aus Vorlesungs- und Forschungsmanuskripten 1918-1926. In: Fleischer, Margot (Hg.): Husserliana, Bd. XI. Den Haag: Nijhoff.

Husserl, Edmund (1976): Erfahrung und Urteil. Untersuchungen zur Genealogie der Logik. Redigiert und herausgegeben von Ludwig Landgrebe. 5. Auflage. Hamburg: Felix Meiner Verlag.

Isaac, Rhys (2004): Landon Carter's Uneasy Kingdom: Revolution and Rebellion on a Virginia Plantation. New York: Oxford University Press.

Imbusch, Peter (2000): Gewalt - Stochern in unübersichtlichem Gelände. In: Mittelweg 36/2, S. $24-40$.

Yetman, Norman R. (1984): Ex-Slaves Interviews and the Historiography of Slavery. In: American Quaterly 36.2 , S. $181-210$.

Jdanoff, Denis: (2006): Gehorsam und Widerstand in Hobbes' "Leviathan" und Rousseaus "Gesellschaftsvertrag" - Ein Vergleich, Berlin: Wissenschaftlicher Verlag.

Jenkins Schwartz, Marie (2014): The WPA Narratives as Historical Sources. In: Ernest, John (Hg.): The Oxford Handbook of the African American Slave Narrative, S. 89-100.

Jones, Ralph J. (1967): Portrait of Georgia Slaves. In: Georgia Review 21, S. 268-273.
Journal of Resistance Studies. URL: https://resistancejournal.org/ (Zugriff am: 24.9.2019).

Kailin, Julie (1998): Toward Nonracist Historiography: The Early Work of Herbert Aptheker. In: Shapiro, Herbert (Hg.): African American History and Radical Historiography. Essays in Honor of Herbert Aptheker. Minneapolis: MEP Publications 1998, S. 19-38.

Kaiser, Ulrich (1997): Das Motiv der Hemmung in Husserls Phänomenologie. München: Fink Verlag.

Kant, Immanuel (1983a): Über das Gefühl des Schönen und Erhabenen. In: Kant. Werke, Bd. 2, S. 825-884.

Kant, Immanuel (1983b): Kritik der Urteilskraft. In: Kant. Werke, Bd. 8, herausgegeben von Wilhelm Weischedel. Darmstadt: Wissenschaftliche Buchgesellschaft.

Kassow, Samuel D. (2010): Ringelblums Vermächtnis. Das geheime Archiv des Warschauer Ghettos. Reinbek bei Hamburg: Rowohlt Verlag.

Kletskin, Boris A. (1912/1913) Der pinkes. Yohrbukh far der geshikhte fun der yudisher literatur un shprakh, far folklor, kritik un biblyografye. Wilna 1912/13.

Koschorke, Albrecht (2010): Institutionentheorie. In: Esslinger, Eva/Schlechtriemen, Tobias/Schweitzer, Doris et al. (Hgg.): Die Figur des Dritten. Ein kulturwissenschaftliches Paradigma. Berlin: Suhrkamp Verlag.

Kranebitter, Andreas/Fleck, Christian (2018): Elmer Luchterhands Forschungen zu nationalsozialistischen Konzentrationslagern. Eine Einleitung. In: Luchterhand, Elmer: Einsame Wölfe und stabile Paare, S. 7-36.

Krochmalnik, Daniel (2007): Pflicht Nr. 122. Das Zeugnisgebot (Mizwat Edut) in Geschichte und Gegenwart. In: Fritz-Bauer-Institut (Hg.): Zeugenschaft des Holocaust. Zwischen Trauma, Tradierung und Ermittlung. Frankfurt a.M./New York: Campus Verlag.

Kruk, Hermann (2002): Getto-Bibliothek und GettoLeser (Wilnaer Getto, September 1942). Übersetzt von Maria Kühn-Ludewig. In: Jüdisches Museum Frankfurt: SCHTARKER FUN AJSN. Konzert- und Theaterplakate aus dem Wilnaer Getto 1941-1943, S. 222-238.

Kuznitz, Cecile Ester (10. November 2010): YIVO. In: YIVO Encyclopedia of Jews in Eastern Europe. URL: http://www.yivoencyclopedia.org/article.aspx/YIVO (Zugriff am 23.02.2019).

Kuznitz, Cecile Esther (2014): YIVO and the Making of Modern Jewish Culture: Scholarship for the Yiddish Nation. Cambridge: Cambridge University Press.

Kydd, Alfred S. (1857): History of the Factory Movement. The Year 1802, to the Enactment of the Ten Hours' Bill in 1847. Vol. 1, London: Simpkin, Marshall, and Co.

Langbein, Hermann (1978): Menschen in Auschwitz. Wien: Europa Verlag.

Langer, Lawrence (1975): The Holocaust and the Literary Imagination. New Haven: Yale University Press. 
Langer, Lawrence (2010): Holocaust-Testimonies: The Ruin of Memory. New Haven: Yale University Press.

Lincoln, Abraham (1953): The Collected Works of Abraham Lincoln, Vol. 5, herausgegeben von Roy P. Basler, New Brunswick, N.J: Rutgers University Press.

Linden, Marcel von der (2003): Transnational Labour History. Explorations. Ashgate: Aldershot; Linden, Marcel von der (2008): Workers of the World. Essays toward a Global Labor History. Leiden: Brill.

Lindenberger, Thomas/Lüdtke, Alf (1995): Einleitung. Physische Gewalt - eine Kontinuität der Moderne. In: Dies. (Hgg.): Physische Gewalt. Studien zur Geschichte der Neuzeit. Frankfurt a.M.: Suhrkamp Verlag, S. 7-30.

Linebaugh, Peter/Rediker, Marcus (2000): Die vielköpfige Hydra. Die verborgene Geschichte des Revolutionären Atlantiks. Übersetzt von Sabine Bartel. Berlin/ Hamburg: Assoziation A.

Lomax, John A. (1941): Supplementary Instructions \#9-E to The American Guide Manual. In: Slave Narratives. A Folk History of Slavery in the United States from Interviews with Former Slaves, by the Library of Congress Project Work Project Administration. Washington, S. xx-xxii.

Löw, Andrea (2013): Chronisten der ,Lebenswelt Ghetto'. Dokumentationstätigkeit in den Ghettos Litzmannstadt und Warschau. In: Hansen, Imke/ Steffen, Katrin/Tauber, Joachim (Hgg.): Lebenswelt Ghetto. Alltag und soziales Umfeld während der nationalsozialistischen Verfolgung. Wiesbaden: Harrassowitz Verlag, S. 310-329.

Luchterhand, Elmer (2018): Einsame Wölfe und stabile Paare. Verhalten und Sozialordnung in den Häftlingsgesellschaften nationalsozialistischer Konzentrationslager, herausgegeben und eingeleitet von Andreas Kranebitter und Christian Fleck. Wien: new academic press.

Ludz, Ursula (2011): In den Untiefen des Allzumenschlichen. In: HannahArendt.net. Zeitschrift für politisches Denken 1/2, Bd. 6. URL: http://www. hannaharendt.net/index.php/han/article/view/17/86 (Zugriff am: 27.02.2019).

Lüdtke, Alf (1993): Eigen-Sinn: Fabrikalltag, Arbeitererfahrungen und Politik vom Kaiserreich bis in den Faschismus, Hamburg: Ergebnisse.

Lüdtke, Alf (1994): Geschichte und Eigensinn. In: Berliner Geschichtswerkstätten (Hg.): Alltagskultur, Subjektivität und Geschichte. Zur Theorie und Praxis von Alltagsgeschichte. Münster: Westfälisches Dampfboot, S. 139-153.

Lüdtke, Alf (2003): Gewalt und Alltag im 20. Jahrhundert. In: Bergsdorf, Wolfgang/Herz, Dietmar/ Hoffmeister, Hans (Hgg.): Gewalt und Terror. 11 Vorlesungen. Weimar: Rhino-Verlag, S. 35-52.

Lüdtke, Alf (2007): Eigensinn. In: Jordan, Stefan (Hg.): Lexikon Geschichtswissenschaft. Hundert Grundbegriffe. Stuttgart: Reclam.

Marcuse, Harold (2010): Holocaust Memorials: The Emergence of a Genre. In: The American Historical Review Vol. 115, No. 1, S. 53-89.
Mandt, Hella (1974): Tyrannislehre und Widerstandsrecht. Studien zur deutschen politischen Theorie des 19. Jahrhunderts. Darmstadt/Neuwied: Luchterhand.

Mar, Maria do/Dhawan, Nikita (2005): Postkoloniale Theorien. Eine kritische Einführung. Bielefeld: transcript.

Martí, Ignasi/Mumby, Dennis K. /Thomas, Robyn et al. et.al. (Hgg.) (2017a): Special Issue: Resistance, Resisting, and Resisters in and around Organizations der Organization Studies Vol. 38, Issue 9.

Martí, Ignasi/Mumby, Dennis K. /Thomas, Robyn et al. et.al. (2017b): Resistance Redux. In Special Issue: Resistance, Resisting, and Resisters in and around Organizations der Organization Studies Vol. 38, Issue 9, S. 1157-1183.

Marx, Karl (1960): Der achtzehnte Brumaire des Louis Bonaparte. In: MEW, Bd. 8, Berlin: Dietz Verlag, S. 111-207.

Marx, Karl (1977): Das Elend der Philosophie. Antwort auf Proudhons „Philosophie des Elends". In: MEW, Bd. 4, Berlin: Dietz Verlag, S. 63-182.

Marx, Karl (1980): Die amerikanische Frage in England (New York Daily Tribune, Nr. 6403 vom 11.Oktober 1861). In: MEW, Bd. 15, Berlin: Dietz Verlag, S. 304-314.

Marx, Karl/Engels, Friedrich (1977): Manifest der Kommunistischen Partei. In: MEW, Bd. 4, Berlin: Dietz Verlag, S. 459-493.

Marx, Karl/Engels, Friedrich (1978): Die deutsche Ideologie. Kritik der neuesten deutschen Philosophie in ihren Repräsentanten Feuerbach, B. Bauer und Stirner, und des deutschen Sozialismus in seinen verschiedenen Propheten. In: MEW, Bd. 3, Berlin: Dietz Verlag, S. 9-438.

Mattheus, Bernd (1984): George Bataille. Eine Tanatographie, Bd. I. München: Matthes \& Seitz.

Meier, August/Rudwick, Elliott (1986): Black History and the Historical Profession, 1915-1980. Urbana/ Chicago: University of Illinois Press.

Meissner, Jochen/Mücke, Ulrich/Weber, Klaus (2008): Schwarzes Amerika. Eine Geschichte der Sklaverei, München C.H. Beck.

Menke, Christoph (2006): Vom Schicksal ästhetischer Erziehung. Rancière, Posa und die Polizei. In: Felix Ensslin (Hg.): Spieltrieb, S. 58-70.

Merleau-Ponty, Maurice (1955): Les aventures de la dialectique. Paris: Éditions Gallimard.

Missling, Bodo (1999): Widerstand und Menschenrechte. Das völkerrechtlich begründete Individualrecht gegen Menschenrechtsverletzungen. Tübingen: Köhler.

Nedelmann, Birgit (1997): Gewaltsoziologie am Scheideweg. Die Auseinandersetzungen in der gegenwärtigen und Wege der künftigen Gewaltforschung. In: Trotha, Trutz von (Hg.): Soziologie der Gewalt, Opladen/Wiesbaden: Westdeutscher Verlag.

Nietzsche, Friedrich (1967-77/88a): Zur Genealogie der Moral. Eine Streitschrift. In: Kritische Studienausgabe, Bd. 5, herausgegeben von Giorgio 
Colli und Mazzino Montinari. Berlin/New York/ München: De Gruyter Verlag/dtv.

Nietzsche, Friedrich (1967-77/88b): Nachlass Oktober November 1888. In: Kritische Studienausgabe, Bd. 13. Northup, Solomon (2014): Zwölf Jahre ein Sklave. Altenmünster: Jazzybee Verlag.

Ott, Michaela (2018): Welches Außen des Denkens? Französische Theorie in postkolonialer Kritik? Wien/ Berlin: Turia + Kant.

Pares, Richard (1960): Merchants and planters, Cambridge: University Press.

Popitz, Heinrich (1986): Phänomene der Macht. Autorität - Herrschaft - Gewalt - Technik. Tübingen: Mohr Siebeck.

Porter, Kenneth W. (1943): Florida Slaves and Free Negroes in the Seminole War, 1825-1842. In: The journal of Negro History 28.4, S. 390-421.

Převrátil, Rudolf/Puar Jasbir K. (2007): Terrorist Assemblages. Homonationalism in Queer Times. Durham \& London: Duke University Press.

Rancière, Jacques (2002): Das Unvernehmen. Politik und Philosophie. Übersetzt von Richard Steurer. Frankfurt a.M.: Suhrkamp Verlag.

Rancière, Jacques (2006a): Schiller und das ästhetische Versprechen. In: Ensslin, Felix (Hg.): Spieltrieb. Was bringt die Klassik auf die Bühne. Schillers Ästhetik heute. Berlin: Theater der Zeit, S. 39-55.

Rancière, Jacques (2006b): Das ästhetische Unbewußte. Übersetzt von Ronald Vouillé. Berlin/Zürich: diaphanes.

Rancière, Jacques (2008): Ist Kunst widerständig? Übersetzt von Frank Ruda und Jan Völker. Berlin: Merve Verlag.

Rancière, Jacques (2013): Die Nacht der Proletarier. Archive des Arbeitertraums. Übersetzt von Brita Pohl, Wien/Berlin: Turia + Kant.

Rásky, Béla/Fritz, Regina/Kovács, Eva (Hgg.) (2016): Als der Holocaust noch keinen Namen hatte / Before the Holocaust had its Name: Zur frühen Aufarbeitung des NS-Massenmords an Jüdinnen und Juden. Wien: new academic press.

Rediker, Marcus (2007): The Slave Ship. A Human History, Chicago: Viking Penguin.

Reemtsma, Jan Philipp (2008): Vertrauen und Gewalt. Versuch über eine besondere Konstellation der Moderne. Hamburg: Hamburger Edition.

Resistence Studies Network. URL: http:// resistancestudies.org (Zugriff am: 24.9.2019).

Ringelblum, Emanuel (1983): Kronika getta warszawskiego. Wrzesień 1939 - styczeń 1943, herausgegeben von Artur Eisenbach. Warszawa: Czytelnik.

Robinson, Jacob/Friedman, Philip (1960): Guide To Jewish History Under Nazi Impact. Biographical Series No. 1, New York: Marstin Press, Inc., S. XVII.

Ronnick, Michel Valerie (1998): Francis Williams. An Eighteenth-Century Tertium Quid. In: Negro History Bulletin 61, S. 19-29.
Roth, Markus/Löw, Andrea (2012): Das Warschauer Getto. Alltag und Widerstand im Angesicht der Vernichtung. München: Beck Verlag.

Rózsa, Ágnes (2006): Solange ich lebe, hoffe ich. In: Diefenbach, Michael/Jochem, Gerhard (Hgg.): "Solange ich lebe, hoffe ich". Die Aufzeichnungen des ungarischen KZ-Häftlings Ágnes Rózsa. Nürnberg: Verlag testimon, S. 95-352.

Scarry, Elaine (1985): The Body in Pain. The Making and Unmaking of the World, New York: Oxford University Press.

Scheidle, Günther (1969): Das Widerstandsrecht. Entwicklung anhand der höchstrichterlichen Rechtsprechung der Bundesrepublik Deutschland, Berlin: Duncker \& Humblot.

Schüler-Springorum, Horst (1983): Strafrechtliche Aspekte zivilen Ungehorsams. In: Glotz, Peter (Hg.): Ziviler Ungehorsam im Rechtsstaat, S. 76-98.

Schiller, Friedrich (1993): Über die ästhetische Erziehung des Menschen in einer Reihe von Briefen. In: Sämtliche Werke, Bd. V, herausgegeben von Gerhard Fricke/Herbert G. Göpfert. 9. Auflage. München/ Darmstadt: Wissenschaftliche Buchgesellschaft.

Schroeter, Gudrun (2002): Konzert- und Theaterplakate aus dem Wilnaer Ghetto 1941 - 1943. http://www. juden-in-europa.de/baltikum/wilnaer-ghetto.htm (Zugriff am 9.4.2019).

Schroeter, Gudrun (2008): Worte aus einer zerstörten Welt: das Ghetto Wilna. St. Ingbert: Röhring.

Schroeter, Gudrun (2010): Jüdischer Widerstand in Ghettos 1939-1944. In: Lernen aus der Geschichte, S. 6-7.

Snyder, Terri L. (2010): Suicide, Slavery, and Memory in North America. In: Journal of American History Vol. 97/1, S. 39-62.

Snyder, Terri L. (2015): The Power to Die. Slavery and Suicide in British North America, Chicago/London: University of Chicago Press.

Sonderegger, Ruth (2018): Kants Ästhetik im Kontext des kolonial gestützten Kapitalismus. In: Zeitschrift für Ästhetik und Allgemeine Kunstwissenschaft: Sensibilität der Gegenwart, herausgegeben von Burkhard Liebsch, Sonderheft 17, S. 109-129.

Sofsky, Wolfgang (1993): Die Ordnung des Terrors. Das Konzentrationslager. 4. Auflage. Frankfurt a.M.: S. Fischer Verlag.

Sofsky, Wolfgang (1996): Traktat über die Gewalt. Frankfurt am Main: S. Fischer Verlag.

Sofsky, Wolfgang (2002): Zeiten des Terrors. Amok. Terror. Krieg. Frankfurt a.M.: S. Fischer Verlag.

Spindel, Donna J. (1996): Assessing Memory: TwentiethCentury Slave Narratives Reconsideres. In: The Journal of Interdisciplinary History 27, No. 2, S. 247-261.

Spivak, Gayatri Chakravorty (2008): "Can the subaltern speak?" Postkolonialität und subalterne Artikulation. Mit einer Einleitung von Hito Steyerl. Übersetzt von Alexander Joskowicz und Stefan Nowotny. Wien: Turia + Kant. 
Stauber, Roni (2010): Laying the Foundations for Holocaust Research - The Impact of Philip Friedman. Göttingen: Wallstein Verlag.

Strickland, Jeff (2014): Teaching the History of Slavery in the United States with Interviews: Born in Slavery: Slaves Narratives from the Federal Writers' Project 1936-1938. In: Journal of American Ethnic History 33, No. 4, S. 41-48.

Suderland, Maja (2004): Territorien des Selbst. Kulturelle Identität als Ressource für das tägliche Überleben im Konzentrationslager, Frankfurt a.M./New York: Campus Verlag.

Suderland, Maja (2009): Ein Extremfall des Sozialen. Die Häftlingsgesellschaft in den nationalsozialistischen Konzentrationslagern, Frankfurt a.M./New York: Campus Verlag.

Thompson, Edward P. (1979): Wahrnehmungsformen und Protestverhalten. Studie zur Lage der Unterschichten im 18. und 19. Jahrhundert. Übersetzt von Detlev Puls. Frankfurt a.M.: Suhrkamp Verlag.

Thompson, Edward P. (1987): Die Entstehung der englischen Arbeiterklasse, 2 Bde. Übersetzt von Lotte Eidenbenz u.a., Frankfurt a.M.: Suhrkamp Verlag.

Thoreau, Henry David (30.10.1859): A Plea for Captain John Brown. URL: http://avalon.law.yale.edu/19th_ century/thoreau_001.asp, (Zugriff am 28.12.2018).

Thoreau, Henry David (1973): Die letzten Tage des John Brown. In: Ders.: Über die Pflicht zum Ungehorsam gegen den Staat und andere Essays. Übersetzt von Walter E. Richartz, Zürich: Diogenes, S. 71-83.

Thoreau, Henry David (2017): Ziviler Ungehorsam. Übersetzt von Ulrich Bossier. In: Braune, Andreas (Hg.): Ziviler Ungehorsam. Texte von Thoreau bis Occupy. Stuttgart: Reclam, S. 42-55.

Trouillot, Michel-Rolph (1995): An Unthinkable History: The Haitian Revolution as a Non-Event. In: Ders.: Silencing the Past: Power and the Production of History. Boston: Beacon Press, S. 70-107.

University of Massachusetts Amherst: Resistance Studies Initiative. URL: https://www.umass.edu/ resistancestudies/ (Zugriff am: 30.12.2018).

Wachsmann, Nikolaus: (2015): KL. Die Geschichte der nationalsozialistischen Konzentrationslager. Berlin: Siedler Verlag.

Wagner, Birgitt (2011): Jüdische Gesellschaft im Mittelpunkt. "Ghetto" und „Judenrat” als Themen der frühen englischsprachigen Holocaustforschung. In: PaRDeS. Zeitschrift der Vereinigung für Jüdische
Studien e.V. 17, S. 53-70. URL: https://core.ac.uk/ download/pdf/11589235.pdf (Zugriff am 27.02.2019). Web, Marek (2013): The Story of YIVO's Polish Jewish Archive. YIVO Institute for Jewish Reearch. http:// polishjews.yivoarchives.org/YIVO-GL-Story-of-YIVOsPolish-Jewish-Archive.pdf (Zugriff am 19.3.2019).

Weinreich, Max (1926/2002): Ein Jiddisches Wissenschaftliches Institut. In: Zeitschrift der Deutschen Morgenländischen Gesellschaft. Neue Folge, Bd. 5 (Bd. 80), Leipzig, S. 68-70; wiederabgedruckt in: Jüdisches Museum Frankfurt (2002): SCHTARKER FUN AJSN. Konzert- und Theaterplakate aus dem Wilnaer Getto 1941-1943. Frankfurt am Main: Jüdisches Museum Ffm, S. 117-119.

Weiss, Peter (1983): Ästhetik des Widerstands. Roman, 3 Bde. Frankfurt a.M.: Suhrkamp Verlag.

Wette, Wolfram (2003): Helfer und Retter in der Wehrmacht als Problem der historischen Forschung. In: Ders. (Hg.): Retter in Uniform. Handlungsspielräume im Vernichtungskrieg der Wehrmacht. 3. Auflage. Frankfurt a.M.: S. Fischer Verlag, S. 11-31.

Wiesen, S. Jonathan (2016): On Dachau and Jim Crow. Holocaust Memory in the Postwar African American Press. In: Rásky, Béla/Fritz, Regina/Kovács, Eva (Hgg.): Als der Holocaust noch keinen Namen hatte. Wien: new academic press, S. 111-131.

Wish, Harvey (1937): American Slave Insurrections before 1861. In: The journal of Negro History 22/3, S. 299-320.

Wirz, Albert (1984): Sklaverei und kapitalistisches Weltsystem. Frankfurt a.M.: Suhrkamp Verlag.

Wolzendorff, Kurt (1968): Staatsrecht und Naturrecht in der Lehre vom Widerstandsrecht des Volkes. Zugleich ein Beitrag zur Entwicklungsgeschichte des modernen Staatsgedankens. 2. Neudruck der Ausgabe Breslau 1916, Aalen: Scientia Verlag.

Woodward, C. Vann (1979): History From Slave Sources. In: American Historical Review 79, No. 2, S. 470-481.

Young, James E. (1997): Beschreiben des Holocaust. Darstellung und Folgen der Interpretation. Übersetzt von Christa Schuenke. Frankfurt a.M.: Suhrkamp Verlag.

Zandt, Stephan (2019): Die Kultivierung des Geschmacks. Eine Transformationsgeschichte der kulinarischen Sinnlichkeit. Erscheint Berlin: De Gruyter Verlag. 